\title{
Characterisation of fungal protein kinases involved in the regulation of the cell cycle in Saccharomyces cerevisiae and of sexual development in Aspergillus nidulans
}

\author{
Dissertation \\ zur Erlangen des Doktorgrades \\ der Mathematisch-Naturwissenschaftlichen Fakultäten \\ der Georg August Universität zu Göttingen
}

vorgelegt von

Fatih Sari

aus Osnabrück

Göttingen, 2007 
Die vorliegende Arbeit wurde in der Arbeitsgruppe von Prof. Dr. Gerhard H. Braus in der Abteilung Molekulare Mikrobiologie des Institutes für Mikrobiologie \& Genetik der Georg-August-Universität Göttingen angefertigt.

Teil dieser Arbeit wurde veröffentlicht in :

Sari, F., Braus, G.H., and Irniger, S. (2007). A Process Independent of the Anaphase-promoting Complex Contributes to Instability of the Yeast S Phase Cyclin Clb5. J Biol Chem 282, 2661426622.

Referent: Priv. Doz. Dr. Stefan IRniger

Korreferent: Prof. Dr. G. Braus

TAg deR MÜndLICHen PrüFung: 1. NOVember 2007 
To my parents Hüsnü \& Saziye Sari 
I am thankful to Gerhard Braus who gave me the opportunity to do my thesis in his department.

Further, I want to thank Stefan Irniger, specially, for his excellent supervision during my PhD work. He had always good ideas which pushed my work always forward.

Partick Dieckhoff, Melanie Bolte, Wiebke Meyer, and Dipak Maskey, and the two internship students Tülin Ersahin and Sevim Dalva contributed a lot for the success of this study. Especially Patrick Dieckhoff, who prepared me for the PhD work, I want to thank for his calm and friendly mentoring during my diploma thesis.

To all members of the department- the Aspergillus group, the Verticillium group, the Neurospora group, and the yeast group- I want to thank for the warm working atmosphere, all of them always being friendly and helpful. Also for the help of the the two technicians in Hannover, Sybille Traupe and Armgard Janczikowski, I am thankfull.

Of course I have to thank Özgür Bayram, who was always a precious friend and helped me a lot with the Aspergillus project. His support and contributions especially during the last year of my PhD work guaranteed the success of the Aspergillus project.

The chats with Ingrid Bahr, Özgür Bayram, Marcia Kress, and the other lab colleques had been very relaxing during the day of work.

For the relaxing atmosphere after work I want to thank my wife Ruhsan Sari. It was always restorative to play with my two sons, Muhammed Enes and Yusuf Emin, on weekends, although they always forced me to look spongebob on tv. All my accumulated frustation during the week, I could kick off on weekends. Special thanks to my soccer club AY YILDIZ!

I want to thank my father, Hüsnü Sari, for the discipline he taught me and my mother, Saziye Sari, for the love she gave me. Finally, I want to thank my sisters Sultan and Elmas and my brother Mehmet, that I was never alone. 


\section{TABLE OF CONTENTS}

$\begin{array}{lr}\text { Summary } & 1\end{array}$

Zusammenfassung 3

CHAPTER 1

Introduction

1. Life Cycle of Saccharomyces cerevisiae 5

2. The Mechanism of Ubiquitination 6

3. Eukaryotic Cell Cycle \& Mitosis

3.1. Cyclins and Cyclin dependant kinases control Cell Cycle 8

3.2. Anaphase Promoting Complex 10

3.3. Role of the APC in Cell Cycle 12

3.4. Regulation of the APC 13

4. Meiosis 14

4.1. Regulation of Meiosis 15

4.2. The protein kinase Ime2 16

5. Life cycle of Aspergillus nidulans 17

5.1. Asexual development 19

$\begin{array}{ll}\text { 5.2. Sexual development } & 21\end{array}$

5.3. Regulating factors of sexual development of A.nidulans 21

5.4. The protein kinase ImeB and MAP kinases 23

6. Aim of this work 25

7. References 27

\section{CHAPTER 2}

A PROCESS INDEPENDENT OF THE ANAPHASE PROMOTING COMPLEX CONTRIBUTES TO INSTABILITY OF THE YEAST S-PHASE CYCLIN CLB5

1. Abstract 33

2. Introduction 34

3. Materials and Methods 36

4. Results 39

5. Discussion 51

6. References 55 


\section{CHAPTER 3}

THE C-TERMINAL REGION OF MEIOSIS-SPECIFIC PROTEIN KINASE IME2 MEDIATES PROTEIN INSTABILITY AND IS REQUIRED FOR NORMAL SPORE FORMATION IN BUDDING YEAST

1. Abstract 58

2. Introduction 59

3. Materials and Methods 62

4. Results 67

5. Discussion 79

6. References

\section{CHAPTER 4}

THE IME2 RELATED PROTEIN KINASE INHIBITS SEXUAL DEVELOPMENT IN ASPERGILLUS NIDULANS

1. Abstract 87

2. Introduction 88

3. Materials and Methods 91

4. Results 95

5. Discussion 108

6. References 111

CONCLUSIONS 114 


\section{Abbreviations}

$\lambda$

${ }^{\circ} \mathrm{C}$

$\mathrm{Amp}^{\mathrm{R}}$

APC

approx.

bp

C

Cdk

CDNA

$\mathrm{Clb}$

Cln

C-terminus

$\Delta$

DAPI

$\mathrm{db}$

DMSO

DNA

DTT

ECL

EDTA

et al.

Fig.

For

G1-, G2-phase

Gal

$G A L$

h

HA

Ime2 $\Delta$ C242

K wavelength

Degree Celsius

Ampicillin resistance

Anaphase-promoting complex

Approximately

Base pairs

Cytosine

Cyclin-dependant kinase

Copy DNA

B-type cyclin

G1 cyclin

Carboxy terminus

Deletion

4'-6'-Diamidino-2' phenylindol

destruction box

Dimethylsulfoxide

deoxyribonucleic acid

Dithiothreitol

Enhanced Chemiluminiscence System

Ethylendiaminotetraacetate

and others

Figure

Forward

Gap-phase 1, Gap-phase 2

Galactose

GAL-promoter

Hour

Hemag-glutinin

Ime2 truncated by the c-terminal 242 amino acids

Lysine 
kd

LB-medium

M

MAT

$\min$

mRNA

$\mathrm{n}$

$\mathrm{N}$-terminus

OD

ORF

PBS

PCR

PEG

PEST

PMSF

Raff

RT

SCF

SDS

S-phase

SPO-medium

STET

Tab

TAE-buffer

TB

TEMED

TLCK

TPCK

Tris

Tween
Kilo Dalton

Luria-Bertani-medium

Molar

MAT locus, determining the mating type

minute

Messenger RNA

Set of chromosome

Amino-Terminus

Optical density

Open reading frame

Protein Block Solution

Polymerase chain reaction

Polyethylene glycol

Amino acid sequence enriched by proline, glutamate, serin, threonin Phenylmethylsulfonylefluoride

Raffinose

Room temperature

SKP1-Cullin-F-Box-Protein

Sodium dodecyl sulfate

Synthesis phase

Sporulation medium

Sucrose/Triton/EDTA-buffer

Table

Tris/Acetate/EDTA-buffer

Transformation buffer

$N^{\prime}, N^{\prime}, N^{\prime}, N^{\prime},-$ Tetramethylethylenediamin

$\mathrm{N}-\alpha-\mathrm{p}$-Tosyl-L-Phenyalanine-Chlorinemethyleketone

$\mathrm{N}$ - $\alpha$-p-Tosyl-L-Lysin-Chlorinemethyleketone

Tris(hydroxymethyle)aminomethane

Polyoxyethylenesorbitanmonolaureat 


\section{Summary}

In this work, fungal model organisms, the single cell budding yeast Saccharomyces cerevisiae and the filamentous fungus Aspergillus nidulans were used to characterize different factors involved cell cycle control and in the regulation of development. In yeast, the cyclin $\mathrm{Clb5}$, a regulatory subunit of cyclin-dependent kinases, and Ime2, a protein kinase with an essential function in the meiotic cell cycle, were studied. In filamentous fungi, the Ime2 homolog protein kinase ImeB, which plays an important role in regulation of asexual and sexual fruiting bodies formation, was characterised.

In the first part of the project, the degradation pathways of the yeast S-phase cyclin Clb5 were analyzed. $\mathrm{Clb5}$ is known to be a substrate of the anaphase promoting complex (APC/C), a multi-subunit ubiquitin ligase essential for the cell cycle. Pulse labelling experiments were applied to determine the half-life of Clb5. In contrast to other cyclins, Clb5 was found to be unstable throughout the cell cycle and also in cells lacking APC/C activity. However, in the presence of an active APC/C, the half-life of $\mathrm{Clb5}$ was further decreased. These data suggest that two pathways, an $\mathrm{APC} / \mathrm{C}$-dependant and an APC/C -independent mechanism, have overlapping roles in triggering $\mathrm{Clb5}$ proteolysis during the cell cycle. Degradation is mediated by the $26 \mathrm{~S}$ proteasome.

The aim of the second project was a better understanding of the regulation of the yeast protein kinase Ime2. This kinase and the cyclin-dependent kinase Cdk1 have many common functions in the regulation of meiosis. Ime2 is not regulated by cyclins, but is itself a highly unstable protein. By constructing a set of deletions, it was shown that the C-terminal region is essential for Ime2 instability and probably contains multiple overlapping degradation signals. A truncated Ime2 lacking the C-terminal 242 amino acids was stable and active. Expression of this version of Ime2 during meiosis did not interfere with meiotic cell divisions, but resulted in abnormalities in spore production. Frequently, asci had a reduced spore number and were mostly dyads. Thus, Ime2 instability mediated by the C-terminal region is important for the efficient enclosure of nuclei into spore walls and for the formation of normal 4-spore asci.

In the final part of this project, the homolog of Ime2 in A. nidulans, ImeB, was characterised. For this purpose an $i m e B$ deletion strain was constructed. On agar plates, the imeBA mutants displayed a slow growth phenotype, but an increased formation of sexual fruiting bodies, the cleistothecia. In contrast to wild-type strains, imeBA strains also formed typical sexual structures, Hülle cells, in liquid media. Overexpression of $i m e B$ blocks conidiophore formation when grown in the dark. imeB transcript levels increase during both the asexual and the sexual life cycle. These data indicate that ImeB acts a regulator of development in $A$. nidulans. In contrast to Ime2 protein 
in yeast, ImeB appears to be an inhibitor of the sexual life cycle. These findings imply that in evolution, these proteins have acquired opposite functions as regulators of sexual development. Ime2 and ImeB belong to the family of mitogen activated protein (MAP) kinases characterised by a TXY motif in their activation loop. A site-directed mutagenesis showed that every single amino acid this of motif is needed for accurate ImeB function. 


\section{Zusammenfassung}

In dieser Arbeit wurden einfache Modellorganismen, die Hefe Saccharomyces cerevisiae und der filamentöse Pilz Aspergillus nidulans, zur Charakterisierung von verschiedenen Faktoren genutzt, die an der Regulation des Zellzyklus und der Entwicklung beteiligt sind. In der Hefe wurde Clb5, eine regulatorische Untereinheit von Zyklin-abhängigen Kinasen, und Ime2, eine Proteinkinase mit essentiellen Funktionen im meiotischen Zellzyklus, untersucht. Im filamentösen Pilz wurde die Proteinkinase ImeB, welche eine wichtige Rolle in der Regulation der asexuellen und sexuellen Fruchtkörperbildung hat, charakterisiert.

Im erstem Teil des Projektes wurde der Abbauweg des S-Phase Zyklins Clb5 aus der Hefe analysiert. Clb5 ist ein Substrat des Anaphase Promoting Complexes (APC/C), einer Ubiquitin-Ligase, die unentbehrlich für den Zellzyklus ist. Pulsmarkierungs-Experimente wurden zur Bestimmung der Halbwertszeit von $\mathrm{Clb5}$ angewandt. Im Gegensatz zu anderen Zyklinen konnte für Clb5 gezeigt werden, dass es während des ganzen Zellzyklus und sogar in Abwesenheit von APC Aktivität instabil ist. Die Halbwertszeit von Clb5 wurde in Anwesenheit von APC Aktivität noch weiter vermindert. Diese Resultate deuten darauf hin, dass zwei Abbauwege, ein APC abhängiger und ein APC unabhängiger mit überlappenden Funktionen vorhanden sind, um den Clb5 Abbau während des Zellzyklus einzuleiten. Der Abbau ist vom $26 \mathrm{~S}$ Proteasom abhängig.

Das Ziel des zweiten Pojektes war es, ein besseres Verständnis über die Regulation der Proteinkinase Ime2 aus der Hefe zu erlangen. Diese Kinase und die Zyklin-abhängige Kinase Cdk1 haben viele gemeinsame Funktion in der Regulation der Meiose. Ime2 wird nicht duch Zykline reguliert, ist aber selbst ein instabiles Protein. Durch Konstruktion einer Reihe von Deletionen wurde gezeigt, dass die C- terminale Region für die Ime2 Instabilität essentiell ist und vermutlich mehrere überlappende Abbausignale beinhaltet. Ein verkürztes Ime2, welchem am C-Terminus 242 Aminosäuren fehlen, ist stabil und aktiv. Expression dieser Ime2 Version während der Meiose verhindert nicht die meiotische Zellteilung, resultiert aber in einer abnormalen Sporenbildung. Häufig hatten Asci eine verminderte Sporenanzahl und waren meistens Dyaden. Demnach ist die Ime2 Instabilität, welche durch die C-terminale Region vermittelt wird, für die effiziente Einschliessung der Kerne in Sporenwände und für die Bildung von normalen 4-sporige Asci wichtig.

Im letzten Teil des Projektes wurde das Ime2 Homologe in A.nidulans, ImeB, charakterisiert. Zu diesem Zweck wurde ein imeB Deletionsstamm erzeugt. Auf Agarplatten zeigten imeBA Mutanten ein langsames Wachstum, hatten aber eine erhöhte Bildung von sexuellen Fruchtkörpern, den Kleistothezien. Im Gegensatz zum Wildtyp bildeten imeBA Stämme typische sexuelle Strukturen, wie die globulären Hülle-Zellen, in Flüssigkultur. Überexpression von imeB verhindert die Bildung von Konidiophoren bei Wachstum im Dunkeln. imeB Transkripte erhöhten sich während 
des asexuellen und sexuellen Lebenszyklus. Diese Ergebnisse deuten darauf hin, dass ImeB als Regulator der Entwicklung von A.nidulans wirkt. Im Gegensatz zum Ime2 Protein der Hefe, scheint ImeB ein Inhibitor des sexuellen Lebenszyklus zu sein. Diese Resultate lassen vermuten, dass diese Proteine in der Evolution gegensätzliche Funktionen als Regulatoren der sexuellen Entwicklung erworben haben. Ime2 und ImeB gehören zu der Familie der Mitogen aktivierten Proteinkinasen (MAK), welche durch ein TXY motif in der Aktivierungsschleife charakterisiert ist. Punktmutationen in den entsprechenden Codons zeigten, dass jede einzelne Aminosäure dieses Motives für die Ime2 Funktion benötigt wird. 


\section{CHAPTER 1}

\section{Introduction}

\section{Life cycle of Saccharomyces cerevisiae}

Saccharomyces cerevisiae is a fast growing ascomycete, which propagates by budding giving rise to a new daughter cell. This process of reproduction is independent from haploidity or diploidity. Haploid S.cerevisiae cells exist in two mating types, "a" and " $\alpha$ " (Fig.1). If cells of different mating types are near each other, the two opposite genders recognize each other by chemical signaling and both cell and nuclear fusion takes place. Secretion of pheromones, the mating factors, allows the recognition of the opposite mating partner. Mating factors cause cells to arrest in the G1 phase thus acting as negative growth factors. The product of "mating" is called zygote which is a diploid cell with a distinctive shape. Diploid cells are not able to mate anymore, but undergo meiosis if they are starved to nutrients and fermentable carbon sources. Since it was shown that diploid MATa/MATa cells do not initiate meiosis (Roman et al., 1955), it is obvious that a second factor is required for meiosis. Kassir and Simchen (1976) displayed the necessity of a diploid S.cerevisiae cell bearing both a MATa and a MAT $\alpha$ loci for initiation of meiosis. Once meiosis is initiated S.cerevisiae cells undergo a process called "sporulation" giving rise to four haploid meiotic progeny which are hold together in a sac, the ascus. These four haploid spores have the ability to emerge out of the ascus once better nutrient supply is available (Neiman, 2005). Although S. cerevisiae is a unicellular organism it shows hyphal like growth pattern. In conditions when a fermentable carbon source is available but a nitrogen source not, S.cerevisiae cells start to elongate and get thinner. Besides polar budding, cells adhere to each other giving the S.cerevisiae cell community the chance to seek fo nutrient sources. This pseudohyphal growth behaviour could only be observed in a/ $\alpha$ diploid cells (Gimeno and Fink, 1992). Under same conditions haploid cells show the same growth mode having a bipolar budding pattern. 


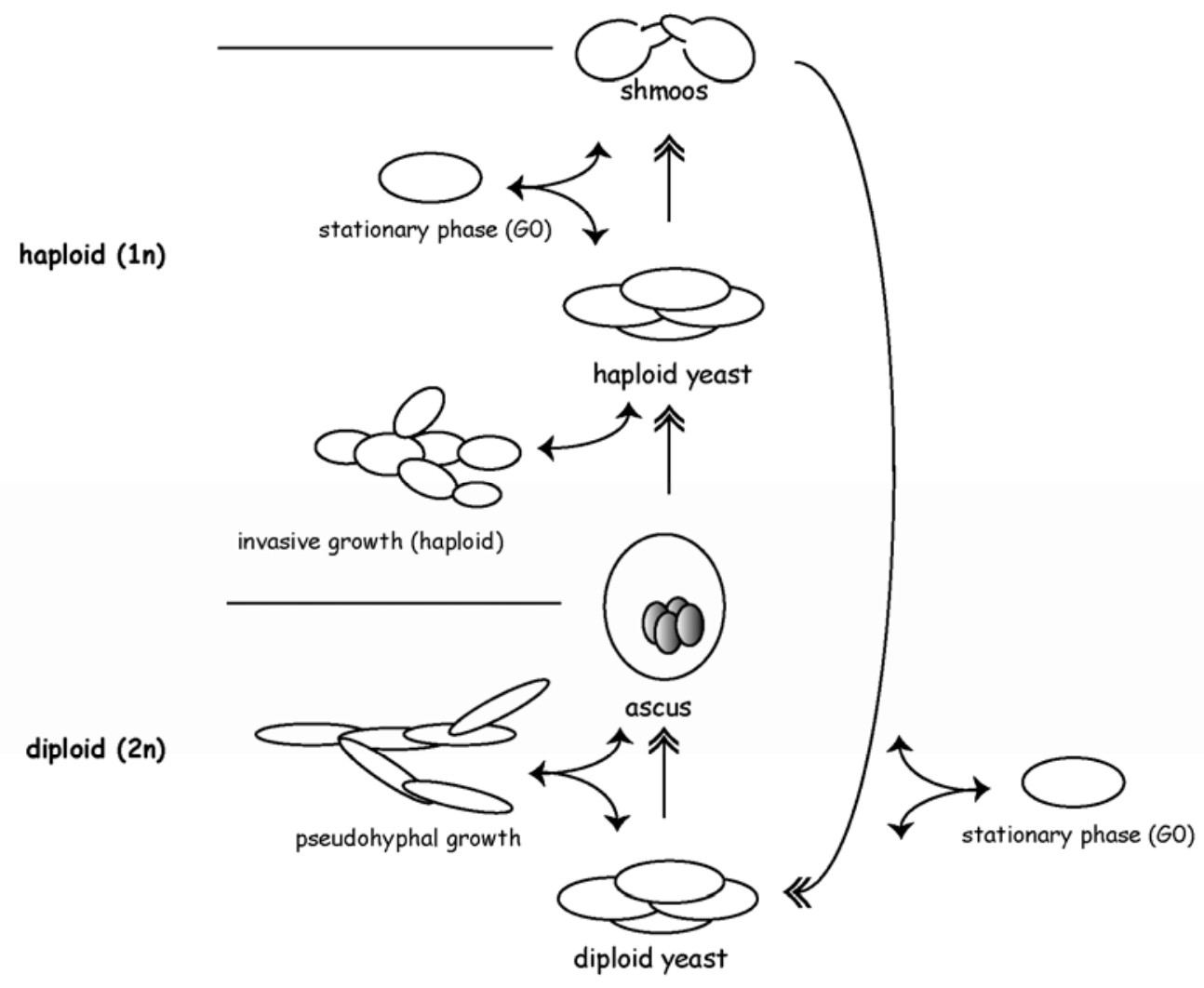

\section{Fig.1: Life Cycle of Saccharomyces cerevisiae}

The ascomycete Saccharomyces cerevisiae is able to propagate asexually and sexually. A lack of nitrogen and the availability of a non-fermentable carbon source induces sporulation in haploid cells. Pseudohyphal growth of diploid or invasive growth for haploid cells can be observed in conditions lacking nitrogen in the presence of a fermentable carbon source.

\section{The mechanism of ubiquitination}

In 2004 the Nobel Prize in chemistry was given for the discovery of a 76 amino acid protein called "ubiquitin". It was proposed that a tagging of target proteins with ubiquitin leads to rapid degradation. Recent works had shown that this process of ubiquitination is also needed for endocytosis, vesicular trafficking, signaling (Haglund and Dikic, 2005), stress response, DNA repair, transcription, gene silencing, and cell cycle control (Kaiser and Huang, 2005). Thus the covalent binding of ubiquitin to proteins comes up as a regulatory post-translational modification such as protein phosphorylation. The road of a protein to the giant proteolysis machinery, the $26 \mathrm{~S}$ proteasome via ubiquitination, is one of the best understood processes investigated in the past (Elsasser and Finley, 2005; Miller and Gordon, 2005). In Fig.2 the ubiquitination pathway and the resulting proteolysis of a protein is illustrated. The proteolysis of the majority of proteins in eukaryotes is managed by the ubiquitination-26 S proteasome 
system taking which is taking place in the cytosol. In more detail this process is described as follows: an ubiquitin activating enzyme (E1) takes in an ATP consuming process an ubiquitin molecule and subsequently transfers it to an ubiquitin conjugating enzyme (E2). With the help of an ubiquitin protein ligase (E3) ubiquitin is tagged to lysine residues of substrates (Hershko et al., 2000; Hochstrasser, 2000). Although mono-ubiquitination was reported to be important for endocytosis, histone regulation etc. (Hicke, 2001), a chain of ubiquitin proteins has to be generated in order to target substrates to the 265 proteasome (Ciechanover and Iwai, 2004). This polyubiquitination is achieved by covalently binding the C-terminus of an ubiquitin molecule to the lysine residue of the next ubiquitin (Pickart, 2000). Recently, it was reported that for multi-ubiquitin conjugates an additional enzyme (E4 e.g. Ufd2) is needed, since conventional ubiquitination enzymes E1, E2 and E3 add only a limited number of ubiquitin molecules to proteins (Hoppe, 2005). Until now, few E1 enzymes, tens of E2 enzymes and hundreds of E3 ligases could be identified (Semple, 2003) suggesting that selectivity of the system is maintained by E3 ligases. There are two types of E3 enzymes: E3 ligases harbouring a HECT domain (homologous to E6-AP carboxy terminus) and E3 ligases ubiquitinating targets via RING (really interesting new gene) finger domains (Nandi, 2006). The difference between the two ligases is the mechanism of ubiquitin transfer to substates. An example for RING finger E3

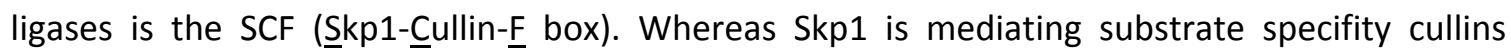
themselfes are targets for modifications (neddylation), thus activating or deactivating the whole SCF ligase (Cardozo and Pagano, 2004). The second big E3 ligase which has roles in mitotic as well as in meiotic cell cycle regulation is named APC/C (Annaphase Promoting Complex/Cyclosome). Once proteins enter the catalytic core of the proteasome, tagged ubiquitin chains are removed and are available for the next round of ubiquitination. This process of deubiquitination is processed by enzymes belonging to UBP (Ubiquitin processing)

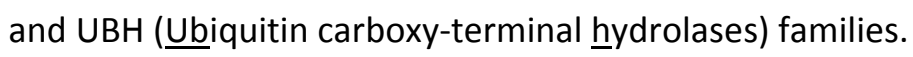

\section{Eukaryotic cell cycle \& Mitosis}

The eukaryotic cell cycle is described as the events in eukaryotic cells between one cell division and the next. The most prominent task of the cell cycle is to duplicate the genetic information and forward it to the next generation. To manage this, cells have to undergo four distinct phases (figure 3): G1 (first growth phase), S (genetic material is duplicated), G2 (second growth phase) and $M$ (mitotic phase). The first three stages are collectively known as interphase where biochemical processes resume at high rate and other processes as chromosome duplication and 
growth of cells occur. If all arrangements are met for seperating the genetic material, cells enter M-phase which is composed of mitosis and cytokinesis.

Mitosis is divided into prophase, prometaphase, metaphase, anaphase, and telophase.

a

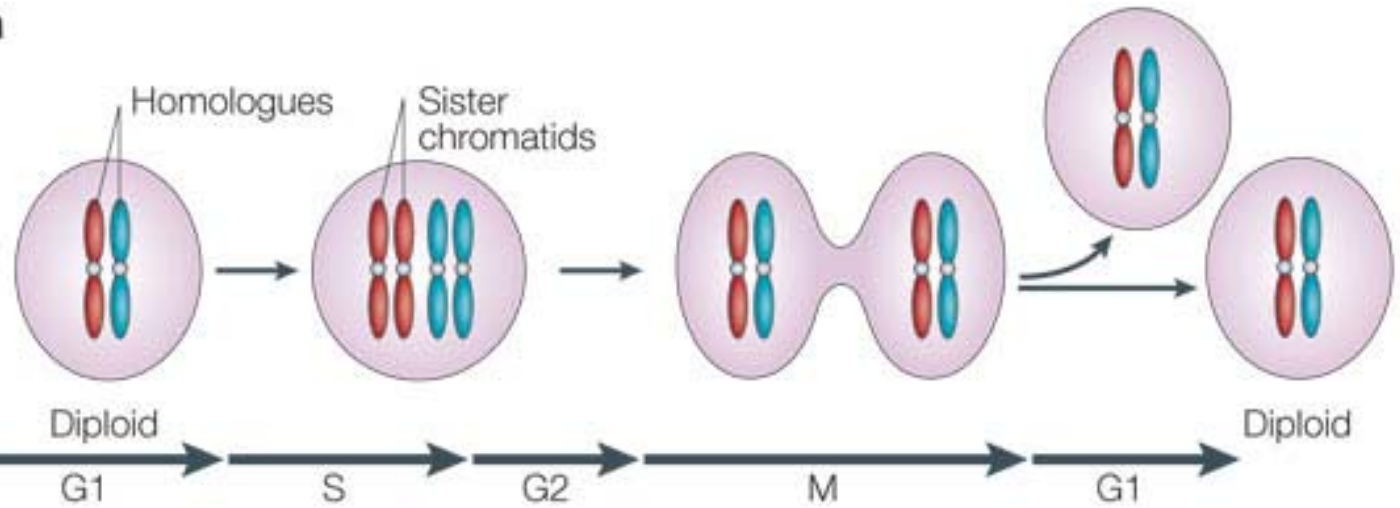

Fig.2: The mitotic cell cycle (Marston and Amon, 2004)

Saccharomyces cerevisiae mitotic cell cycle is divided into four phases: G1 phase (first growth), S-phase (Synthesis of DNA), G2 phase (second growth), M phase (mitotic phase). Overall aim of mitosis is to duplicate the genomic material and portion it to the two offsprings.

\subsection{Cyclins and cyclin dependant kinases control Cell Cycle}

Cyclin dependant kinases (Cdks) control progression through the eukaryotic cell cycle. In contrast to higher eukaryotes the budding yeast, Saccharomyces cerevisiae, has only one Cdk essential for the cell cycle, Cdk1, also known as Cdc28. Since Cdc28 is present during the entire cell cycle it is questioning how the serine/threonine protein kinase should take over regulatory functions. Indeed, $\mathrm{Cdc} 28$ alone can not find its targets during cell cycle progression. Only in association with cyclins it will get specifity allowing different cell cycle events happen. The term "cyclin" refers to the periodic appearance of these proteins due to production or proteolysis at defined timepoints during cell cycle. Figure 3 illustrates the different phases of cell cycle and the corresponding cyclins. 


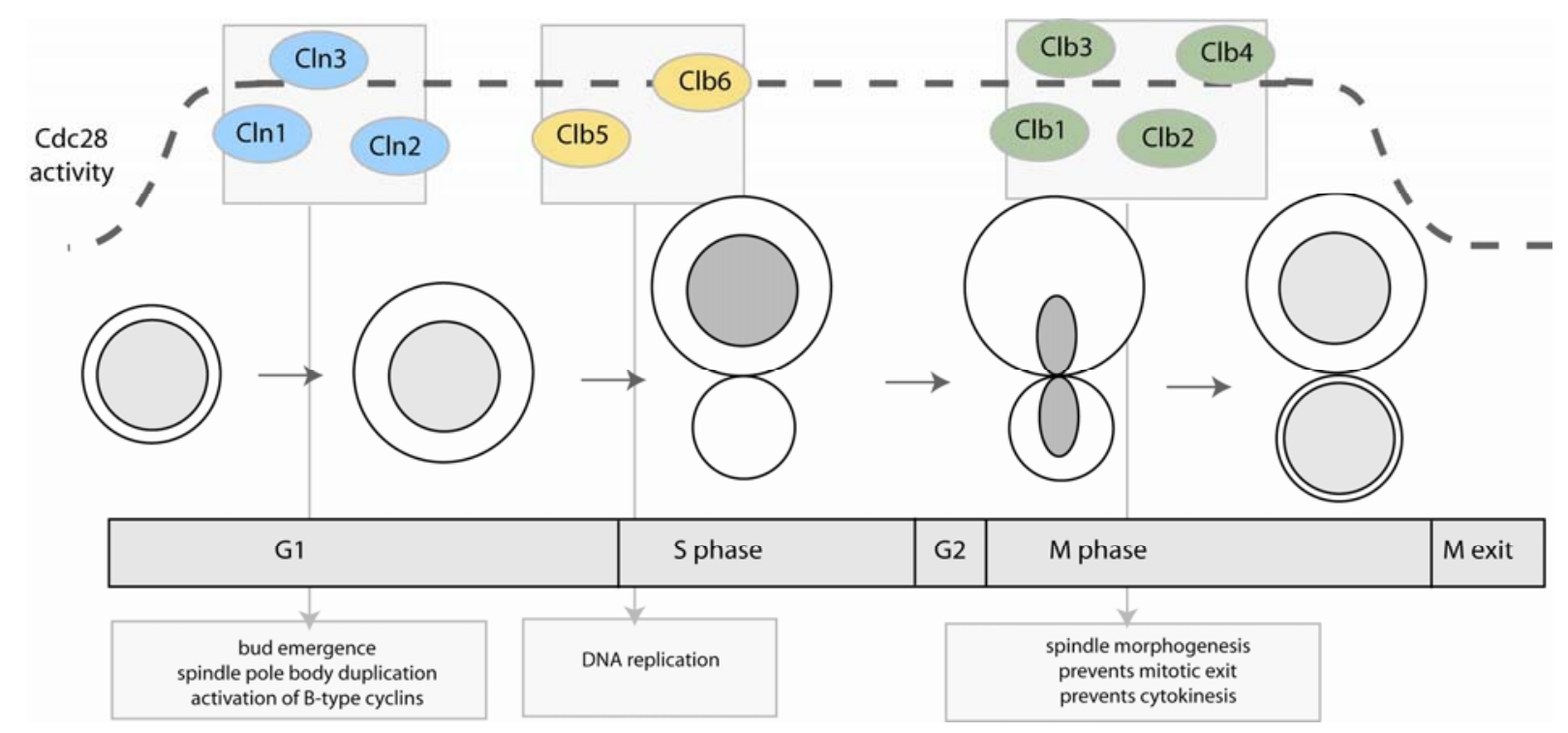

Fig.3: Cyclins at different phases of the eukaryotic cell cycle

Cell cycle phases are characterized by the presence of different cyclins which bind to $\mathrm{Cdc} 28$ and mediate specifity of the Cdc28/cyclin complex. Different cyclins in complex with Cdc28 trigger different processes in cell cycle phases. Cdc28 activity is lowered to the end of mitosis and rises again at the onset of the next G1 phase .

It was proposed that events as bud emergence and spindle pole body (SPB) duplication require the $\mathrm{G} 1$ phase cyclins, $\mathrm{Cln} 1, \mathrm{Cln} 2$, and $\mathrm{Cln} 3$ since cells arrest in $\mathrm{G} 1$ phase if all of these cyclins are missing. The B-type cyclins $\mathrm{Clb5}$ and $\mathrm{Clb} 6$ are needed for $\mathrm{S}$ phase events, and later expressed cyclins Clb1-4 are required for mitotic events and also prevent mitotic exit and cytokinesis if they are not removed to the end of mitosis. Due to this blocking effect of cyclins it is obvious that cyclins have to be degraded in order to enter the next phase of the cell cycle. This cyclin degradation is one mechanism which gives the cell cycle machinery its specifity. All cyclins are eliminated throught the ubiquitination-proteasome pathway. For example, Cln1 and Cln2 degradation is mediated by the SCF complex (Skowyra et al., 1997). The cyclin Clb6 is the only B-type cyclin shown to be degraded by th SCF complex, all the other B-type cyclins are targeted by the APC complex (Peters, 2006). During the exit from metaphase, when Clb5 is not needed anymore, $\mathrm{Clb5}$ is targeted by APC,which is bound to its co-activator Cdc20 (co-activators described below). Later in mitosis, the second co-activator, Cdh1, binds to the APC, which is needed for targeting the other B-type cyclins. Allthough APC complexes regulate Cdc28 activity by cyclin degradation, they themselves are regulated by $\mathrm{Cdc} 28$ activity. Thus, Cdc28/Clb2 phosphorylates APC subunits allowing the assembly of the APC ${ }^{\mathrm{Cd} 20}$ complex (Rudner and Murray, 2000). At the same time this phosphorylation reaction inactivates the APC ${ }^{\text {Cdh1 }}$ complex by the phosphorylation of Cdh1 (Zachariae et al., 1998). This reciprocal regulation assures that 
cell cylce events are forwarded in one direction and happen only once during cell cycle progression. Another mechanism contributing to cyclin specifity and thus to cell cycle specifity is the transcriptional regulation of cyclins. Transcription of the CLN3 gene is prior to the other Cln cyclins, CLN1 and CLN2, which peak during G1-S transition. Both genes CLB5 and CLB6 peak also during G1-S transition, followed by the transcription of $C L B 3$ and $C L B 4$ genes and then the CLB1 and CLB2 genes (Bloom and Cross, 2007). Not only expression but also localization provides specifity. For example, the $\mathrm{G} 1 \mathrm{cyclin} \mathrm{Cln} 3$ is primarily nuclear, whereas $\mathrm{Cln} 2$ is primarily cytoplasmic (Miller and Cross, 2000) showing that the two cyclins have distinct functions. The localization of $\mathrm{Cln} 3$ is consistent with its task, since $\mathrm{Cln} 3$ promotes transcription by phosphorylation (e.g. Whi5). Clb2 is localized to the bud neck suggesting a function in polarized growth (Miller and Cross, 2001). Another player regulating the cell cycle engine is Sic1. Sic1 is an inhibitor of the B-type cyclin/Cdc28 complexes (Nugroho and Mendenhall, 1994). Sic1 is stable until the G1-S transition. In S phase $\mathrm{Cln} / \mathrm{Cdc} 28$ complexes can phoshorylate Sic1 enabling the recognition by the SCF ${ }^{\mathrm{Cdc4}}$ ubiquiting ligase (Skowyra et al., 1997; Verma et al., 1997a). This elimination of the inhibitor allows Clb/Cdc28 complexes to fulfill its tasks (Schwob et al., 1994). Then $\mathrm{Clb} / \mathrm{Cdc} 28$ complexes phosphorylate Sic1 to enhance and maintain their activity. In summary, one can say that cell cycle specifity is achieved either by differential transcription of cyclins, the degradation of cyclins, the association of cyclins/Cdk complexes with Cdk inhibitors, the localization of cyclins and the inhibitory phophorylation of Cdks.

\subsection{Anaphase Promoting Complex}

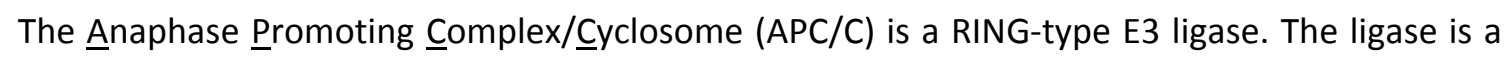
giant complex being in the same size class as the ribosomes and 26S proteasomes. (Passmore et al., 2005) revealed that the three-dimensional structure of the APC/C is rather an asymmetric triangle having an internal cavity enclosed by an outer wall. Unexpectedly, ubiquitination reaction takes place outside of the cavity (Dube et al., 2005). The APC of S. cerevisiae is composed of at least 13 subunits assembling into a large $1.5 \mathrm{kDa}$ complex. Apc2 and Apc11, which bear a cullin and a RING-finger domain, respectively, form the catalytic core. Four subunits Cdc27, Apc5, Cdc16 and Cdc23 have TPR (tetratricopeptide) repeats resembling protein-protein interaction motifs (Acquaviva and Pines, 2006). Some subunits, such as Apc9, Cdc26 and Apc13, have scaffolding roles. The latter subunit seems to have essential functions only in meiosis (Hall et al., 2003; Passmore et al., 2003). Another subunit, Doc1, is needed for APC activity in yeast. It contains a DOC domain common in proteins, which have roles in 
ubiquitination reaction (Grossberger et al., 1999). It is suggested that Doc1 may interact with APC substrates through this DOC domain. There are also subunits having roles exclusively in meiosis such as Mnd2/APC15. Mnd2 prevents degradation of securin and thus the loss of cohesin in meiosis I by the APC. None of these subunits mediate substrate specifity. Instead, so called co-activators, which are interchangable, allow the APC recognition and binding to targets. In the yeast Saccharomyces cerevisiae three co-activators could be identified: Cdc20; Cdc1 (also known as Hct1), and Ama1 (Zachariae and Nasmyth, 1999). A summary of APC subunits and their functions is listed in Table1.

Table1: APC/C subunits and co-activators (modified from Peters ,2006)

\begin{tabular}{|c|c|c|}
\hline APC subunit & Motifs & Functions \\
\hline Apc1 & RPN1 and RPN homology & - \\
\hline Apc2 & Cullin homology & Apc11 and Doc1 binding \\
\hline Cdc27 & TPRs & Cdh1 binding \\
\hline Apc4 & WD40 repeats & - \\
\hline Apc5 & TPRs & - \\
\hline Cdc16 & TPRs & - \\
\hline Cdc23 & TPRs & - \\
\hline Doc1/Apc10 & Doc domain & Processivity \\
\hline Apc11 & RING-H2 finger & E2 recruitment, E3 activity \\
\hline Cdc26 & - & - \\
\hline Apc13 & - & - \\
\hline Apc9 & - & - \\
\hline Mnd2 & - & Ama1 inhibition \\
\hline \multicolumn{3}{|c|}{ Co-activators: } \\
\hline Cdc20 & C-box, WD40 repeats, IR tail & Substrate recognition \\
\hline Cdh1/Hct1 & C-box, WD40 repeats, IR tail & Substrate recognition \\
\hline Ama1 & C-box, WD40 repeats, IR tail & Substrate recognition \\
\hline
\end{tabular}




\subsection{Role of APC in cell cycle}

In mitosis, the APC is crucial for the transition from metaphase to anaphase, and for exit from mitosis. For cell cycle progression, a vast amount of divergent tasks have to be managed at special timepoints of cell cycle. To cope this challenge APC needs its co-activators to get specifity and thus to fulfil its job. In S.cerevisiae two coactivators, Cdc20 and Cdh1 (Cdc20 homolouge 1) seem to be essential for the mitotic cell cycle (Harper et al., 2002). Important motifs on co-activators help for substrate recognition, such as the WD40 domain. This domain directly interacts with recognition signals on substrates. For example Cdc20 recognizes substrates which have destruction box (D-box) motifs. On the other hand, KEN-box motifs are targets of Cdh1. Recently, several more degradation motifs have been identified, such as the Abox and O-box (Castro et al., 2005). It was proven that both Cdc20 and Cdh1 can bind to those boxes. Acquaviva and Pines (2006) pointed out that not only the co-activators but also APC subunits themselves, such as Doc1/Apc10, might be involved in substrate selection.

Initially, APC was discovered as an enzyme complex needed for cyclin destruction in mitosis (Irniger et al., 1995; Sudakin et al., 1995). As described above, cyclins act as partners of cyclin dependent kinases which have central regulatory functions in cell cycle. Thus, it is necessary that Cdk1 is kept inactive while exiting from mitosis. Since activity of Cdk1 is cyclin dependent, degradation of cyclins leads to a conformational change blocking the active site of protein substrates (Jeffrey et al., 1995). At that stage cyclin proteolysis is initiated by APC in association with the co-activator Cdc20. Deactivation of Cdk1 gives protein phosphatases the chance to dephosphorylate Cdk1 substrates. As a net result this chain of reactions allows the disassembly of the mitotic spindle, chromosome decondensation, reformation of a nuclear envelope etc. Also right after exit from mitosis, during telophase and G1 phase, Cdk1 activity has to be kept low since Cdk1 activity inhibits the formation of pre-replicative complexes (pr-RCs). This important task which is a prerequisite for the next $\mathrm{S}$ phase and DNA replication is managed by APC ${ }^{\text {Cdh1 }}$. Additionally, APC ${ }^{\text {Cdh1 }}$ inhibits the activity of SCF E3 ligase that also has controlling functions during G1-S transition (Vodermaier, 2004). Once arrived in S phase the APC has to do probably its most prominent role, promoting anaphase. In metaphase sister chromatids are aligned along the aquitorial plate and are hold together by a cohesin ring. For proper sister chromatid seperation in anaphase the cohesin ring has to be cleaved thus enabling the microtuble apparatus pulling sister chromatids to the poles. In budding yeast the separase Esp1 cleaves the subunit Scc1 of cohesin rings. To ensure that Scc1 cleavage is not initiated before the onset of anaphase the inhibitor protein Pds1 blocks separase activity (Nasmyth et al., 2001). And here the APC comes into game again. In complex with Cdc20 the separase inhibitor 
Pds1 is ubiquitinated and targeted for proteolysis allowing the accomplishment of mitosis. Due to the fact that meiosis has two chomosome segregation rounds without an intervening $S$ phase suggests a more complicated regulation of the meiotic cell cycle. Also the discovery of a third co-activator, Ama1, having functions only in meiosis underlines this matter (Cooper et al., 2000). Oelschlaegel et al. (2005) pointed out that $A P C^{A m a 1}$ is required for sporulation and contributes to the degradation of the securin Pds1 in anaphase of meiosis I. The importance of a proper working APC complex is demonstrated by Wirth et al. (2004) showing that inactivation of APC causes lethality in all organisms from fungi to mouse.

\subsection{Regulation of APC}

As described above, the co-activators $\mathrm{Cdc} 20$ and Cdh1 associate only transiently to the APC complex determining the activity of the APC during cell cycle. Allthough Cdc20 is transcribed during $S$ and $G 2$ phase it can only bind to the APC once cyclin dependant kinases have phosphorylated APC subunits. This phosphorylation reaction inhibits the assembly of the $A P C^{\text {Cdh1 } 1}$ complex, whereas APC ${ }^{\text {Cdc20 }}$ assembly is promoted by phosphorylation. As a result $A P C^{C d c 20}$ is active in early mitosis. Later $A P C^{\operatorname{Cdc20}}$ decreases Cdk activity thus leading to the dissociation of the APC ${ }^{\mathrm{Cdc20}}$ complex. Once Cdc20 is released Cdh1 will bind to the complex with the help of the phosphatase Cdc14 (Visintin et al., 1998). This opposing effect of phosphorylation switches Cdk activity from high to low, which is required for exit from mitosis (Hagting et al., 2002). APC ${ }^{\text {Cah1 }}$ is inactivated later in G1-S transition, which is essential for accumulation of cyclins necessary for DNA replication and entry into mitosis. Another way of regulating the APC is represented by the spindle assembly checkpoint. The spindle assembly checkpoint is monitoring in metaphase whether chromosomes have been attached properly to the mitotic spindle. Mad and Bub proteins are sitting on kinetochores and in case of improper spindle assembly bind to the Cdc20 adaptor protein of the APC (Prinz et al., 1998). Since $\mathrm{APC}^{\mathrm{Cdc20}}$ inactivates $\mathrm{Cdc} 28 / \mathrm{Clb}$, ubiquitination of B-type cyclins is blocked and so a delay of mitotic exit is achieved. At the beginning of mitosis, in prophase, when the spindle checkpoint is not active yet, another protein, Emi1, inhibits the activity of $\mathrm{APC}^{\mathrm{Cdc} 20}$ by binding to $\mathrm{Cdc} 20$ (Reimann et al., 2001). Another inhibitor is Mnd2 (meiotic nuclear division potein $\underline{2}$ ) regulating the co-activator Ama1, but not the other two co-activators, Cdh1 and Cdc20 (Oelschlaegel et al., 2005). Regulation mechanism is not known but inactivation of Mnd2 is needed at the onset of anapahase I to get APC ${ }^{\text {Ama1 }}$ active again. In fission yeast another meiosis specific inhibitor of APC was identified, namely Mes1. Small Mes1 proteins inhibit $\mathrm{APC}^{\mathrm{Cdc20}}$ thus preventing complete degradation of cyclins during the exit from meiosis I (Izawa et al., 2005). 


\section{Meiosis}

In budding yeast, the G1 phase is the timepoint when cells decide to enter mitosis or meiosis. The decision to enter meiosis depends on nutrient availability and other factors (regulation of meiosis is described below). The meiotic cycle is illustrated in figure 5 .

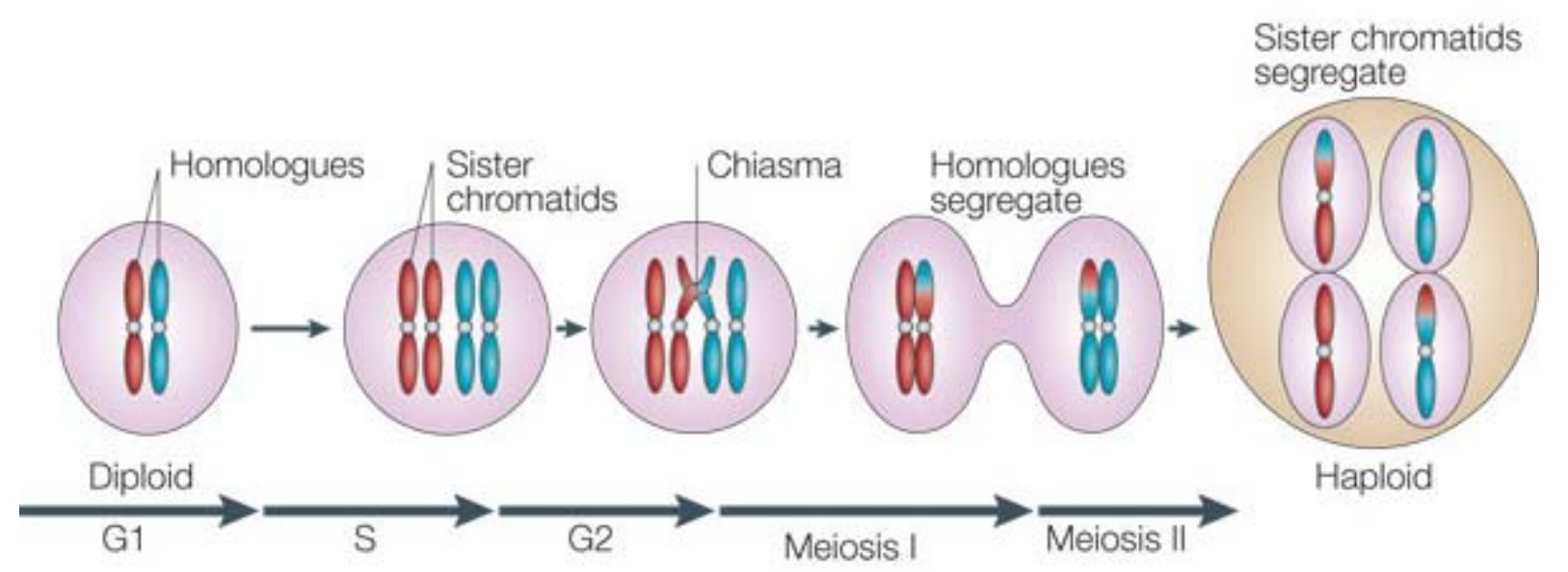

Fig.4: The meiotic cell cycle (Marston and Amon, 2004)

Meiosis is a similar process to mitosis, but having one round of DNA replication followed by two sequential rounds of chromosome generation. Homologous chromosomes form chiasma as a result of crossing over in prophase I. In meiosis I homologous chromosomes and in meiosis II sister chromatides are pulled apart. The overall aim of meiosis is the generation of four haploid cells out of one diploid parent cell.

The most significant difference to the mitotically cycling cell is that in meiosis the offspring cell has a haploid set of chromosomes, whereas in mitosis the daughter cells have diploid sets of chromosomes. The reason for this outcome is that in meiosis one round of DNA replication is followed by two sequential rounds of chromosome segregation. Once decided for meiosis in G1 phase the following S phase was shown to be substantially longer than the mitotic S-phase (Cha et al., 2004). In S phase the composition of the meiotic DNA replication machinery is triggered by Cdks associated to B-type cyclins Clb5 and Clb6 (Collins and Newlon, 1994). In G2 phase landmark events such as meiotic recombination, pairing of homolouges, and the formation of the synaptonemal complex occur. Homologous chromosomes are linked to each other and meiotic recombination takes place. This assembly which is unique to meiosis is called chiasma and holds the homologues pairs together. In meiosis I homologue chromosome pairs segregate from each other, rather than sister chromatids. It is eminent that the linkage (cohesin) between sister chromatids must be maintained beyond meiosis I. In meiosis II separase becomes active 
and cleaves the cohesin ring allowing sister chromatids to apart to the poles. The processes in anaphase of mitosis is much likely the same as the anaphase II of meiosis.

\subsection{Regulation of meiosis}

At least three external signals have to be sensed in order to force S.cerevisiae cells to undergo meiosis and spore formation which is ascribed together as sporulation: lack of nutrient, availabality of a non-fermentable carbon sources and the absence of glucose. There are several signal transduction pathways (Thevelein and de Winde, 1999; Raught et al., 2001) which have mediator functions but all converge to one point: the central regulators of meiosis IME1 and IME2. IME1 encodes a transcription factor activating the expression of genes needed early in meiosis including IME2. IME2 itself is needed for early and later stages of meiosis (Mitchell, 1994). The promoter region of IME1 has four distinct upstream control regions (UCS 1-4) which can be targets of activators or repressors. For example, an Rme1 protein, highly expressed in haploid cells, binds to the regulatory region RRE1 of IME1 thus blocking its transcription (Blumental-Perry et al., 2002). As a result haploid cells are hindered in entering meiosis. IME1 transcription is repressed if glucose binds to the upstream control region, whereas non fermentable carbon sources as acetate activates the expression (Sagee et al., 1998). In contrast to the complex promoter region of IME1, IME2 has only one single regulatory element, URS (upstream repression site). Under IME2 repressing conditions the transcription factor Ume6 binds to the URS site of IME2. In cooperation with the Sin3/Rpd3 complex transcription of IME2 is blocked. For IME2 activation first the Sin3/Rpd3 complex has to be removed and second Ime1 has to get in complex with Ume6 (Washburn and Esposito, 2001). Both transcription factors, Ime1 and Ume6, are phosphorylated by Rim11 which stabilizes the complex (Malathi et al., 1997). During late stages of meiosis the protein kinase Ime2 phosphorylates Ime1, thereby targeting it for degradation (Guttmann-Raviv et al., 2002). One example for sensing pathways promoting sporulation is the glucose repression pathway (Johnston and Lowndes, 1992). The central component of this pathway is Snf1, a kinase downregulated in the presence of glucose. Also G-coupled receptors have glucose sensing capability as Gpr1 (Lorenz et al., 2000). Once activated this pathway this causes activation of protein kinase A (PKA) which in turn lowers the level of both IME1 and IME2 transcription level (Donzeau and Bandlow, 1999). Microarray data have shown that at least 300 genes are upregulated during the programm of meiosis (Chu et al., 1998). 


\subsection{The protein kinase Ime2}

IME2 transcription starts at early stages of meiosis and peaks again later at time of chromosome segregation. The transcription factor Ime1 promotes the first wave of IME2 expression and another transcription factor, Ndt80, a transcriptional activator of middle sporulaion genes, the second one. After positively regulating transcription of early meiosis specific genes (Mitchell et al., 1990) it is required for downregulating early meiosis specific genes at later stages. Ime1 is probably targeted for degradation via phosphorylation by Ime2 (Guttmann-Raviv et al., 2002). At later stages Ime2 has several tasks such as phosphorylation of replication protein A (RPA) (Clifford et al., 2005), positively regulating Ndt80 (Benjamin et al., 2003) and negatively regulating Sum1, a repressor of Ndt80 (Pak and Segall, 2002). Since the serin/threonine protein kinase Ime2 is functionally related to $\mathrm{Cdc} 28$ it was proposed that Ime2 has similar functions in meiosis. Indeed, Ime2 controls the S phase in meiosis which is normally managed by Cdc28 during the mitotic cell cycle (Honigberg, 2004). The role of targeting the Cdk inhibitor Sic1 for destruction is taken over by Ime2 during meiosis (Dirick et al., 1998). Despite this functional similarity, the mechanism of regulating Ime2 and Cdc28 seem to be different, since there were no binding partners like cyclins identified, which regulate Ime2 activity. Direct influence of Ime2 on APC function was demonstrated by (Bolte et al., 2002). It could be shown that Ime2 negatively regulates $C d h 1$, thereby inactivating the $A P C^{C d h 1}$ complex in meiosis. This enables chromosome segregation in anaphase I. Ime2 contains a TXY motif in its activation loop similar to mitogen activated protein kinases (MAPKs). It was shown that the disruption of this TXY motif leads to a decrease of Ime2 activity (Schindler et al., 2003) illustrating the requirement of Thr and Tyr phosphorylation for activity. Once active, Ime2 autophosphorylates its activation loop. Recently, (Schindler and Winter, 2006) could show that the residues $\mathrm{Thr}^{242}$ and $\mathrm{Tyr}^{244}$ of the TXY motif are phosphorylated in an Cak1 dependent manner. In addition, two other residues $\operatorname{Ser}^{520}$ and $\mathrm{Ser}^{625}$, C-terminally located, are phosphorylated to the end of meiotic division. Mutants lacking the phosphorylation sites at the C-terminus show an increase in dyad formation. 


\section{Life cycle of Aspergillus nidulans}

Although both Saccharomyces cerevisiae and Aspergillus nidulans belong to ascomycetes, they have differences in many aspects. Perhaps the most apparent one is the formation of mycelia of A.nidulans cells which resembles a network of interconnected cells. Such morphogenesis is attained by the capacity of A.nidulans hyphal cells to grow polarized having always a fixed growth axis. In contrast, yeast cells undergo repeated cycles of polarization and depolarization. For sure, in environment this feature of A.nidulans cells is of advantage. With a constant fast expand rate of $0.5 \mathrm{~mm} \mathrm{~h}^{-1}$ A.nidulans has good chances against competitors struggling for nurtrient resources (Lee and Adams, 1994). In contrast to unicellular yeasts the mold, A. nidulans, is a multicellular organism always growing as a hyphae. Nevertheless, yeast cells show a specialised form of hyphal growth, the pseudohyphal growth where individual cells do not loose their identity and form a chain of individual cells.

The developmental cycle of A.nidulans starts with a spore being either originated mitotically or meiotically since A.nidulans strains can propagate both sexually or asexually (Adams et al., 1998)(Fig.5). 16h after spore germination hyphal specialization of cells becomes apparent. Branching of hyphae and subsequent differentiation leads to formation of conidiophores which rise from the agar surface. Conidiophores are asexual spore carrying structures of A.nidulans responsible for production and spreading of spores. After $24 \mathrm{~h}$ the former germinating spore gives rise to thousands of spores which can reinitiate the cycle again. If grown in liquid culture A.nidulans strains will not produce conidiophores, suggesting that for conidiophore production an air interphase is needed. Meiotically reproducing A.nidulans strains form fruit bodies, cleistothecia, wich are surrounded by globose, thick walled 'Hülle cells'. So called 'nests' (Lat. nidulans $=$ nest former) are formed by fused hyphae surrounded by mycelium which then differentiate to multinucleate Hulle cells. Once a mature cleistothecia is formed, $100 \mathrm{~h}$ after initial spore germination, it will give rise to about 80.000 ascopores (Braus et al., 2002). Different from mitotic spores, meiotic spores are characteristically reddish due to the red pigment called asperthecin. In contrast to budding yeast mating types are not known for A.nidulans. Nevertheless, in $A$. nidulans sexual development can be initiated by a process called selfing when two dicaryotic hyphae fuse together. Also the teleomorph Emericella (=Aspergillus) nidulans refers to its ability to propagate sexually even in absence of a partner. 


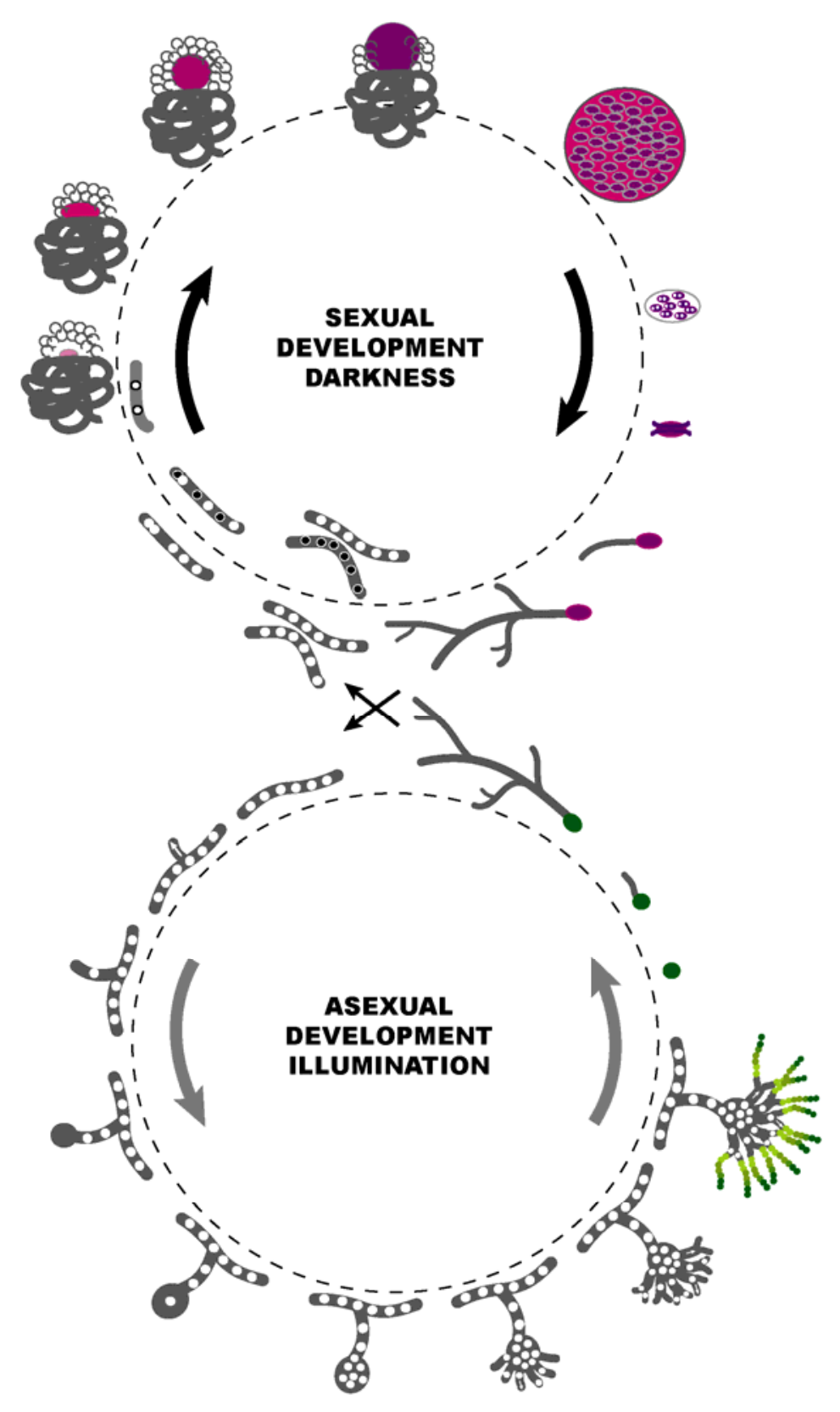

\section{Fig.5 : Life Cycle of Aspergillus nidulans}

Light induces asexual development starting with the rise of aerial hyphae which develops later to a three-dimensional conidia carrying structure, conidiophore. Mono- or Dikaryotic hyphae enter sexual life cycle forming first "nest" cells which develop to Hülle cells. Later Hülle cells nurse the fruiting bodies, cleistothecia, which carry the sexual ascospore. 


\subsection{Asexual development}

The initiation of conidiophore formation requires a hyphal pregrow of $18 \mathrm{~h}$ in order to respond to the signal provided by air exposure (Yager et al., 1982). Another inductor for conidiation is light. Phytochrome like molecules, as FphA, detect red light and thus repressing sexual development (Blumenstein et al., 2005). Although it has been reported that nutrient limitations or other stress factors increase the number of conidiophores (Morton, 1961; Martinelli, 1976) it seems as conidiation is medium independent (Adams et al., 1998).

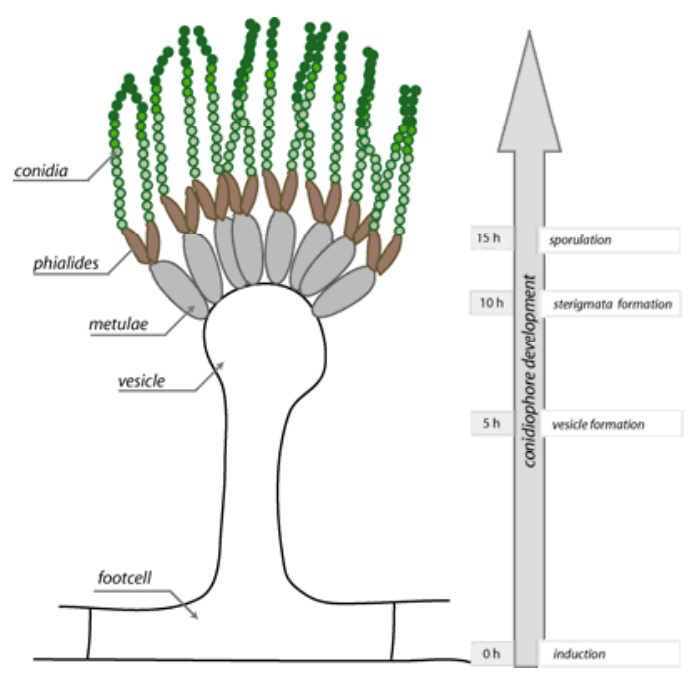

Fig.6: Aspergillus nidulans conidiophore development

Conidiophores are conidia spore carrying structures formed during asexual development. First conidia appear 15 hours after conidiophore induction. A footcell links the conidophore to the ground mycelium. Formed chains of conidia are exposed to air (Adams et al., 1998).

The conidiophore (see fig.6) formation starts with the branching of an aeral stalk out of the vegetative hyphae (Timberlake, 1990). The stalk grows without any branching to a defined height starting to swell at the apical extension. This forming vesicle, the stalk, and the footcell, which connects the vegetative hyphae to the former conidiophore, form a single unit. The next specialized cell type emerging from the vesicle are the metulae. Each of the about 60 metulae sitting on a vesicle, buds twice giving rise to a layer of 120 phialides. If considered that one phialide can produce 100 spores, probably the total number exceeds 10.000 .

The central regulatory network of asexual sporulation is composed of three genes which act in concert: wetA, $b r l A, a b a A$. brlA is an early regulator of development. brlA null mutants fail to propagate conidiophores and stop early at development (Clutterbuck, 1970). brlA regulation is 
complicated since there are two overlapping transcripts, $b / r A \alpha$ and $b r I A \beta$, which are tightly regulated and have different functions in early stages of development (Han et al., 1993). Genetically the loss of $b r l A$ effects also the later transcripts wet $A$ and $a b a A$. $a b a A$ mutants are described as "abacus" because they produce conidiophores missing conidia (Sewall et al., 1990). WetA is required late in development. Thus wetA mutants produce conidia, but never become pigmented and autolyse themselves (Sewall et al., 1990). The RNA accumulation pattern of the series $b r \mid A, a b a A$, and wetA is in consistent with the proposed model for the temporal control of genes during differentiation of conidiophore development. Adams et al. (1998) suggested that activation of $b r l A$ initiates a cascade coordinated by the interactions of $b r l A, a b a A$ and wetA in a temporal manner. Upstream of this central regulatory network other genes have been described which have direct influence on $b r l A$ expression and thus the central regulatory network of asexual development. Collectively they were defined as "fluffy" mutants showing undifferentiated masses of vegetative hyphae forming cotton-like colonies (Wieser et al., 1994). This group of genes includes nucleic acid binding proteins ( $I|b B, f| b C$, fluE, and $f \mid b D)$, a G-protein antagonizing protein $(f / b A)$, and a gene required for the production of an extracellular factor (fluG). Despite different functions, a mutation of these six genes leads to a distinct reduction of brlA expression (Adams et al., 1998). It was reported that FluGdependent conidiation in A. nidulans occurs via derepression (Seo et al., 2006). Heterotrimeric G-proteins seem to have roles in governing growth and development in $A$. nidulans. The $\mathrm{G}$ gamma subunit GpgA is required for asexual and sexual developmental progression (Seo et al. 2005). One other G-protein which negatively regulates asexual development is the G alpha protein GanB (Chang et al., 2004). Recently, a transmembrane protein, TmpA, was identified as a regulator of conidiation (Soid-Raggi et al., 2006). Deletion of tmpA resulted in a decreased brlA expression and conidiation. A decrease in conidia formation could be also observed in ksfA mutants (Takeshita et al., 2007). KsfA (kinase for septation) is a putative kinase which plays a role septation and in asexual spore formation. 


\subsection{Sexual development}

The fungus Aspergillus (Emericella) nidulans can reproduce sexually allthough no abvious male or female structures could be observed. Thus one spore can produce up to 1000 ascospores by self-fertilization, a process called selfing. This ascospores are meiotically derived and mature in the sexual fruit bodies, cleistothecia, of A.nidulans. Among Ascomycetes subgroups are classified according to the morphological structures of their sexual fruit bodies. Three sexual fruit bodies are described: the vase-shaped perithecia (e.g. Neurospora crassa), the linear apothecium (e.g. Sordaria macrospora), and the closed cleistothecia (e.g. Aspergillus nidulans). The formation of cleistothecia and thus the sexual development is initiated by one fusion event of hyphal tips. The first sign of sexual structure appears after 50 hours, when fused hyphae are surrounded by growing mycelium form 'nest'. Nests later differentiate to multinucleate globose Hülle cells which are encircling the developing cleistothecia. In detail, for cleistothecia generation heterokaryotic hyphae starts to form a crozier, a hook shaped structure where two nuclei start to divide synchronously. Once two different nuclei are brought together in one compartment nuclear fusion (karyogamie) initiates further ascus development (Pontecorvo et al., 1953). Meiotic events result in eight nuclei propagating to eight red pigmented ascospores within each ascus (Pöggeler et al., 2006).

\subsection{Regulating factors of sexual development of $A$. nidulans}

The first prerequesite for sexual development induction is the developmental competence of A.nidulans strains, because it was observed that mature fruit bodies appear after $100 \mathrm{~h}$ of vegetative growth (Champe et al., 1994). Another factor for induction of sexual development is darkness. Mooney and Yager (1990) could show that light stimulates formation of conidiophores, since strains incubated in light form less fruit bodies when compared to strains grown in the dark. The central light dependent element controlling the balance between conidiation and sexual development is VeA. Mutants lacking veA display an increase of conidiation, presumably, as a result of elevated brlA transcription, a gene responsible for conidiation (see above)(Axelrod et al., 1973). Todd et al. (2006) could show that the gene rcoA is required for veA- dependent sexual development A.nidulans. Another protein, BasA, which regulates the asexual/sexual sporulation ratio in A.nidulans was identified recently (Li et al., 2007). It was proposed that BasA has also additional functions in cell wall organization. Fruit body formation depends also on a surface and the $\mathrm{CO}_{2}$ content of the air, since $\mathrm{CO}_{2}$ is required for carbon metabolism. It is known that $\mathrm{CO}_{2}$ favors fruit body formation, whereas aeration 
(removal of $\mathrm{CO}_{2}$ ) promotes asexual sporulation (Champe et al., 1994). Nutrient supply also determines the decision of development, since high concentrations of potassium, sodium or magnesium ions changes the sexual mode to asexual mode of development. For this saltdependent regulation the genetic elements IsdA (Lee et al., 2001) and the cyclin dependent kinase phoA are required (Bussink and Osmani, 1998). Fruit body formation is also reduced when carbon sources are limited ( $0.8 \%$ glucose). Carbon sources are required for $\alpha$-1,3-glucan, a component needed for cleistothecial cell wall (Zonneveld, 1974). Also the amino acid availability influences the developmental program of A.nidulans. A lack of arginine but also tryptophan deficiency blocks cleistothecia formation (Serlupi-Crescenzi et al., 1983; Yelton et al., 1983). For tryptophan it could be shown that lowest amounts are required for mycelial growth and the highest for the formation of fruit bodies (Eckert et al., 1999). In A. nidulans amino acid starvation blocks sexual development different from the budding yeast Saccharomyces cerevisiae, where amino acid limitation promotes sporulation, the sexual development of yeast.

Genes having functions in signal transduction are also characterised in A.nidulans. A subgroup is collectively named flu (=fluffy) genes. The typical flu phenotype is a cotton like colony morphology without any sexual structures. Both the atypical conidiophore formation and the inability to perform the sexual cycle indicates a connection between the asexual and sexual developmental program. One example for a fluffy gene is flbA, a homolog of the yeast SST2, which encodes an RGS (=regulator of G-protein signaling) (Yu et al., 1996). An important function ascribed to FlbA is the choice between vegetative growth and the program of sporulation.

One other fluffy gene, $f l b D$, encodes a DNA binding protein with a bZIP dimerization domain (Wieser and Adams, 1995). The linkage between the asexual and sexual development is shown by two other transcription factors, medA and stuA. Both genes exhibit clear effects on asexual as well as on sexual differentiation. medA mutants stop development at the stage of Hülle cell formation, but also asexual structures as conidiophores have atypical morphology (Clutterbuck, 1990). stuA mutants are unable to form cleistothecia and form abnormal conidiophores with spores emerging from the vesicles (Miller et al., 1991). Two additional transcription factors, $n s d D$ and steA, seem to have crucial roles during sexual development. Deletion of $n s d D$ inhibits fruit body development at the stage of Hülle cell formation (Han et al., 2001). It was demonstrated that SteA, a $\mathrm{C}_{2} / \mathrm{H}_{2}$ zinc finger transcription factor, is required for sexual reproduction (Vallim et al., 2000). Like medA mutant strains, steA mutants stop the sexual developmental program after the formation of Hülle cells. To understand the sexual life cycle 
of A.nidulans in more detail Han et al. (1990) identified in a genetic screen mutants defective in sexual development and classified them in two groups : nsd (never sexual development) mutants being unable to form any sexual structures and bsd (blocked in sexual development) mutants showing differences in morphology or timing of production of sexual structures. Two $\mathrm{Zn}(\mathrm{II}) 2$ Cys6 putative transcription factors, RosA and NosA, seem to have exclusively roles in sexual development. RosA acts as repressoor of sexual development under low-carbon conditions (Vienken et al., 2005). The other transcription factor is NosA which controls fruiting body formation (Vienken and Fischer, 2006). The linkage between protein degradation and sexual development could be proven by Busch et al. (2007). They investigated the multiprotein COP9 siganlosome complex and showed that a deletion of one of the subunits leads to a block of sexual fruit body formation. This suggests that a proper working COP9 signalosome (CSN) is crucial for the progression of sexual development.

\subsection{The protein kinase ImeB and MAP kinases}

Mitogen activated protein kinases (MAPK) transmit external stimuli to the interior of the cell, which enables an adequate respond of the cell. The MAPK module consists of three units collaborating together: MAPKK (also MEKK) kinases, MAPK (also MEK) kinases, and MAP kinases. The first protein kinase in this relay system which is activated is the MAPKK kinase which in turn activates MAPK kinases via phosphorylation on conserved serine and threonine residues. The MAP kinase, the last unit of the module, is activated by phosphorylation on tyrosine and threonine residues. Once activated MAP kinases can translocate to the nucleus and perform its task as transcription factor (Dickman and Yarden, 1999). The catalytic domain of all kinases can be subdivided into 12 conserved domains (Hanks and Hunter, 1995). The activation of MAP kinases is achieved by two closely spaced Thr and Tyr residues (Thr-X-Tyr) found in the catalytic subdomain VIII; X can be Pro, Gly, or Glu. Mutations of the X residue does not appear to affect activation by MAPKK (Wang et al., 1997) but mutations of the neighboring residues (Thr, Tyr) strongly inactivates the MAP kinase (Gotoh and Nishida, 1993). The MAP kinase module is unique in all eukaryotes from yeast to mammalian. In S.cerevisiae several independent MAPK modules exist which respond to osmotic stress, pheromones, cell wall integrity, spore formation, and pseudohyphal growth. In the pathogenic fungus Aspergillus fumigatus four MAP kinases hogA, $m p k A, m p k B$ and $m p K C$ could be identified until now (May et al., 2005). Recent data, showed that MAPK modules also exist in the homothallic fungus, Aspergillus nidulans. Up to now, besides a MAPKK kinase, SteC, (Wei et al., 2003) only one MAP kinase, SakA, (Kawasaki et al., 2002) could be discovered. This also reflects how little is done in 
concern of MAP kinases in Aspergillus nidulans, since the first mammalian MAP kinase was characterized and cloned two decades ago (Banuett, 1998). Another protein kinase identified recently as a MAP kinase in A. nidulans is ImeB. In a blast search of the A. nidulans genome data base it was found as the homologue of the yeast serin threonine protein Ime2. A.nidulans ImeB shares $40 \%$ identity with Ime2 from S. cerevisiae. Both proteins have a highly conserved protein kinase domain in the $\mathrm{N}$-terminus. The conserved mitogen activated protein kinase motif, TXY, is also present in ImeB suggesting a role in signal transduction. 


\section{Aim of this work}

Budding yeast Saccharomyces cerevisiae and the filamentous fungus Aspergillus nidulans became commonly used model organisms to investigate fundamental cellular processes in eukaryotes. Many processes and factors are highly conserved from yeast to human. The aim of this work was to get a better knowledge of factors involved in the regulation of the cell cycle and of sexual development.

In the first project, the yeast cyclin $\mathrm{Clb5}$ should be analysed. Cyclins are regulatory subunits of cyclin-dependent kinases (CDKs), which are key enzymes for cell cycle progression. In yeast, Cdk1 is the only CDK with an essential role in the cell cycle and this enzyme is activated by different types of cyclins. Cyclins are highly unstable proteins. Whereas degradation of mitotic cyclins is fully dependent on the ubiquitin ligase $A P C / C$, previous data indicate that proteolytic destruction of the S-phase cyclin is significantly different. Cells containing Clb5 lacking its destruction box were viable and did not display defects in progression through the cell cycle (Wasch and Cross, 2002). These data argue against an important role of APC/C in Clb5 proteolysis. Other reports came to opposite conclusions and identified $\mathrm{Clb5}$ as an essential target of APC/C (Thornton et al., 2004). The aim of this part of the project was to perform a detailed analysis of the stability of $\mathrm{Clb5}$ throughout the cell cycle. Furthermore, by using temperature-sensitive mutants, it should be elucidated whether $\mathrm{Clb5}$ proteolysis is dependent on the APC/C. Stability should be measured by a pulse labeling approach which allows a precise determination of the half-life of proteins. It should also be tested whether the second important ubiquitin ligase in the cell cycle, the SCF complex, is involved in Clb5 degradation, and whether proteolysis is mediated by the $26 \mathrm{~S}$ proteasome.

The second project of this work focused on the meiosis-specific Ime2. Meiosis is a specialized cell cycle with two rounds of chromosome segregation, resulting in the production of four haploid spores in yeast. Ime2 and Cdk1 are known to act in concert to drive the meiotic cell cycle. In contrast to Cdk1, Ime2 is not regulated by cyclins, but is itself an unstable protein (Bolte et al., 2002). The aim of this part of the project was to elucidate whether Ime2 activity may be controlled by its own instability. First, it should be determined, which sequence elements in Ime2 are responsible for the instability of Ime2. By deletion of the degradation elements, it should then be possible to construct a stabilised version of Ime2. After testing that this stable Ime2 is still active, it should be expressed in the efficiently sporulating yeast strains SK1. Then it can be tested, whether stabilized Ime2 interferes with the progression through the meiotic cell cycle and/or spore formation. These experiments should clarify the relevance of Ime2 instability for the sporulation program in yeast 
In the third project, the Ime2-homolog in Aspergillus nidulans should be characterized. A data base search identified ImeB, which has $40 \%$ homology to Ime2 in its $\mathrm{N}$-terminal kinase domain. To elucidate the function of ImeB, an imeB deletion strain should be constructed and analysed in detail on agar plates and liquid medium and under conditions of asexual and sexual development. Furthermore, ImeB should be overexpressed from the alcA promoter. These experiments should reveal whether ImeB has similar functions as Ime2 in the yeast Saccharomyces cerevisiae. ImeB expression levels during asexual and sexual development, as well as the intracellular localization of ImeB, should also be determined. Furthemore, it should be also analysed, whether the TXY motif, a highly conserved element present in all MAP kinases, is important for ImeB function. For this purpose, site-directed mutagenesis can be applied. 


\section{References}

Acquaviva, C., and Pines, J. (2006). The anaphase-promoting complex/cyclosome: APC/C. J Cell Sci 119, 2401-2404.

Adams, T.H., Wieser, J.K., and Yu, J.H. (1998). Asexual sporulation in Aspergillus nidulans. Microbiol Mol Biol Rev 62, 35-54.

Axelrod, D.E., Gealt, M., and Pastushok, M. (1973). Gene control of developmental competence in Aspergillus nidulans. Dev Biol 34, 9-15.

Banuett, F. (1998). Signalling in the yeasts: an informational cascade with links to the filamentous fungi. Microbiol Mol Biol Rev 62, 249-274.

Benjamin, K.R., Zhang, C., Shokat, K.M., and Herskowitz, I. (2003). Control of landmark events in meiosis by the CDK Cdc28 and the meiosis-specific kinase Ime2. Genes Dev 17, 1524-1539.

Bloom, J., and Cross, F.R. (2007). Multiple levels of cyclin specificity in cell-cycle control. Nat Rev Mol Cell Biol 8, 149-160.

Blumenstein, A., Vienken, K., Tasler, R., Purschwitz, J., Veith, D., Frankenberg-Dinkel, N., and Fischer, R. (2005). The Aspergillus nidulans phytochrome FphA represses sexual development in red light. Curr Biol 15, 1833-1838.

Blumental-Perry, A., Li, W., Simchen, G., and Mitchell, A.P. (2002). Repression and activation domains of RME1p structurally overlap, but differ in genetic requirements. Mol Biol Cell 13, 1709-1721.

Bolte, M., Steigemann, P., Braus, G.H., and Irniger, S. (2002). Inhibition of APC-mediated proteolysis by the meiosis-specific protein kinase Ime2. Proc Natl Acad Sci U S A 99, 43854390.

Braus, G.H., Krappmann, S., and Eckert, S. (2002). Sexual development in ascomycetes: Fruit body formation in Aspergillus nidulans. In Molecular Biology of Fungal Development, Osiewacz, ed (New York: Marcel Dekker Inc), pp. 215-244.

Busch, S., Schwier, E.U., Nahlik, K., Bayram, O., Helmstaedt, K., Draht, O.W., Krappmann, S., Valerius, O., Lipscomb, W.N., and Braus, G.H. (2007). An eight-subunit COP9 signalosome with an intact JAMM motif is required for fungal fruit body formation. Proc Natl Acad Sci U S A 104, 8089-8094.

Bussink, H.J., and Osmani, S.A. (1998). A cyclin-dependent kinase family member (PHOA) is required to link developmental fate to environmental conditions in Aspergillus nidulans. Embo J 17, 3990-4003.

Cardozo, T., and Pagano, M. (2004). The SCF ubiquitin ligase: insights into a molecular machine. Nat Rev Mol Cell Biol 5, 739-751.

Castro, A., Bernis, C., Vigneron, S., Labbe, J.C., and Lorca, T. (2005). The anaphase-promoting complex: a key factor in the regulation of cell cycle. Oncogene 24, 314-325.

Champe, S.P., Nagle, D.L., and Yager, L.N. (1994). Sexual sporulation. Prog Ind Microbiol 29, 429454.

Chang, M.H., Chae, K.S., Han, D.M., and Jahng, K.Y. (2004). The GanB Galpha-protein negatively regulates asexual sporulation and plays a positive role in conidial germination in Aspergillus nidulans. Genetics 167, 1305-1315.

Chu, S., DeRisi, J., Eisen, M., Mulholland, J., Botstein, D., Brown, P.O., and Herskowitz, I. (1998). The transcriptional program of sporulation in budding yeast. Science 282, 699-705.

Ciechanover, A., and Iwai, K. (2004). The ubiquitin system: from basic mechanisms to the patient bed. IUBMB Life 56, 193-201.

Clifford, D.M., Stark, K.E., Gardner, K.E., Hoffmann-Benning, S., and Brush, G.S. (2005). Mechanistic insight into the Cdc28-related protein kinase Ime2 through analysis of replication protein A phosphorylation. Cell Cycle 4, 1826-1833. 
Clutterbuck, A.J. (1970). A variegated position effect in Aspergillus nidulans. Genet Res 16, 303-316.

Clutterbuck, A.J. (1990). The genetics of conidiophore pigmentation in Aspergillus nidulans. J Gen Microbiol 136, 1731-1738.

Collins, I., and Newlon, C.S. (1994). Chromosomal DNA replication initiates at the same origins in meiosis and mitosis. Mol Cell Biol 14, 3524-3534.

Cooper, K.F., Mallory, M.J., Egeland, D.B., Jarnik, M., and Strich, R. (2000). Ama1p is a meiosisspecific regulator of the anaphase promoting complex/cyclosome in yeast. Proc Natl Acad Sci U S A 97, 14548-14553.

Dickman, M.B., and Yarden, O. (1999). Serine/threonine protein kinases and phosphatases in filamentious fungi. Fungal Genet Biol 26, 99-117.

Dirick, L., Goetsch, L., Ammerer, G., and Byers, B. (1998). Regulation of meiotic S phase by Ime2 and a Clb5,6-associated kinase in Saccharomyces cerevisiae. Science 281, 1854-1857.

Donzeau, M., and Bandlow, W. (1999). The yeast trimeric guanine nucleotide-binding protein alpha subunit, Gpa2p, controls the meiosis-specific kinase Ime2p activity in response to nutrients. Mol Cell Biol 19, 6110-6119.

Dube, P., Herzog, F., Gieffers, C., Sander, B., Riedel, D., Muller, S.A., Engel, A., Peters, J.M., and Stark, H. (2005). Localization of the coactivator Cdh1 and the cullin subunit Apc2 in a cryoelectron microscopy model of vertebrate APC/C. Mol Cell 20, 867-879.

Eckert, S.E., Hoffmann, B., Wanke, C., and Braus, G.H. (1999). Sexual development of Aspergillus nidulans in tryptophan auxotrophic strains. Arch Microbiol 172, 157-166.

Elsasser, S., and Finley, D. (2005). Delivery of ubiquitinated substrates to protein-unfolding machines. Nat Cell Biol 7, 742-749.

Gimeno, C.J., and Fink, G.R. (1992). The logic of cell division in the life cycle of yeast. Science 257, 626.

Gotoh, Y., and Nishida, E. (1993). [MAP kinase kinase/MAP kinase cascade]. Tanpakushitsu Kakusan Koso 38, 1625-1628.

Grossberger, R., Gieffers, C., Zachariae, W., Podtelejnikov, A.V., Schleiffer, A., Nasmyth, K., Mann, M., and Peters, J.M. (1999). Characterization of the DOC1/APC10 subunit of the yeast and the human anaphase-promoting complex. J Biol Chem 274, 14500-14507.

Guttmann-Raviv, N., Martin, S., and Kassir, Y. (2002). Ime2, a meiosis-specific kinase in yeast, is required for destabilization of its transcriptional activator, Ime1. Mol Cell Biol 22, 20472056.

Haglund, K., and Dikic, I. (2005). Ubiquitylation and cell signaling. Embo J 24, 3353-3359.

Hagting, A., Den Elzen, N., Vodermaier, H.C., Waizenegger, I.C., Peters, J.M., and Pines, J. (2002). Human securin proteolysis is controlled by the spindle checkpoint and reveals when the APC/C switches from activation by Cdc20 to Cdh1. J Cell Biol 157, 1125-1137.

Hall, M.C., Torres, M.P., Schroeder, G.K., and Borchers, C.H. (2003). Mnd2 and Swm1 are core subunits of the Saccharomyces cerevisiae anaphase-promoting complex. J Biol Chem 278, 16698-16705.

Han, D.M., Han, Y.J., Lee, Y.H., Jahng, K.Y., Jahng, S.H., and Chae, K.S. (1990). Inhibitory conditions of asexual development and their application for the screening of mutants defective in sexual development. Korean Journal Mycol 18, 225-232.

Han, K.H., Han, K.Y., Yu, J.H., Chae, K.S., Jahng, K.Y., and Han, D.M. (2001). The $n s d D$ gene encodes a putative GATA-type transcription factor necessary for sexual development of Aspergillus nidulans. Mol Microbiol 41, 299-309.

Han, S., Navarro, J., Greve, R.A., and Adams, T.H. (1993). Translational repression of brlA expression prevents premature development in Aspergillus. Embo J 12, 2449-2457.

Hanks, S.K., and Hunter, T. (1995). Protein kinases 6 . The eukaryotic protein kinase superfamily: kinase (catalytic) domain structure and classification. Faseb J 9, 576-596.

Harper, J.W., Burton, J.L., and Solomon, M.J. (2002). The anaphase-promoting complex: it's not just for mitosis any more. Genes Dev 16, 2179-2206. 
Hershko, A., Ciechanover, A., and Varshavsky, A. (2000). Basic Medical Research Award. The ubiquitin system. Nat Med 6, 1073-1081.

Hicke, L. (2001). A new ticket for entry into budding vesicles-ubiquitin. Cell 106, 527-530.

Hochstrasser, M. (2000). Biochemistry. All in the ubiquitin family. Science 289, 563-564.

Honigberg, S.M. (2004). Ime2p and Cdc28p: co-pilots driving meiotic development. J Cell Biochem 92, 1025-1033.

Hoppe, T. (2005). Multiubiquitylation by E4 enzymes: 'one size' doesn't fit all. Trends Biochem Sci 30, 183-187.

Irniger, S., Piatti, S., Michaelis, C., and Nasmyth, K. (1995). Genes involved in sister chromatid separation are needed for B-type cyclin proteolysis in budding yeast. Cell 81, 269-278.

Izawa, D., Goto, M., Yamashita, A., Yamano, H., and Yamamoto, M. (2005). Fission yeast Mes1p ensures the onset of meiosis II by blocking degradation of cyclin Cdc13p. Nature 434, 529533.

Jeffrey, P.D., Russo, A.A., Polyak, K., Gibbs, E., Hurwitz, J., Massague, J., and Pavletich, N.P. (1995). Mechanism of CDK activation revealed by the structure of a cyclinA-CDK2 complex. Nature 376, 313-320.

Johnston, L.H., and Lowndes, N.F. (1992). Cell cycle control of DNA synthesis in budding yeast. Nucleic Acids Res 20, 2403-2410.

Kaiser, P., and Huang, L. (2005). Global approaches to understanding ubiquitination. Genome Biol 6, 233.

Kassir, Y., and Simchen, G. (1976). Regulation of mating and meiosis in yeast by the mating-type region. Genetics 82, 187-206.

Kawasaki, L., Sanchez, O., Shiozaki, K., and Aguirre, J. (2002). SakA MAP kinase is involved in stress signal transduction, sexual development and spore viability in Aspergillus nidulans. Mol Microbiol 45, 1153-1163.

Lee, B.N., and Adams, T.H. (1994). Overexpression of flbA, an early regulator of Aspergillus asexual sporulation, leads to activation of brlA and premature initiation of development. Mol Microbiol 14, 323-334.

Lee, D.W., Kim, S., Kim, S.J., Han, D.M., Jahng, K.Y., and Chae, K.S. (2001). The IsdA gene is necessary for sexual development inhibition by a salt in Aspergillus nidulans. Curr Genet 39, 237-243.

Li, S., Bao, D., Yuen, G., Harris, S.D., and Calvo, A.M. (2007). basA regulates cell wall organization and asexual/sexual sporulation ratio in Aspergillus nidulans. Genetics 176, 243-253.

Lorenz, M.C., Pan, X., Harashima, T., Cardenas, M.E., Xue, Y., Hirsch, J.P., and Heitman, J. (2000). The $\mathrm{G}$ protein-coupled receptor gpr1 is a nutrient sensor that regulates pseudohyphal differentiation in Saccharomyces cerevisiae. Genetics 154, 609-622.

Malathi, K., Xiao, Y., and Mitchell, A.P. (1997). Interaction of yeast repressor-activator protein Ume6p with glycogen synthase kinase 3 homolog Rim11p. Mol Cell Biol 17, 7230-7236.

Martinelli, S. (1976). Conidiation of Aspergillus nidulans in submerged culture. Trans. Br. Mycol. Soc. 67, 121-128.

May, G.S., Xue, T., Kontoyiannis, D.P., and Gustin, M.C. (2005). Mitogen activated protein kinases of Aspergillus fumigatus. Med Mycol 43 Suppl 1, S83-86.

Miller, J., and Gordon, C. (2005). The regulation of proteasome degradation by multi-ubiquitin chain binding proteins. FEBS Lett 579, 3224-3230.

Miller, K.Y., Toennis, T.M., Adams, T.H., and Miller, B.L. (1991). Isolation and transcriptional characterization of a morphological modifier: the Aspergillus nidulans stunted (stuA) gene. Mol Gen Genet 227, 285-292.

Miller, M.E., and Cross, F.R. (2000). Distinct subcellular localization patterns contribute to functional specificity of the $\mathrm{Cln} 2$ and $\mathrm{Cln} 3$ cyclins of Saccharomyces cerevisiae. Mol Cell Biol 20, 542-555. 
Miller, M.E., and Cross, F.R. (2001). Mechanisms controlling subcellular localization of the $G(1)$ cyclins Cln2p and Cln3p in budding yeast. Mol Cell Biol 21, 6292-6311.

Mitchell, A.P. (1994). Control of meiotic gene expression in Saccharomyces cerevisiae. Microbiol Rev 58, 56-70.

Mitchell, A.P., Driscoll, S.E., and Smith, H.E. (1990). Positive control of sporulation-specific genes by the IME1 and IME2 products in Saccharomyces cerevisiae. Mol Cell Biol 10, 2104-2110.

Mooney, J.L., and Yager, L.N. (1990). Light is required for conidiation in Aspergillus nidulans. Genes Dev 4, 1473-1482.

Morton, A.G. (1961). The induction of sporulation in mould fungi. Proc. R. Soc. London Ser B 153, 548-569.

Nandi, D., Tahiliani, P., Kumar, A., and Chandu, D. (2006). The ubiquitin-proteasome system. J Biosci 31, 137-155.

Nasmyth, K., Peters, J.M., and UhImann, F. (2001). Splitting the chromosome: cutting the ties that bind sister chromatids. Novartis Found Symp 237, 113-133; discussion 133-118, 158-163.

Neiman, A.M. (2005). Ascospore formation in the yeast Saccharomyces cerevisiae. Microbiol Mol Biol Rev 69, 565-584.

Nugroho, T.T., and Mendenhall, M.D. (1994). An inhibitor of yeast cyclin-dependent protein kinase plays an important role in ensuring the genomic integrity of daughter cells. Mol Cell Biol 14, 3320-3328.

Oelschlaegel, T., Schwickart, M., Matos, J., Bogdanova, A., Camasses, A., Havlis, J., Shevchenko, A., and Zachariae, W. (2005). The yeast APC/C subunit Mnd2 prevents premature sister chromatid separation triggered by the meiosis-specific APC/C-Ama1. Cell 120, 773-788.

Pak, J., and Segall, J. (2002). Role of Ndt80, Sum1, and Swe1 as targets of the meiotic recombination checkpoint that control exit from pachytene and spore formation in Saccharomyces cerevisiae. Mol Cell Biol 22, 6430-6440.

Passmore, L.A., McCormack, E.A., Au, S.W., Paul, A., Willison, K.R., Harper, J.W., and Barford, D. (2003). Doc1 mediates the activity of the anaphase-promoting complex by contributing to substrate recognition. Embo J 22, 786-796.

Passmore, L.A., Booth, C.R., Venien-Bryan, C., Ludtke, S.J., Fioretto, C., Johnson, L.N., Chiu, W., and Barford, D. (2005). Structural analysis of the anaphase-promoting complex reveals multiple active sites and insights into polyubiquitylation. Mol Cell 20, 855-866.

Peters, J.M. (2006). The anaphase promoting complex/cyclosome: a machine designed to destroy. Nat Rev Mol Cell Biol 7, 644-656.

Pickart, C.M. (2000). Ubiquitin in chains. Trends Biochem Sci 25, 544-548.

Pöggeler, S., Nowrousian, M., and Kück, U. (2006). Fruiting-Body Development in Ascomycetes. In The Mycota I Growth, Differentiation and Sexuality, K. Fischer, ed (Heidelberg: SpringerVerlag), pp. 325-355.

Pontecorvo, G., Roper, J.A., Hemmons, L.M., Macdonald, K.D., and Bufton, A.W. (1953). The genetics of Aspergillus nidulans. Adv Genet 5, 141-238.

Prinz, S., Hwang, E.S., Visintin, R., and Amon, A. (1998). The regulation of Cdc20 proteolysis reveals a role for APC components Cdc23 and Cdc27 during S phase and early mitosis. Curr Biol 8, 750-760.

Raught, B., Gingras, A.C., and Sonenberg, N. (2001). The target of rapamycin (TOR) proteins. Proc Natl Acad Sci U S A 98, 7037-7044.

Reimann, J.D., Freed, E., Hsu, J.Y., Kramer, E.R., Peters, J.M., and Jackson, P.K. (2001). Emi1 is a mitotic regulator that interacts with $\mathrm{Cdc} 20$ and inhibits the anaphase promoting complex. Cell 105, 645-655.

Roman, H., Phillips, M.M., and Sands, S.M. (1955). Studies of Polyploid Saccharomyces. I. Tetraploid Segregation. Genetics 40, 546-561.

Rudner, A.D., and Murray, A.W. (2000). Phosphorylation by Cdc28 activates the Cdc20-dependent activity of the anaphase-promoting complex. J Cell Biol 149, 1377-1390. 
Sagee, S., Sherman, A., Shenhar, G., Robzyk, K., Ben-Doy, N., Simchen, G., and Kassir, Y. (1998). Multiple and distinct activation and repression sequences mediate the regulated transcription of IME1, a transcriptional activator of meiosis-specific genes in Saccharomyces cerevisiae. Mol Cell Biol 18, 1985-1995.

Schindler, K., and Winter, E. (2006). Phosphorylation of Ime2 regulates meiotic progression in Saccharomyces cerevisiae. J Biol Chem 281, 18307-18316.

Schindler, K., Benjamin, K.R., Martin, A., Boglioli, A., Herskowitz, I., and Winter, E. (2003). The Cdkactivating kinase Cak1p promotes meiotic $S$ phase through Ime2p. Mol Cell Biol 23, 87188728.

Schwob, E., Bohm, T., Mendenhall, M.D., and Nasmyth, K. (1994). The B-type cyclin kinase inhibitor p4OSIC1 controls the $\mathrm{G} 1$ to $S$ transition in S. cerevisiae. Cell 79, 233-244.

Semple, C.A. (2003). The comparative proteomics of ubiquitination in mouse. Genome Res 13, 1389-1394.

Seo, J.A., Guan, Y., and Yu, J.H. (2006). FluG-dependent asexual development in Aspergillus nidulans occurs via derepression. Genetics 172, 1535-1544.

Seo, J.A., Han, K.H., and Yu, J.H. (2005). Multiple roles of a heterotrimeric G-protein gammasubunit in governing growth and development of Aspergillus nidulans. Genetics 171, 81-89.

Serlupi-Crescenzi, O., Kurtz, M.B., and Champe, S.P. (1983). Developmental defects resulting from arginine auxotrophy in Aspergillus nidulans. J Gen Microbiol 129, 3535-3544.

Sewall, T.C., Mims, C.W., and Timberlake, W.E. (1990). abaA controls phialide differentiation in Aspergillus nidulans. Plant Cell 2, 731-739.

Skowyra, D., Craig, K.L., Tyers, M., Elledge, S.J., and Harper, J.W. (1997). F-box proteins are receptors that recruit phosphorylated substrates to the SCF ubiquitin-ligase complex. Cell 91, 209-219.

Soid-Raggi, G., Sanchez, O., and Aguirre, J. (2006). TmpA, a member of a novel family of putative membrane flavoproteins, regulates asexual development in Aspergillus nidulans. Mol Microbiol 59, 854-869.

Sudakin, V., Ganoth, D., Dahan, A., Heller, H., Hershko, J., Luca, F.C., Ruderman, J.V., and Hershko, A. (1995). The cyclosome, a large complex containing cyclin-selective ubiquitin ligase activity, targets cyclins for destruction at the end of mitosis. Mol Biol Cell 6, 185-197.

Takeshita, N., Vienken, K., Rolbetzki, A., and Fischer, R. (2007). The Aspergillus nidulans putative kinase, KfsA (kinase for septation), plays a role in septation and is required for efficient asexual spore formation. Fungal Genet Biol.

Thevelein, J.M., and de Winde, J.H. (1999). Novel sensing mechanisms and targets for the cAMPprotein kinase A pathway in the yeast Saccharomyces cerevisiae. Mol Microbiol 33, 904918.

Thornton, B.R., Chen, K.C., Cross, F.R., Tyson, J.J., and Toczyski, D.P. (2004). Cycling without the cyclosome: modeling a yeast strain lacking the APC. Cell Cycle 3, 629-633.

Timberlake, W.E. (1990). Molecular genetics of Aspergillus development. Annu Rev Genet 24, 5-36.

Todd, R.B., Hynes, M.J., and Andrianopoulos, A. (2006). The Aspergillus nidulans rcoA gene is required for veA-dependent sexual development. Genetics 174, 1685-1688.

Vallim, M.A., Miller, K.Y., and Miller, B.L. (2000). Aspergillus SteA (sterile12-like) is a homeodomain- $\mathrm{C} 2 / \mathrm{H} 2-\mathrm{Zn}+2$ finger transcription factor required for sexual reproduction. Mol Microbiol 36, 290-301.

Verma, R., Feldman, R.M., and Deshaies, R.J. (1997). SIC1 is ubiquitinated in vitro by a pathway that requires CDC4, CDC34, and cyclin/CDK activities. Mol Biol Cell 8, 1427-1437.

Vienken, K., and Fischer, R. (2006). The Zn(II)2Cys6 putative transcription factor NosA controls fruiting body formation in Aspergillus nidulans. Mol Microbiol 61, 544-554.

Vienken, K., Scherer, M., and Fischer, R. (2005). The Zn(II)2Cys6 putative Aspergillus nidulans transcription factor repressor of sexual development inhibits sexual development under low-carbon conditions and in submersed culture. Genetics 169, 619-630. 
Visintin, R., Craig, K., Hwang, E.S., Prinz, S., Tyers, M., and Amon, A. (1998). The phosphatase Cdc14 triggers mitotic exit by reversal of Cdk-dependent phosphorylation. Mol Cell 2, 709718.

Vodermaier, H.C. (2004). APC/C and SCF: controlling each other and the cell cycle. Curr Biol 14, R787-796.

Wang, H., Meury, L., and Morais, R. (1997). Cloning and characterization of cDNAs encoding chicken mitogen-activated protein kinase kinase type 2, MEK2: downregulation of MEK2 in response to inhibition of mitochondrial DNA expression. Biochemistry 36, 15371-15380.

Wasch, R., and Cross, F.R. (2002). APC-dependent proteolysis of the mitotic cyclin Clb2 is essential for mitotic exit. Nature 418, 556-562.

Washburn, B.K., and Esposito, R.E. (2001). Identification of the Sin3-binding site in Ume6 defines a two-step process for conversion of Ume6 from a transcriptional repressor to an activator in yeast. Mol Cell Biol 21, 2057-2069.

Wei, H., Requena, N., and Fischer, R. (2003). The MAPKK kinase SteC regulates conidiophore morphology and is essential for heterokaryon formation and sexual development in the homothallic fungus Aspergillus nidulans. Mol Microbiol 47, 1577-1588.

Wieser, J., and Adams, T.H. (1995). flbD encodes a Myb-like DNA-binding protein that coordinates initiation of Aspergillus nidulans conidiophore development. Genes Dev 9, 491-502.

Wieser, J., Lee, B.N., Fondon, J., 3rd, and Adams, T.H. (1994). Genetic requirements for initiating asexual development in Aspergillus nidulans. Curr Genet 27, 62-69.

Wirth, K.G., Ricci, R., Gimenez-Abian, J.F., Taghybeeglu, S., Kudo, N.R., Jochum, W., VasseurCognet, M., and Nasmyth, K. (2004). Loss of the anaphase-promoting complex in quiescent cells causes unscheduled hepatocyte proliferation. Genes Dev 18, 88-98.

Yager, L.N., Kurtz, M.B., and Champe, S.P. (1982). Temperature-shift analysis of conidial development in Aspergillus nidulans. Dev Biol 93, 92-103.

Yelton, M.M., Hamer, J.E., de Souza, E.R., Mullaney, E.J., and Timberlake, W.E. (1983). Developmental regulation of the Aspergillus nidulans trpC gene. Proc Natl Acad Sci U S A 80, 7576-7580.

Yu, J.H., Wieser, J., and Adams, T.H. (1996). The Aspergillus FlbA RGS domain protein antagonizes G protein signaling to block proliferation and allow development. Embo J 15, 5184-5190.

Zachariae, W., and Nasmyth, K. (1999). Whose end is destruction: cell division and the anaphasepromoting complex. Genes Dev 13, 2039-2058.

Zachariae, W., Schwab, M., Nasmyth, K., and Seufert, W. (1998). Control of cyclin ubiquitination by CDK-regulated binding of Hct1 to the anaphase promoting complex. Science 282, 17211724.

Zonneveld, B.J. (1974). Alpha-1,3 glucan synthesis correlated with alpha-1,3 glucanase synthesis, conidiation and fructification in morphogenetic mutants of Aspergillus nidulans. J Gen Microbiol 81, 445-451. 


\title{
CHAPTER 2
}

\section{A PROCESS INDEPENDENT OF THE ANAPHASE PROMOTING COMPLEX CONTRIBUTES TO INSTABILITY OF THE YEAST S-PHASE CYCLIN CLB5}

\begin{abstract}
Proteolytic destruction of many cyclins is induced by a multi-subunit ubiquitin ligase termed the anaphase promoting complex/cyclosome (APC/C). In the budding yeast Saccharomyces cerevisiae, the S-phase cyclin Clb5 and the mitotic cyclins Clb1-4 are known as substrates of this complex. The relevance of $\mathrm{APC} / \mathrm{C}$ in proteolysis of $\mathrm{Clb5}$ is still under debate. Importantly, a deletion of the $\mathrm{Clb5}$ destruction box has little influence on cell cycle progression. To understand $\mathrm{Clb5}$ degradation in more detail, we applied in vivo pulse labellings to determine the half-life of $\mathrm{Clb5}$ at different cell cycle stages and in the presence or absence of APC/C activity. $\mathrm{Clb5}$ is significantly unstable, with a half-life of about 8-10 minutes, at cell cycle periods when APC/C is inactive and in mutants impaired in APC/C function. A Clb5 version lacking its cyclin destruction box is similarly unstable. The half-life of $\mathrm{Clb5}$ is further decreased in a destruction box dependent manner to 3-5 min in mitotic or $\mathrm{G} 1$ cells with active APC/C. Clb5 instability is highly dependent on the function of the proteasome. We conclude that $\mathrm{Clb5}$ proteolysis involves two different modes for targeting of $\mathrm{Clb5}$ to the proteasome, an APC/C-dependent and an APC/C- independent mechanism. These different modes apparently have overlapping functions in restricting $\mathrm{Clb5}$ levels in a normal cell cycle, but APC/C function is essential in the presence of abnormally high Clb5 levels.
\end{abstract}




\section{Introduction}

Cyclin-dependent kinases (CDKs) are pivotal regulators of the eukaryotic cell cycle. The activity of these enzymes depends on the interaction with regulatory subunits, the cyclins. In yeast, nine cyclins are known to associate with the cyclin-dependent kinase Cdk1, also known as Cdc28 (Mendenhall and Hodge, 1998; Bloom and Cross, 2007). Six of these cyclins, Clb1-6, are members of the family of B-type cyclins. Two of these, $\mathrm{Clb5}$ and $\mathrm{Clb6}$, are expressed early in S-phase and are required for the timely initiation of DNA replication (Epstein and Cross, 1992; Schwob and Nasmyth, 1993). Activation of Cdk1 associated with S-cyclins requires the removal of the Sic1 protein (Schwob et al., 1994; Schneider et al., 1996). Proteolytic destruction of this Cdk1 inhibitor is initiated by Sic1 phosphorylation, mediated by G1-specific Cdk1 (Verma et al., 1997b). The Clb1-4 cyclins are expressed later in the cell cycle and have important functions in G2 and M phase (Fitch et al., 1992; Richardson et al., 1992).

Cyclins have important roles in the cell cycle regulation of Cdk1 activity and in establishing substrate specificity (Bloom and Cross, 2007). Cyclins are unstable proteins and their rapid destruction is important for inactivation of Cdk1. Cyclin ubiquitination is mediated by the anaphase promoting complex/cyclosome (APC/C). This ubiquitin ligase is a large complex consisting of 13 subunits in Saccharomyces cerevisiae and has a highly conserved function in eukaryotes (Peters, 2006). APC/C activity requires the association of coactivators, either Cdc20 or Cdh1, which are involved in recognition and recruitment of substrates to the APC/C core complex. Coactivators bind directly to destruction motifs, the D-box $(K \operatorname{xxLxxxxN)}$ or the KEN-box of substrates (Burton et al., 2005; Kraft et al., 2005). Cdc20 activates APC/C in metaphase, when all chromosomes are properly attached to the mitotic spindle, whereas $C d h 1$ binds $A P C / C$ in late anaphase and keeps the ubiquitin-ligase active during G1 phase (Peters, 2006).

Five of the six $\mathrm{Clb}$ cyclins are known to be substrates of the APC/C. The sole exception is Clb6, which recently was identified as substrate of another ubiquitin ligase, the Skp1/Cullin/F-box complex (SCF) (Jackson et al., 2006). Clb5, the second S-phase cyclin, seems to be degraded by an APC/C-dependent process (Irniger and Nasmyth, 1997), but in contrast to the mitotic Clb cyclins, it was observed that Clb5 was unstable throughout the cell cycle (Seufert et al., 1995; Jacobson et al., 2000).

Different previous studies came to opposite conclusions concerning the importance of $\mathrm{APC} / \mathrm{C}$ in controlling Clb5 levels. Initially, a clb5 mutation was identified in a screening for suppressors of the lethality of a strain lacking the essential coactivator Cdc20 and the securin Pds1 
(Shirayama et al., 1999). The viability of a cdc20 $\Delta$ pds1 1 clb5 4 mutant suggested that Clb5 degradation is a key process of APC/C-Cdc20.

Subsequent experiments however demonstrated that a deletion of the D-box of $\mathrm{Clb5}$ did not cause defects in mitosis, in contrast to a stabilised version cyclin Clb2 lacking the D-box which efficiently blocked exit from mitosis (Wasch and Cross, 2002). The presence of Clb5 without destruction box did not significantly affect cell cycle progression, although protein levels of this version of $\mathrm{Clb5}$ were deregulated compared to normal $\mathrm{Clb5}$. These data implied that APC/Cmediated proteolysis of $\mathrm{Clb} 5$ is not essential for cell cycle progression

Later data showed that cells lacking essential APC/C subunits were viable in the presence of very high levels of the Cdk1 inhibitor Sic1, but only in a strain containing deletions of the PDS1 and CLB5 genes (Thornton et al., 2004). These experiments showing that cells can survive without APC/C under specific conditions raised again the model that $\mathrm{Clb5}$ is a key target of APC/C.

These conflicting data on the role of $\mathrm{APC} / \mathrm{C}$ in $\mathrm{Clb5}$ proteolysis prompted us to perform a comprehensive analysis of the cell cycle regulation of $\mathrm{Clb5}$ stability, by applying in vivo pulse labelling experiments. Our data on Clb5 stability imply that $\mathrm{Clb5}$ degradation involves at least two different pathways, one APC/C-dependent and one APC/C-independent. We further found that Clb5 instability is highly dependent on the $26 \mathrm{~S}$ proteasome, but independent of the Skp1/Cullin/F-box protein (SCF) ubiquitin ligase. 


\section{Materials and Methods}

Yeast strains - All strains are derivatives of the S. cerevisiae W303 strain. Strains are listed in Table 1. Yeast strains were usually produced by crossing of strains from opposite mating types, subsequent sporulation and tetrad dissection with a micromanipulator. Strains carrying HA-tagged versions of Clb2 (Zachariae et al., 1998), Clb3 (Irniger and Nasmyth, 1997), Clb5 (Schwob et al., 1994) and the strains carrying N-terminally HA-tagged CDH1 expressed from the weak GALL promoter (Zachariae et al., 1998) have been previously described. Strains containing a destruction box deletion variant of CLB5 (CLB5 $A D B)$ expressed from the CLB5 promoter lacked a selectable marker (Wasch and Cross, 2002), but were verified by PCR analysis.

Growth of yeast strains and cell cycle arrests - Either complete medium (YP) or minimal medium was used for cultivation of yeast. Medias were supplemented with either $2 \%$ glucose or $2 \%$ raffinose as carbon sources. Prior to gene expression from the GAL1 promoter, cells were pre-grown in raffinose medium. The GAL1 promoter was induced by the addition of galactose ( $2 \%$ final concentration). To turn off the GAL1 promoter, cells were filtered, washed and resuspended in medium containing $2 \%$ glucose. To arrest cells in G1 phase, alpha-factor pheromone was added to exponentially growing cultures and cells were incubated for 2.5 hours in the presence of $5 \mu \mathrm{g} / \mathrm{ml}$ alpha-factor. For all pheromone arrests, strains hypersensitive to alpha-factor by bar1 mutations were used. For cell cycle arrest in S-phase, cells were treated with $5 \mathrm{mg} / \mathrm{ml}$ hydroxyurea. To arrest cells in metaphase, cultures were incubated for 2,5 hours in the presence of $15 \mu \mathrm{g} / \mathrm{ml}$ of the microtubuli-depolymerising drug nocodazole (added from a $1,5 \mathrm{mg} / \mathrm{ml}$ stock solution in dimethylsulfoxide). To arrest cells by temperature-sensitive mutations, cells were pre-grown at $25^{\circ} \mathrm{C}$ and then shifted for 2,5 hours to $36^{\circ} \mathrm{C}$. 
Table 1: Saccharomyces cerevisiae strains used in this study

\begin{tabular}{ll}
\hline Strain & Relevant genotype \\
\hline S001 & W303-1A wild-type strain \\
& MATa, ade2-1, trp1-1. leu2-3,112, his3-11,15, ura3, can1-100, GAL, psi+ \\
S006 & MATa, bar1::HisG \\
S026 & MATa, cdc16-123 \\
S028 & MATa, cdc16-123, GAL1-CLB2-HA3/URA3 \\
S030 & MATa, cdc16-123, GAL1-CLB5-HA3/URA3, bar1::HisG \\
S039 & MATa, cdc23-1 \\
S040 & MATa, cdc23-1, GAL1-CLB2-HA3/URA3 \\
S056 & MATa, GAL1-CLB3-HA3/URA3 \\
S057 & MATa, apc10-22 \\
S095 & MATa, cdc28-4, GAL1-CLB5-HA3/URA3, bar1::HisG \\
S114 & MATa, GAL1-CLB5-HA3/URA3, bar1::HisG \\
S116 & MATa, GAL1-CLB5ADB-HA3/URA3, bar1::HisG \\
S117 & MATa, cdc23-1 cdc28-4, GAL1-CLB5-HA3/URA3, bar1::HisG \\
S119 & MATa, apc10-22 cdc28-4, GAL1-CLB5-HA3/URA3, bar1::HisG \\
S128 & MATa, cdc15-2, GAL1-CLB5-HA3/URA3 \\
S130 & MATa, cdc15-2, GAL1-CLB5ADB -HA3/URA3 \\
S131 & MATa, cdc23-1, GAL1-CLB5-HA3/URA3, \\
S132 & MATa, apc10-22, GAL1-CLB5-HA3/URA3, bar1::HisG \\
S148 & MATa, cdc23-1, GAL1-CLB5-HA3/URA3, bar1::HisG \\
S160 & MATa, cdc34-2, GAL1-CLB5-HA3/URA3 \\
S401 & MATa, cdc4-1, GAL1-CLB5-HA3/URA3 \\
S403 4 MATa, cdc34-2 cdc23-1, GAL1-CLB5-HA3/URA3 \\
S432
\end{tabular}

Pulse-labelling experiments - To determine the half-life of proteins, pulse labelling experiments were performed as described (Amon et al., 1994). In brief, cells were pregrown in minimal medium lacking methionine and containing raffinose as sole carbon source. The GAL1 promoter was induced by galactose addition ( $2 \%$ end concentration). For in vivo labellings, $0,5 \mathrm{mCi}\left[{ }^{35} \mathrm{~S}\right]$-methionine was added and cells were incubated for 5 min (pulse), followed by the addition of $2 \mathrm{mM}$ unlabelled methionine (chase). At the same time, glucose ( $2 \%$ end concentration) was added to turn off the promoter. Samples were collected at specific time points after the chase. Cells were broken with 
glass beads and immunoprecipitations were performed with anti-hemaglutinin antibodies (anti-HA, 1:10 dilutions). Proteins were loaded on SDS-polyacrylamide gels and bands were quantified with a Fuji phosphoimager. To verify cell cycle arrests, DNA content was determined by FACS analysis. Cultures for FACS analysis were treated similarly to the main culture except that ${ }^{35} \mathrm{~S}$-methionine was omitted.

Immunoblot analysis - Preparation of yeast cell extracts and protein immunoblot analysis were performed as described (Surana et al., 1993). The enhanced chemiluminescence detection system (Amersham) was used for the detection of specific proteins. Antibodies were used in 1:1000 (HA) or 1:2000 (Cdc28) concentrations.

FACS analysis and immunofluorescence - To determine the DNA content of cells, FACS analysis was performed as previously described (Epstein and Cross, 1992), using a Becton-Dickinson FACScan. Cells were fixed with $70 \%$ ethanol and stained with propidiumiodide. For indirect immunofluorescence, cells were fixed in $3.7 \%$ formaldehyde. Spheroplasts were prepared as described (Pringle et al., 1991). DAPI (4',6-diamidino-2-phenylindole) staining and anti-tubulin antibodies (YOL37, 1:60 dilution) were used for visualisation of nuclei and spindles, respectively. 


\section{Results}

\section{Determination of the half-lives of Clb5 and Clb5 $\triangle D B$ at different cell cycle stages.}

Previously, Clb5 stability has been analysed by promoter shut-off experiments with the glucoserepressible GAL1 promoter (Seufert et al., 1995; Jacobson et al., 2000). A comprehensive analysis of Clb5 stability by pulse labelling experiments has not been performed up to present and therefore the knowledge of the accurate half-life of this protein is unclear. We applied this method to determine the half-life of $\mathrm{Clb5}$ at different stages of the cell cycle. The stability of a cyclin destruction box mutant of $\mathrm{Clb5}$, termed here $\mathrm{Clb} 5 \Delta \mathrm{DB}$, was also measured.

Yeast strains carrying $\mathrm{HA} 3$-tagged versions of $\mathrm{Clb} 5$ or $\mathrm{Clb} 5 \Delta \mathrm{DB}$, expressed from the inducible GAL1 promoter were arrested at specific periods of the cell cycle. First, we determined the half-life of $\mathrm{Clb5}$ and $\mathrm{Clb5} \triangle \mathrm{DB}$ in the absence of $\mathrm{APC} / \mathrm{C}$ activity, in cells arrested in metaphase with the spindle depolymerising drug nocodazole. Upon cell cycle arrest, galactose was added to express the GAL1-CLB5-HA3 or GAL1-CLB5 ADB-HA3 constructs. Cells were incubated for $5 \mathrm{~min}$ with radiolabelled ${ }^{35} \mathrm{~S}$-methionine and then chased with an excess of unlabelled methionine. $\mathrm{Clb5}$ was immunoprecipitated from samples collected at different periods after the chase. Pulse labelling experiments showed that $\mathrm{Clb5}$ and $\mathrm{Clb5} \triangle \mathrm{DB}$ were similarly unstable in metaphase cells (Fig. $1 \mathrm{~A}$ ). The half-life of both proteins was approximately 8-10 minutes. This instability indicates that $\mathrm{Clb5}$ is subject to a degradation mechanism independent of the destruction-box and of APC/C-activity. 
$\begin{array}{lllllll}0 & 4 & 8 & 15 & 30 & \mathrm{~min}\end{array}$

Clb5

$\mathrm{Clb} 5 \Delta \mathrm{DB}$
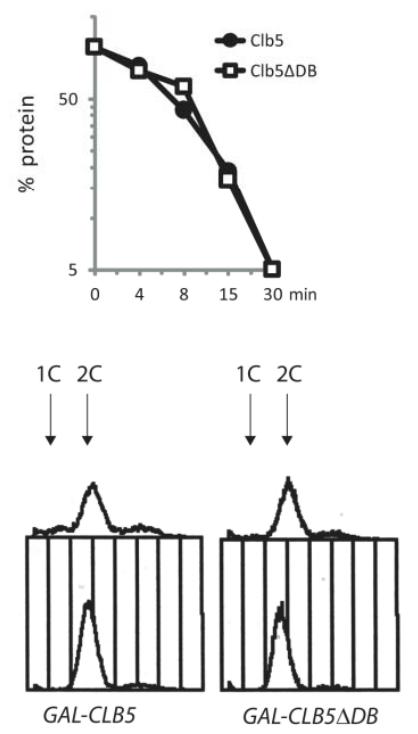
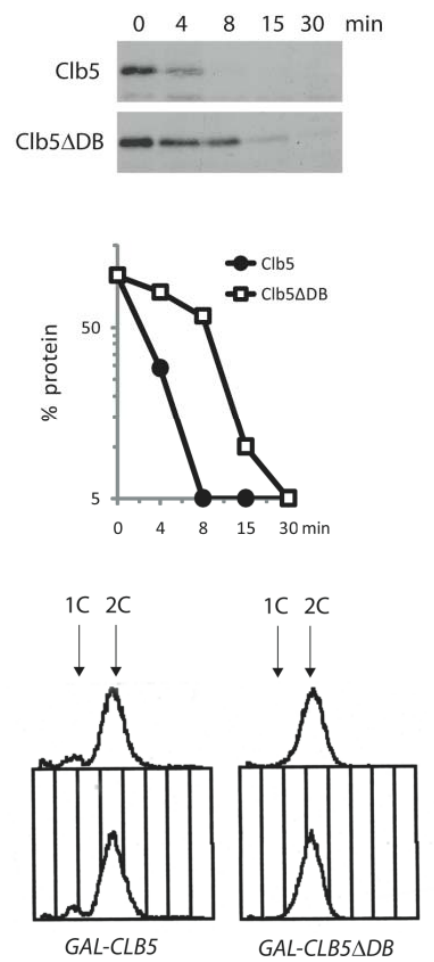

C
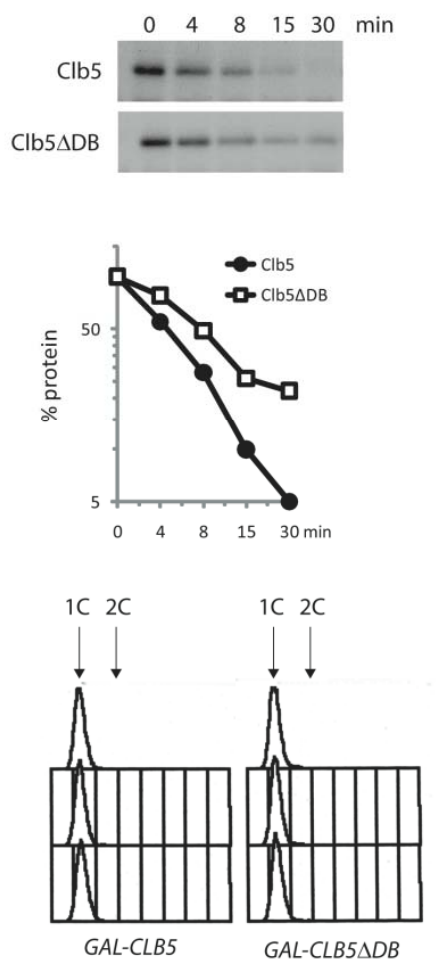

Fig.1 Stability of $\mathrm{Clb5}$ and $\mathrm{Clb} 5 \Delta \mathrm{DB}$ proteins at different cell cycle stages

(A) Yeast strains containing either a GAL1-CLB5-HA3 (S116) or a GAL1-CLB5 ADB-HA3 (S117) construct were grown at $30^{\circ} \mathrm{C}$ in minimal medium lacking methionine with raffinose as carbon source and arrested in metaphase by nocodazole addition. Galactose was added for $30 \mathrm{~min}$, followed by the addition of $\left.{ }^{35} \mathrm{~S}\right]-$ methionine. After $5 \mathrm{~min}$., glucose and an excess of unlabelled methionine $(2 \mathrm{mM})$ were added $(0 \mathrm{~min}$ time point). HA-tagged proteins were immunoprecipitated at the indicated time points. A quantification of the amount of protein levels is shown in graphs. Cell cycle arrests were verified by FACS analysis. (B) cdc15-2 mutants containing either a GAL1-CLB5-HA3 (S130) or a GAL1-CLB5 $D D B-H A 3$ (S131) construct, were grown at $25^{\circ} \mathrm{C}$ and then arrested at $36^{\circ} \mathrm{C}$ for 2,5 hours. Galactose was added and cells were then pulse-chased as described in (A). Protein levels, quantification and FACS analysis are shown. (C) Yeast strains S116 or S117, which both are bar1 mutants, were grown at $30^{\circ} \mathrm{C}$ and then arrested with the pheromone alpha-factor. Cells were pulse-chased in the presence of alpha-factor as in (A). Protein levels, quantification and FACS analysis are shown. 
Destruction box further destabilises Clb5 in late mitosis and G1-Phase. To test the degradation of $\mathrm{Clb} 5$ and $\mathrm{Clb} 5 \Delta \mathrm{DB}$ later in mitosis, we used $c d c 15-2$ mutants, impaired in a protein kinase essential for the exit from mitosis. cdc15-2 mutants carrying GAL1-CLB5-HA3 or GAL1CLB5 $\triangle D B-H A 3$ constructs were arrested in telophase by a shift to a restrictive temperature, $36^{\circ} \mathrm{C}$. Pulse chase experiments showed that the half-life of $\mathrm{Clb5}$ is further reduced to less than $5 \mathrm{~min}$, whereas the stability of $\mathrm{Clb} 5 \Delta \mathrm{DB}$ is only modestly different from metaphase arrested cells (Fig. 1B). Thus, a further destabilisation of $\mathrm{Clb5}$ occurs during anaphase, consistent with the findings that $\mathrm{Clb5}$ is a substrate of APC/C-Cdc20, which is highly active in telophase cells (Rudner and Murray, 2000).

To compare the stability of $\mathrm{Clb} 5$ and $\mathrm{Clb} 5 \Delta \mathrm{DB}$ in $\mathrm{G} 1$ phase, cells were arrested in G1 phase with the pheromone alpha-factor. In this period of the cell cycle, APC/C-Cdh1 is active (Schwab et al., 1997; Visintin et al., 1997). We found that Clb5 is more unstable than Clb5 $\Delta \mathrm{DB}$ in pheromone arrested $\mathrm{G} 1$ cells (Fig. 1C). The half-life of $\mathrm{Clb5}$ in these cells is approximately 5 minutes.

These findings support the model that $\mathrm{Clb5}$ is unstable throughout the cell cycle and that a more rapid Clb5 turnover occurs during telophase and G1 phase in an APC/C- dependent manner.

$\mathrm{Clb5}$ is degraded by an APC/C-independent pathway. The instability of $\mathrm{Clb5}$ and of $\mathrm{Clb5} \triangle \mathrm{DB}$ in metaphase (Fig. $1 \mathrm{~A}$ ) suggests that $\mathrm{Clb5}$ is degraded by a process independent of APC/C. To underline this assumption, we determined $\mathrm{Clb} 5$ stability in temperature-sensitive mutants defective in APC/C function, $c d c 16-123$ and $c d c 23-1$.

The half-life of Clb5 was measured in G1-arrested mutant strains. Cells were first arrested at the permissive temperature in G1 phase by the addition of alpha-factor. Subsequently, cells were shifted to the restrictive temperature and then pulse-labelling experiments were performed in the presence of the pheromone. Clb5 was unstable in both mutants with a half-life of approximately 10 minutes, but moderately stabilised compared to wild-type cells (Fig. 2A). FACS analysis confirmed that cells did not escape from the G1 arrest during the course of the experiment. 
A

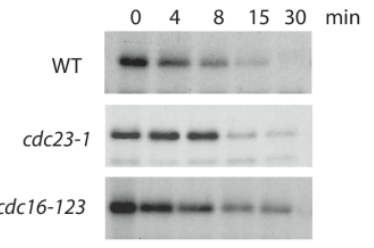

B

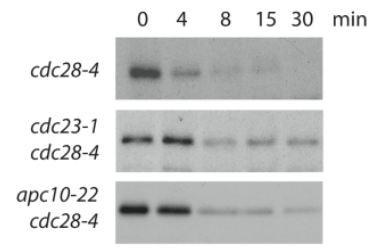

C

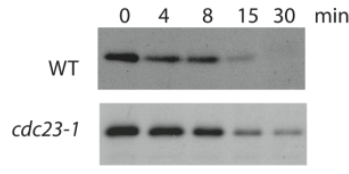

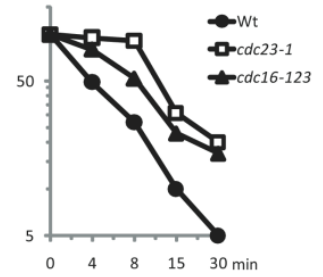
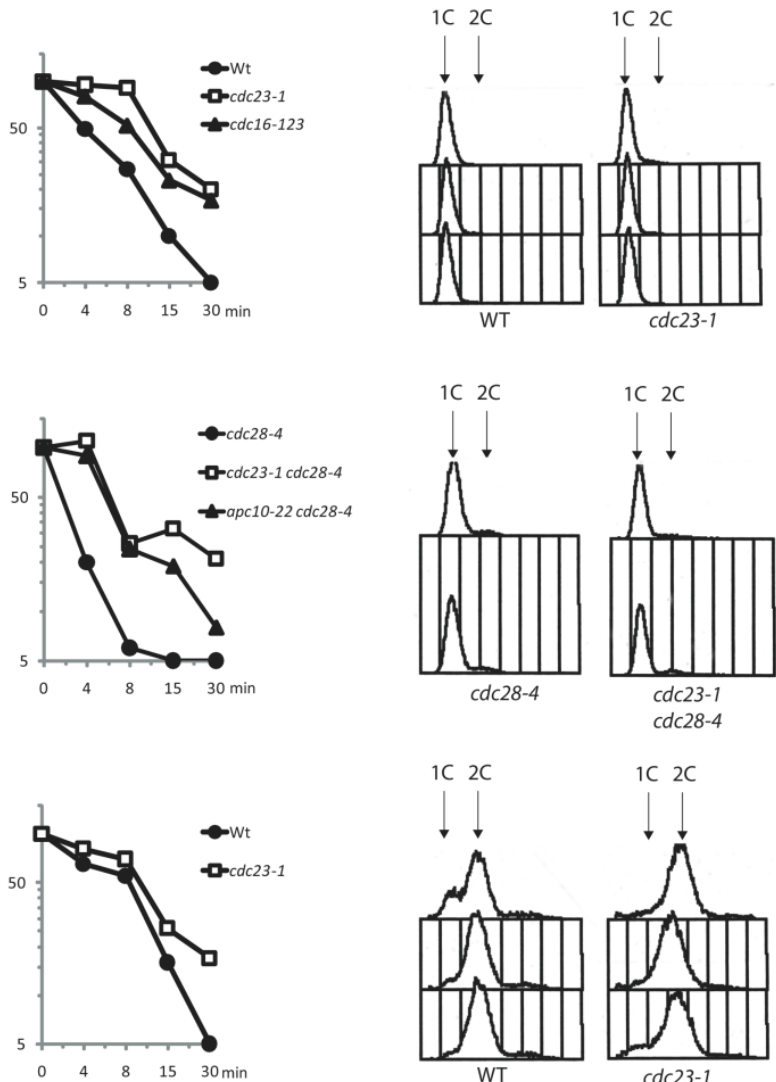

WT

$1 C 2 C$

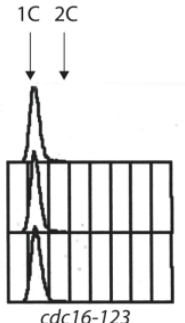

1C $2 C$
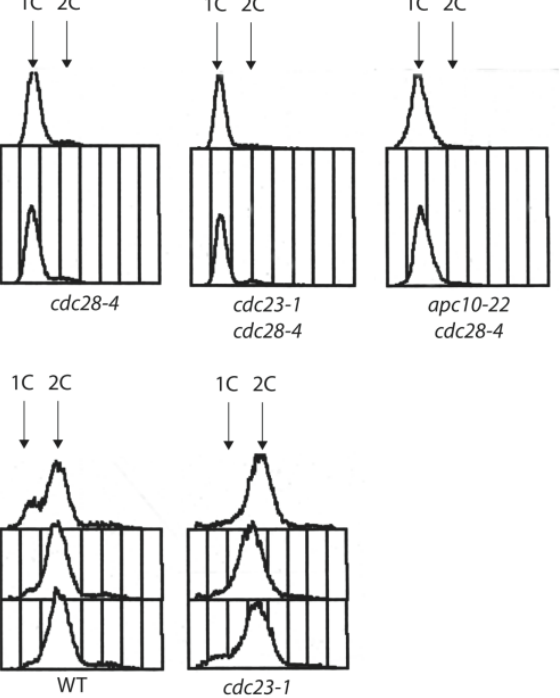

Fig.2 Clb5 is unstable in mutants defective in APC/C function

(A) Wild-type cells (S116), cdc16-123 mutants (S030) and cdc23-1 mutants (S160) containing GAL1-CLB5-HA3, all bar1, were pre-grown at $25^{\circ} \mathrm{C}$ and arrested in $\mathrm{G} 1$ phase with alpha-factor. Then galactose was added and the temperature was shifted to $36^{\circ} \mathrm{C}$. After 30 min incubation, cells were pulse chased as described in Fig. $1 \mathrm{~A}$ at $36^{\circ} \mathrm{C}$ in the presence of alpha-factor. Cultures for FACS analysis were treated similarly except that $\left[{ }^{35} \mathrm{~S}\right]$ methionine was omitted. (B) cdc28-4 mutants (S114), cdc23-1 cdc28-4 mutants (S119) and apc10-22 cdc28-4 mutants (S128) containing GAL1-CLB5-HA3, all bar, were arrested and pulse chased as in (A). (C) Wild-type cells (S116) and $c d c 23-1$ mutants (S160) containing GAL-CLB5-HA3 were pregrown at $25^{\circ} \mathrm{C}$ in minimal medium lacking methionine containing raffinose as carbon source and were then arrested in nocodazole at $25^{\circ} \mathrm{C}$. Then galactose was added and the temperature was shifted to $36^{\circ} \mathrm{C}$. After 30 min incubation, cells were pulse chased at $36^{\circ} \mathrm{C}$ in the presence of nocodazole.

To further exclude the possibility, that cells lacking APC/C are not properly arrested in G1 phase, we used $c d c 28-4$ mutants combined with mutants in APC/C functions. The $c d c 28-4$ mutation prevents cells from entering S-phase upon the temperature shift. We tested Clb5 stability in G1arrested $c d c 28-4 c d c 23-1$ and $c d c 28-4$ apc10-22 double mutants. Cells were arrested in G1 phase at the permissive temperature and then $\mathrm{Clb5}$ stability was determined at the restrictive temperature. 
In both double mutants, Clb5 was more stable than in the $c d c 28-4$ single mutant, but still significantly unstable (Fig. 2B).

It cannot be completely ruled out that residual APC/C activity contributes to $\mathrm{Clb5}$ instability in G1- arrested mutants. To further support the model, that $\mathrm{Clb5}$ proteolysis is independent of APC/C, we performed pulse labelling experiments with $c d c 23-1$ cells arrested in metaphase, when $\mathrm{APC} / \mathrm{C}$ is inactive. Wild-type and $c d c 23-1$ mutants were arrested in metaphase with nocodazole at the permissive temperature. Upon a shift to $36^{\circ} \mathrm{C}$, the half-life of $\mathrm{Clb5}$ was measured. In both strains, Clb5 stability was similar, with a half-life of approximately 10 minutes (Fig. 2C). Thus, even in cdc23-1 mutants arrested in a period of the cell cycle when APC is inactive, Clb5 is still unstable. These data underline that an APC/C-independent mechanism contributes to $\mathrm{Clb5}$ proteolysis.

Mitotic cyclins are more stable than $\mathrm{Clb5}$ in the absence of $\mathrm{APC} / \mathrm{C}$ activity. After having determined the half-life of Clb5 by pulse labelling, we applied the more convenient promoter shutoff method for further experiments. Although not as precise in the determination of the half-lives of proteins, the application of this method provided results of sufficient clarity.

We next tested, whether $\mathrm{Clb5}$ is indeed more unstable than mitotic cyclins in the absence of $\mathrm{APC} / \mathrm{C}$ activity. Therefore, we compared the stability of $\mathrm{Clb5}$ with the stability of $\mathrm{Clb2}$ and $\mathrm{Clb3}$ in cells arrested in metaphase. Strains carrying HA-tagged versions of these cyclins expressed from the GAL1 promoter were arrested with nocodazole. Then, the expression of cyclin genes was induced by galactose addition, followed by a shift to glucose medium. In accordance with the pulse labelling experiments in Fig. $1 \mathrm{~A}, \mathrm{Clb5}$ is rapidly degraded (Fig. 3). In contrast, $\mathrm{Clb2}$ and $\mathrm{Clb3}$ levels decreased slowly in these metaphase-arrested cells. These data underline that $\mathrm{Clb5}$, but not $\mathrm{Clb2}$ or $\mathrm{Clb}_{3}$, is subject to a distinct APC-independent mode of proteolysis. 


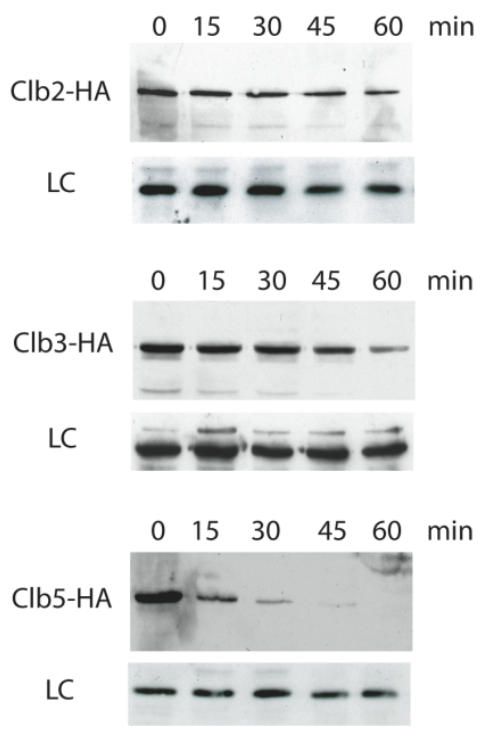

Fig.3 $\mathrm{Clb5}$ is more unstable than other $\mathrm{Clb}$ cyclins in the absence of APC/C activity

Yeast strains carrying either GAL1-CLB2-HA3 (S057), GAL1-CLB3-HA3 (S056) or GAL1-CLB5-HA3 (S116) were grown at $30^{\circ} \mathrm{C}$ in YP medium containing raffinose as carbon source (YP+Raf). Cells were arrested in $\mathrm{M}$-phase by nocodazole addition for 2,5 hours. The arrest was confirmed by light microscopy (not shown). Galactose was added for 60 minutes, then cells were filtered and transfererd to YP medium containing glucose (YP+Glu). Samples were collected at the indicated time points after galactose addition and analysed by immunoblotting using the anti-HA-antibody. Cdc28 antibody was used as a loading control (LC).

Clb5 instability depends on the proteasome. We next tested, whether the persistent instability of $\mathrm{Clb5}$ during the cell cycle requires the function of the proteasome. To this end, the stability of $\mathrm{Clb5}$ was analysed in mutants impaired in the function of the proteasome, the temperature-sensitive cim3-1 and cim5-1 mutants (Ghislain et al., 1993). Cim3, also known as Sug1/Rpt6, and Cim5, also known as Rpt1, are both ATPases of the regulatory 195 particle of the 26S proteasome and essential for viability (Voges et al., 1999). To determine the stability of Clb5, promoter shut-off experiments were performed at the restrictive temperature. We found that $\mathrm{Clb5}$ was virtually stable during the course of the experiment (Fig. 4A). Similar experiments were performed with cell cycle arrested cells, by nocodazole treatment of cells prior to the promoter shutoff experiments (Fig. 4B). Also in these arrested cells, Clb5 appeared to be distinctly stabilised compared to wild-type cells. We conclude that $\mathrm{Clb} 5$ degradation is highly dependent on the function of the $26 \mathrm{~S}$ proteasome. 
A
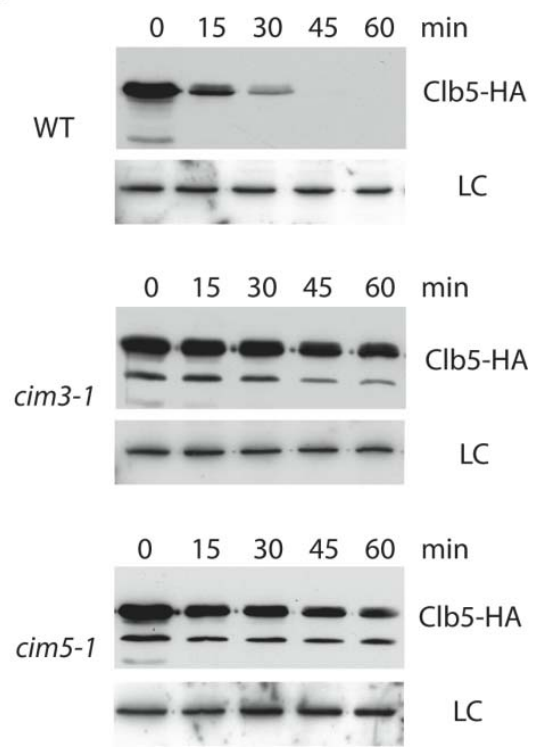

B
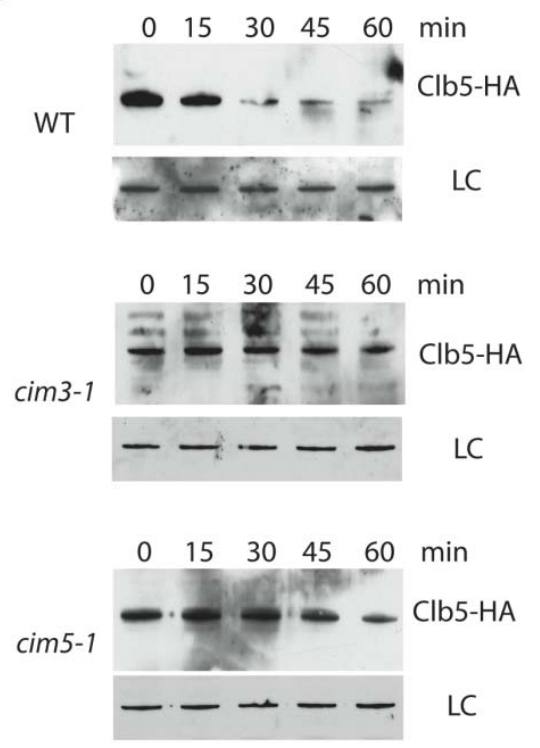

\section{Fig.4 Clb5 instability is mediated by the proteasome}

Wild-type cells (S116), and the proteasomal mutants cim3-1 mutants (S713) and cim5-1 mutants (S714), all containing GAL1-CLB5-HA3, were grown at $25^{\circ} \mathrm{C}$ in YP+Raf medium. Promoter shut-off experiments were performed with either cycling cells (A) or cells arrested in M-phase with nocodazole for 2,5 hours (B). Galactose was added to induce the GAL1 promoter. After $30 \mathrm{~min}$, the temperature was shifted to $36^{\circ} \mathrm{C}$ and cells were incubated for another $30 \mathrm{~min}$. To turn off the GAL1 promoter, cells were filtered and transferred to YP+Glu medium (pre-warmed to $36^{\circ} \mathrm{C}$ ) without $(A)$ or with nocodazole (B). Samples collected at the indicated time points after transfer to glucose medium were analysed by immunoblotting using the anti-HA antibody. Cdc28 antibody was used as a loading control (LC).

Clb5 instability does not involve the SCF ubiquitin ligase. The findings that $\mathrm{Clb5}$ is targeted to the proteasome by an APC/C-independent process prompted us to test, whether this alternative mode may be mediated by the activity of the SCF (Skp-Cullin-F-box) ubiquitin ligase. Remarkably, the S-phase cyclin Clb6 was recently identified as SCF-Cdc4 target (Jackson et al., 2006). Involvement of SCF in Clb5 proteolysis has been suggested earlier by Bai et al. (Bai et al., 1996) whereas data from Wäsch and Cross (Wasch and Cross, 2002) resulted in opposite conclusions. These experiments, however, were performed in dividing cells and did not uncouple the APC/Cdependent and APC/C-independent degradation modes. 
To exclude APC/C activity, we used S- or M-phase arrested cells. To test whether SCF is involved in Clb5 degradation, we compared wild-type and cdc34-2 mutants. CDC34 encodes the essential E2 ubiquitin-conjugating enzyme of the yeast SCF complex (Goebl et al., 1988). Cells were arrested in S-phase or metaphase with hydoxyurea or nocodazole, respectively. Then promoter shut-off experiments were performed. $\mathrm{Clb5}$ and $\mathrm{Clb} 5 \Delta \mathrm{DB}$ were both unstable in these arrested mutant cells, similarly as in wild-type cells (Fig. 5A, B).

A

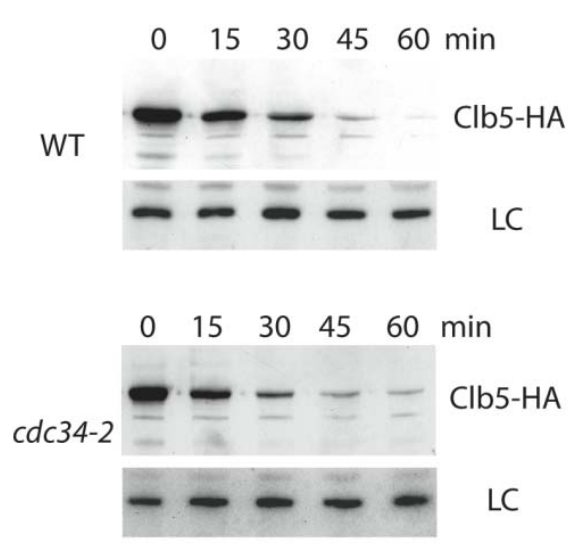

C

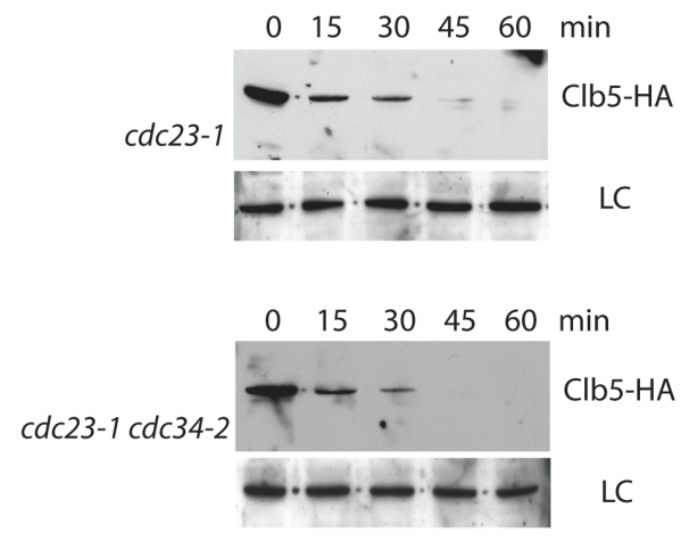

B

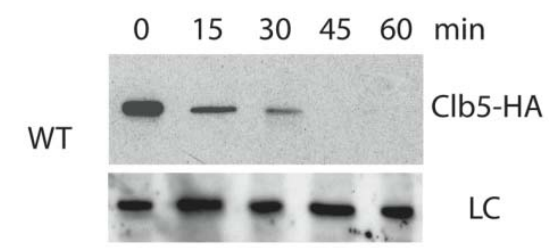

cdc34-2

$0 \quad 15 \quad 30 \quad 45 \quad 60 \quad \min$ Clb5-HA

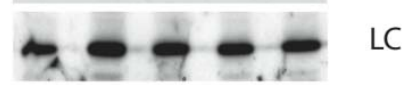

D

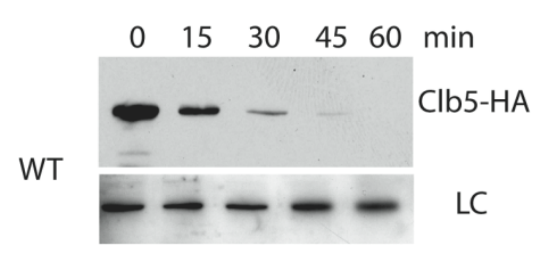

$0 \quad 15 \quad 30 \quad 45 \quad 60 \quad \min$

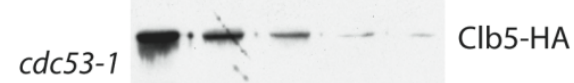

$-\rightarrow-\pi+4 \pi$ c

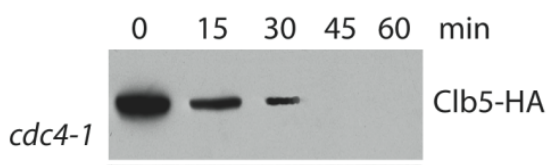

cdc4-1

LC 
Fig.5 Clb5 instability is independent of SCF activity

Wild-type cells (S116) and a cdc34-2 mutant (S401) both containing GAL1-CLB5-HA3 were grown at $25^{\circ} \mathrm{C}$ in YP+Raf medium. Yeast strains were treated for 2,5 hours with either nocodazole (A) or hydroxyurea (B) to arrest cells in M-Phase or S-phase, respectively. Galactose was added to induce the GAL1 promoter. After 30 min, the temperature was shifted to $36^{\circ} \mathrm{C}$ and cells were incubated for another $30 \mathrm{~min}$. To turn off the GAL1 promoter, cells were filtered and transferred to $\mathrm{YP}+\mathrm{Glu}$ medium (prewarmed to $36^{\circ} \mathrm{C}$ ) containing nocodazole (A) or hydroxyurea (B). Immunoblotting was performed using the anti-HA antibody to detect $\mathrm{Clb5}-\mathrm{HA}$ and Cdc28 antibody as a loading control (LC). (C) cdc23-1 (S132) and cdc23-1 cdc34-2 (S432) mutants containing GAL1-CLB5-HA3 were grown at $25^{\circ} \mathrm{C}$. Galactose was added to induce the GAL1 promoter. After 30 min, the temperature was shifted to $36^{\circ} \mathrm{C}$ and cells were incubated for another $30 \mathrm{~min}$. To turn off the GAL1 promoter, cells were filtered and transferred to $\mathrm{YP}+\mathrm{Glu}$ medium (prewarmed to $36^{\circ} \mathrm{C}$ ). Immunoblotting was performed with anti-HA and Cdc28 (LC) antibodies. (D) Promoter shut-off experiments and immunoblotting with S116, a cdc53-1 mutant (S711) and a cdc4-1 mutant (S403) were performed with nocodazole-arrested cells as in (A).

To further support the idea that $\mathrm{Clb5}$ is degraded by a pathway independent of $\mathrm{APC} / \mathrm{C}$ and SCF, we constructed yeast strains with temperature sensitive mutations causing defects in both ubiquitin ligases, $c d c 34-2$ cdc23-1 double mutants. Promoter shut-off experiments showed that Clb5 are significantly unstable in this yeast strain, similarly as in a cdc23-1 mutant (Fig. 5C). By performing similar experiments as described in Fig. 5A, we found that $\mathrm{Clb5}$ was also unstable in cdc53-1 and cdc4-1 mutants (Fig. 5D). Cdc53 is the cullin subunit of SCF, Cdc4 is an F-box protein (Bai et al., 1996; Willems et al., 1996).

Thus, targeting of $\mathrm{Clb5}$ to the $26 \mathrm{~S}$ proteasome can apparently occur by a pathway independent of the two ubiquitin-ligases with known roles in cell cycle progression, APC/C and SCF. 


\section{APC/C-mediated Clb5 degradation is essential under conditions of elevated CLB5}

expression levels. It was previously shown that CLB5 $\triangle D B$ expressed from its own promoter does not exhibit distinct cell cycle defects, whereas GAL1-CLB5 $\triangle D B$ is toxic to yeast cells (Jacobson et al., 2000). The APC/C-independent pathway may be sufficient for Clb5 proteolysis in a normal cell cycle, but not when CLB5 is over-expressed.

A
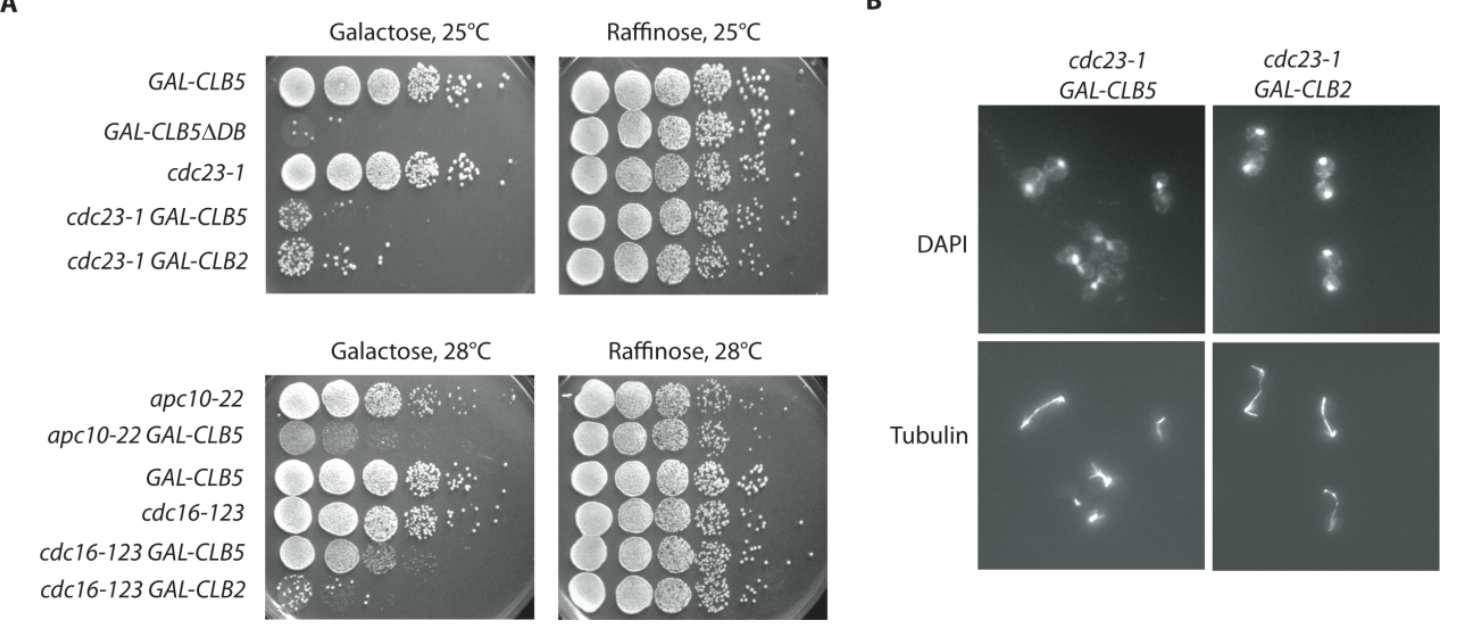

B

Fig.6 Elevated Clb5 levels are lethal for mutants impaired in APC/C function

(A) Serial dilutions (1:10) of the indicated strains were spotted on YP medium containing either galactose or raffinose as carbon source, respectively. (B) Immunofluorescene microscopy of cells grown for 4 hours in the presence of galactose at $25^{\circ} \mathrm{C}$.

To test the relevance of $A P C / C$ in the presence of abnormally high levels of $\mathrm{Clb5}$, we analysed the elevated CLB5 expression in $c d c 23-1$ mutants. Viability of $c d c 23-1$ mutants containing a single copy of GAL1-CLB5-HA3 was tested on galactose plates (Fig. 6A). cdc23-1 mutants are viable at $25^{\circ} \mathrm{C}$, but the expression of elevated levels of CLB5 was highly deleterious for this mutant. The toxicity of high levels of $\mathrm{Clb5}$ to $c d c 23-1$ mutants was comparable to increased CLB2 expression. The expression of GAL1-CLB5 had no discernible effects on wild-type cells. In contrast, high levels of Clb5 affected the viability of additional temperature-sensitive mutants, $c d c 16-123$ and apc10-22. Both of these strains defective in $A P C / C$ subunit genes are viable at $28^{\circ} \mathrm{C}$, but the expression of GAL1-CLB5 inhibited growth. The findings that cells impaired in APC/C function are sensitive to high levels of Clb5 even at permissive temperatures implies that the alternative degradation pathway is not 
sufficient to control $\mathrm{Clb5}$ as soon as this cyclin is expressed to high levels. Under these conditions, $\mathrm{APC} / \mathrm{C}$ gets essential for $\mathrm{Clb5}$ degradation.

Remarkably, increased CLB5 expression in cdc23-1 mutants caused a cell cycle arrest, which differed from CLB2 expression. GAL1-CLB2 resulted in an uniform telophase arrest in cdc23-1 mutants (Fig. 6B). In contrast, in cdc23-1 mutants expressing CLB5 only about 30 percent of cells contained divided nuclei and elongated spindles. Most cells had short spindles and undivided nuclei, indicating that cells arrested predominantly prior to anaphase. These data support the model that high Clb5 levels do not inhibit the exit from mitosis (Wasch and Cross, 2002).

\section{$A P C / C$ is required for preventing S-phase entry in cells expressing high levels of CLB5.}

We also tested the relevance of APC/C-mediated degradation of Clb5 in G1 arrested cells. Strains expressing CLB5 and CLB5 $A D B$ from its own promoter and strains expressing either CLB5 or CLB5 $\triangle D B$ from the GAL1 promoter were arrested with alpha-factor in G1 phase. Galactose was added and the incubation in the presence of pheromone was continued. We found that DNA replication did not occur in cells expressing high levels of CLB5, whereas the expression of GAL1CLB5 $\triangle D B$ efficiently triggered the initiation of DNA replication (Fig. 7A). This is most likely due to the appearance of the Clb5 $\triangle \mathrm{DB}$ protein, which accumulated to higher levels than normal Clb5 (Fig. 7B). Cells containing CLB5 $A D B$ expressed from its own promoter did not initiate DNA replication (Fig. $7 A)$.

An important process for the initiation of DNA replication is the phosphorylation of Cdh1, which results in the inactivation of $\mathrm{APC} / \mathrm{C}$. We tested the potential of $\mathrm{Clb5}$ and $\mathrm{Clb} 5 \triangle \mathrm{DB}$ to phosphorylate Cdh1 in vivo. Cdh1 phosphorylation results in a slower migrating form (Zachariae et al., 1998). We found that the expression of GAL1-CLB5 $D D B$ caused a distinct shift of most of Cdh1 to a slower migrating version (Fig. 7C). In contrast, the expression of GAL1-CLB5 did not result in a significant modification of Cdh1. Cdh1 was also not affected in cells expressing CLBADB5 from its own promoter.

These results show that under normal CLB5 expression conditions, the destruction-box is not required in G1 cells to prevent DNA replication and Cdh1 phosphorylation. In contrast, upon expression of CLB5 to abnormally high levels, destruction-box mediated proteolysis is essential, suggesting that the APC/C-dependent pathway is needed to prevent a precocious entry into S-phase under these conditions. High Clb5 levels apparently exceed the potential of the APC/C-independent mode to control the levels of this cyclin. We conclude that the two different degradation modes have relevant roles in restricting $\mathrm{Clb5}$ activity upon deregulated CLB5 expression. 
A

CLB5

GAL-CLB5 $\triangle D B$

GAL-CLB5

$C L B 5 \triangle D B$

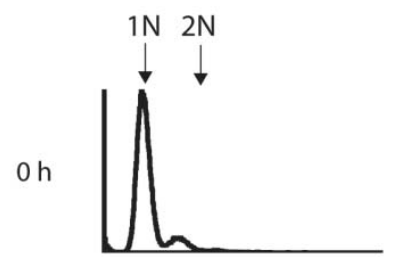

$1 \mathrm{~N} 2 \mathrm{~N}$
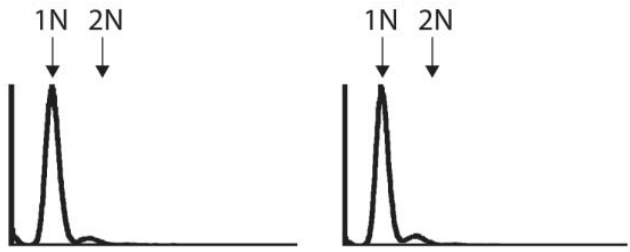

$1 \mathrm{~N} 2 \mathrm{~N}$
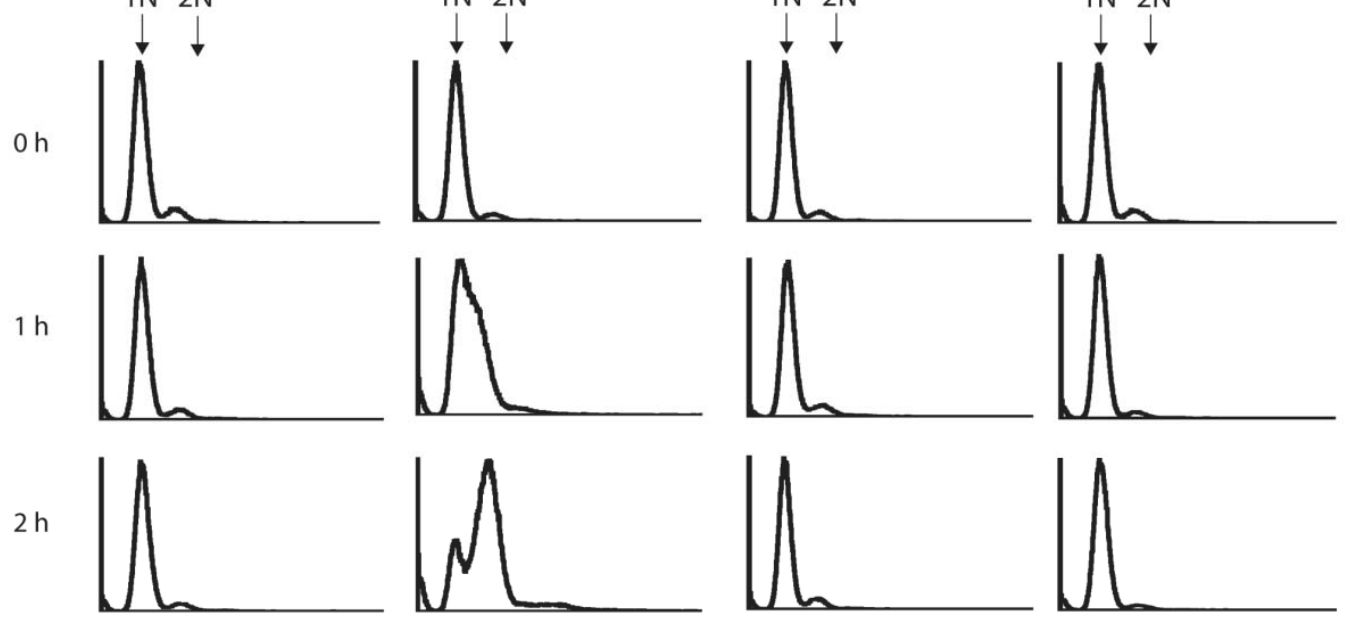

B

$\frac{G A L-C L B 5-H A}{03060120} \frac{G A L-C L B 5 \Delta D B-H A}{03060120 \mathrm{~min}}$

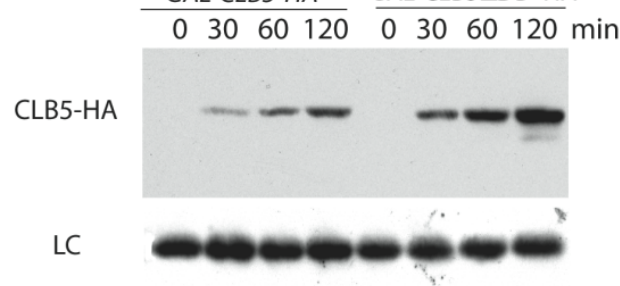

C

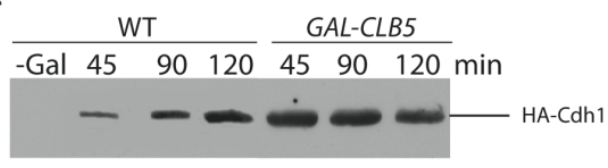

GAL-

CLB5 $\triangle D B \quad C L B 5 \triangle D B$

$45 \quad 90 \quad 120 \overline{45 \quad 90 \quad 120} \mathrm{~min}$

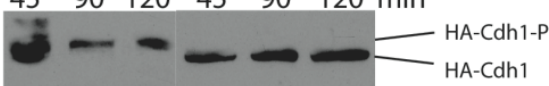

Fig.7 APC/C is required in G1 cells to restrict S-phase entry under conditions of abnormal CLB5 expression levels

A wild-type strain (S006) and strains containing either GAL1-CLB5-HA3 (S116), GAL1-CLB5 ADB-HA3 (S117) or CLB5 $\triangle D B-H A 3$ (S583) construct were arrested at $30^{\circ} \mathrm{C}$ in YP+Raf medium with alpha-factor. $2 \%$ Galactose was added and cells were incubated further in the presence of pheromone. (A) FACS analysis of cells collected at indicated time points after galactose addition. (B) Immunoblotting of samples collected from strains S116 and S117 at indicated time points after galactose addition. (C) A strain carrying GALL-HA-CDH1 (S474) and strains carrying GALL-HA-CDH1 and in addition either GAL1-CLB5-HA3 (S596), GAL1-CLB5 ADB-HA3 (S597) or CLB5 $\triangle D B-H A 3$ (S598) strains were arrested at $30^{\circ} \mathrm{C}$ in YP+Raf medium with alpha-factor. $2 \%$ Galactose was added and cells were incubated further in the presence of pheromone. Samples for immunoblotting were collected at the indicated time points after galactose addition. 


\section{Discussion}

Cyclin proteolysis is an important process for the regulation of the activity of cyclin-dependent kinases during the cell cycle. APC/C has a crucial role in the cell cycle regulation of the stability of Btype cyclins. Various previous reports indicated that the yeast S-phase cyclin Clb5 appears to be differently regulated than the mitotic Clb cyclins (Seufert et al., 1995; Irniger and Nasmyth, 1997; Jacobson et al., 2000; Wasch and Cross, 2002). To better understand regulation of Clb5 stability, we have presented here the first in-depth analysis of the half-life of $\mathrm{Clb5}$ by in vivo pulse labelling experiments. We have shown that $\mathrm{Clb5}$ lacking its cyclin destruction box, Clb5 $\Delta \mathrm{DB}$, is an unstable protein with a half-life of 8-10 minutes and that $\mathrm{Clb5}$ is similarly unstable in the absence of APC/C activity. In cells with active APC/C, Clb5 is further destabilised. Our data underline the model that two distinct modes, an APC/C-dependent and an alternative APC/C-independent mode, both contribute to $\mathrm{Clb} 5$ instability.

The remarkable instability of $\mathrm{Clb5}$ in the absence of APC/C activity indicates that the alternative $\mathrm{Clb5}$ degradation pathway has a considerable role in restricting the activity of this cyclin during the cell cycle. The two modes may have overlapping functions in restricting Cdk1-Clb5 kinase activity. Indeed, destruction-box mediated proteolysis of $\mathrm{Clb5}$ is dispensable for cell cycle progression, as manifested by the viability of a strain expressing CLB5 $\triangle D B$ (Wasch and Cross, 2002).

In contrast to this model, two previous studies have provided evidence that Clb5 is an essential target of APC/C. Shirayama et al. identified that a deletion of CLB5 suppressed the lethality of cdc20 pds1 strains (Shirayama et al., 1999). This effect is probably indirect, because Cdh1 is abnormally active in such a strain background and probably substitutes Cdc20 function (Huang et al., 2001; Yeong et al., 2001). Thornton and Toczyski (Thornton et al., 2004) showed that yeast cells completely devoid of APC/C activity are viable, when the PDS1 and CLB5 genes were deleted and when in addition SIC1 was strongly over-expressed. These cells cannot survive if $\mathrm{Clb5}$ is present, even if the Sic1 inhibitor protein is present in excess amounts. Thus, at least under these specific conditions the failure of $\mathrm{APC} / \mathrm{C}$ to degrade $\mathrm{Clb5}$ results in lethality. One possible explanation suggested by the authors of this study was the idea that Cdk1-Clb5 counteracted the Sic1 protein, targeting it for efficient proteolysis. In these cells requiring vast amounts of Sic1 for viability, the absence of Cdk1-Clb5 is therefore of crucial importance. However, it is important to point out, that this does not necessarily mean, that this also applies to wild-type cells, which do not rely on the presence of excessive amounts of Sic1. The importance of APC/C for $\mathrm{Clb5}$ proteolysis in a normal cell cycle is still not fully understood. Our data showing the continuous APC/C-independent instability 
of $\mathrm{Clb} 5$ rather support the idea, that the different modes of $\mathrm{Clb} 5$ proteolysis have redundant roles in controlling this cyclin.

An interesting question is now, whether $\mathrm{Clb5}$ degradation by at least one of these mechanisms is important for a proper cell cycle. A substantial evidence for the importance of $\mathrm{Clb5}$ instability was provided by experiments with an $\mathrm{N}$-terminal tagged version of $\mathrm{Clb5}$ lacking the destruction box (Wasch and Cross, 2002). This $\mathrm{N}$-terminal modification resulted accidentally in a completely stabilised Clb5 protein. Importantly, the expression of this stable Clb5 variant was lethal for cells. Therefore, it seems that at least one proteolytic mechanism is essential for restricting $\mathrm{Clb5}$ activity.

How may Clb5 get degraded in the absence of APC/C? It was recently shown that the second S-phase cyclin in yeast, Clb6, is degraded by the ubiquitin ligase SCF-Cdc4 (Jackson et al., 2006). Previous studies on a possible role of SCF in Clb5 degradation revealed contradictory results. Whereas the analysis of $s k p 1-11$ mutants revealed a stabilisation of Clb5 (Bai et al., 1996), Clb5 was found to be highly unstable in the same mutant by others (Wasch and Cross, 2002). It was not ruled out in this report that $\mathrm{Clb5}$ instability is due to APC/C activity. Here, we have tested, whether SCF is involved in the APC/C-independent degradation pathway by using cells arrested in periods of the cell cycle, where APC/C is inactive. Therefore APC/C-dependent and APC/C-independent modes were uncoupled. We showed that $\mathrm{Clb5}$ is unstable in mutants defective in SCF activity and also in cdc23-1 cdc34-2 double mutants. Our data argue against a role of SCF in Clb5 proteolysis.

The significant stabilisation of Clb5 in proteasomal mutants suggests that degradation of Clb5 is dependent on the activity of the proteasome. At present it is unknown, how Clb5 is targeted to the proteasome in the absence of APC/C activity and whether this alternative pathway involves ubiquitination. Intriguingly, ubiquitin-independent targeting to the proteasome has been observed for different cell cycle regulatory proteins such as p53, c-jun and p21/Kip1 (Hoyt and Coffino, 2004; Asher et al., 2006). Each of these proteins is degraded by both ubiquitin-dependent and ubiquitinindependent processes. Examination of p53 degradation revealed that ubiquitin-independent degradation appeared to be mediated by the $20 \mathrm{~S}$ proteasome (Asher et al., 2006). Since Clb5 is stabilised in cim3 und cim5 strains, mutated in genes of the $19 \mathrm{~S}$ regulatory particle of the $26 \mathrm{~S}$ proteasome (Ghislain et al., 1993; Voges et al., 1999), Clb5 degradation seems to be rather mediated by the $26 \mathrm{~S}$ proteasome.

Why is a persistent Clb5 instability important in the cell cycle and why may this instability have evolved for $\mathrm{Clb5}$ rather than for mitotic cyclins? CLB5 expression is strongly induced at the G1/S phase transition (Schwob and Nasmyth, 1993) and permanent Clb5 instability could be a process to prevent $\mathrm{Clb5}$ accumulation to exceedingly high levels, which could then interfere with 
cell cycle events after completion of S-phase. Clb5 instability in G2- and early M-phase may be a process to lower $\mathrm{Clb5}$ levels, before APC/C activation at the metaphase/anaphase transition occurs. Clb5 instability and dissociation from Cdk1 molecules may allow the efficient association of Cdk1 with mitotic cyclins Clb1-4. These cyclins are essential in early mitosis for spindle formation and other processes, which need to occur before APC/C is activated. $\mathrm{Clb5}$ instability may be required for reducing and/or reversing the phosphorylation of S-phase specific substrates, enabling the dephosphorylation of targets before the activation of APC/C. It is known that Cdk1-Clb5 exhibits much higher substrate specificity than Cdk1-Clb2 (Loog and Morgan, 2005). Cdk1-Clb5 specifically phosphorylates various proteins required for DNA replication, whereas Cdk1-Clb2 has a higher kinase activity, but phosphorylates Cdk1 targets with low specificity. Thus, Clb5 instability could be important for restricting the activity of the $\mathrm{Cdk1-Clb5}$ kinase against its substrates.

Remarkably, cyclin A, the S-phase cyclin in vertebrate cells, was found to be degraded earlier than cyclin B (Geley et al., 2001) during mitosis. In this case however, this preceding degradation is mediated by $\mathrm{APC} / \mathrm{C}-\mathrm{Cdc} 20$, but occurs prior to the inactivation of the spindle assembly checkpoint.

Different degradation pathways for Clb5 may have further significant roles. It is conceivable that they are important for preventing a disastrous outcome due to an expression of $\mathrm{Clb5}$ to exceedingly high levels. Although Clb5 expression is normally tightly regulated, failures in this process may result in elevated expression levels. In this regard, it is worth mentioning that such abnormalities in gene expression are often identified in cancer cells. Overexpression of cyclins, such as cyclin D1, is frequently found in human malignancies, resulting in upregulated cyclin-dependent kinases (Tashiro et al., 2007).

It is important to point out, that high levels of Clb5 kinase activity, as in strains expressing GAL1CLB5 $\triangle D B$, does not cause a reversible cell cycle arrest, but instead causes cell death (Jacobson et al., 2000). In contrast, a stabilised $\mathrm{Clb2}$ induces a reversible cell cycle arrest in telophase and does not cause cell death (Jacobson et al., 2000). These findings highlight the importance of alternative processes for $\mathrm{Clb} 5$ degradation, acting in concert to ensure that toxic effects of a deregulated Cdk1Clb5 activity are efficiently prevented.

We have provided evidence that this also applies to G1 cells, in order to prevent an uncontrolled entry into S-phase. In G1 phase, Clb5 is controlled by multiple mechanisms: repression of CLB5 expression, the presence of Sic 1 and Clb5 instability (Bloom and Cross, 2007). Each process contributes to maintain a solid G1 arrest. Control of Clb5 in G1 phase is crucial because Cdk1-Clb5 phosphorylates many substrates required for S-phase, including Cdh1, with high substrate specificity (Loog and Morgan, 2005) and it is a potent inducer of DNA replication. We found that 
elevated levels of $\mathrm{Clb5}$ lacking a destruction box, which is therefore inaccessible by APC/C, triggered efficient Cdh1 phosphorylation in G1 cells and induced DNA replication. Thus, an increase in CLB5 expression renders APC/C activity essential for proteolysis of this cyclin. Under such conditions, the APC/C-independent mode is not any more sufficient and destruction-box mediated degradation gets essential for preventing Cdh1 phosphorylation and S-phase entry in the presence of pheromone.

The findings on $\mathrm{Clb5}$ regulation are an example showing how different mechanisms with overlapping functions may help to prevent defects in the cell cycle, even if other processes, such as transcriptional regulation, fail. Thereby, death of dividing cells or abnormal cell cycle entry of G1arrested cells is avoided. 


\section{References}

Amon, A., Irniger, S., and Nasmyth, K. (1994). Closing the cell cycle circle in yeast: G2 cyclin proteolysis initiated at mitosis persists until the activation of G1 cyclins in the next cycle. Cell 77, 1037-1050.

Asher, G., Reuven, N., and Shaul, Y. (2006). 20S proteasomes and protein degradation "by default". Bioessays 28, 844-849.

Bai, C., Sen, P., Hofmann, K., Ma, L., Goebl, M., Harper, J.W., and Elledge, S.J. (1996). SKP1 connects cell cycle regulators to the ubiquitin proteolysis machinery through a novel motif, the F-box. Cell 86, 263-274.

Bloom, J., and Cross, F.R. (2007). Multiple levels of cyclin specificity in cell-cycle control. Nat Rev Mol Cell Biol 8, 149-160.

Burton, J.L., Tsakraklides, V., and Solomon, M.J. (2005). Assembly of an APC-Cdh1-substrate complex is stimulated by engagement of a destruction box. Mol Cell 18, 533-542.

Epstein, C.B., and Cross, F.R. (1992). CLB5: a novel B cyclin from budding yeast with a role in S phase. Genes Dev 6, 1695-1706.

Fitch, I., Dahmann, C., Surana, U., Amon, A., Nasmyth, K., Goetsch, L., Byers, B., and Futcher, B. (1992). Characterization of four B-type cyclin genes of the budding yeast Saccharomyces cerevisiae. Mol Biol Cell 3, 805-818.

Geley, S., Kramer, E., Gieffers, C., Gannon, J., Peters, J.M., and Hunt, T. (2001). Anaphasepromoting complex/cyclosome-dependent proteolysis of human cyclin A starts at the beginning of mitosis and is not subject to the spindle assembly checkpoint. J Cell Biol 153, 137-148.

Ghislain, M., Udvardy, A., and Mann, C. (1993). S. cerevisiae 265 protease mutants arrest cell division in G2/metaphase. Nature 366, 358-362.

Goebl, M.G., Yochem, J., Jentsch, S., McGrath, J.P., Varshavsky, A., and Byers, B. (1988). The yeast cell cycle gene CDC34 encodes a ubiquitin-conjugating enzyme. Science 241, 1331-1335.

Hoyt, M.A., and Coffino, P. (2004). Ubiquitin-free routes into the proteasome. Cell Mol Life Sci 61, 1596-1600.

Huang, J.N., Park, I., Ellingson, E., Littlepage, L.E., and Pellman, D. (2001). Activity of the APC(Cdh1) form of the anaphase-promoting complex persists until $S$ phase and prevents the premature expression of Cdc20p. J Cell Biol 154, 85-94.

Irniger, S., and Nasmyth, K. (1997). The anaphase-promoting complex is required in G1 arrested yeast cells to inhibit B-type cyclin accumulation and to prevent uncontrolled entry into Sphase. J Cell Sci 110 (Pt 13), 1523-1531.

Jackson, L.P., Reed, S.I., and Haase, S.B. (2006). Distinct mechanisms control the stability of the related S-phase cyclins Clb5 and Clb6. Mol Cell Biol 26, 2456-2466.

Jacobson, M.D., Gray, S., Yuste-Rojas, M., and Cross, F.R. (2000). Testing cyclin specificity in the exit from mitosis. Mol Cell Biol 20, 4483-4493.

Kraft, C., Vodermaier, H.C., Maurer-Stroh, S., Eisenhaber, F., and Peters, J.M. (2005). The WD40 propeller domain of Cdh1 functions as a destruction box receptor for APC/C substrates. Mol Cell 18, 543-553.

Loog, M., and Morgan, D.O. (2005). Cyclin specificity in the phosphorylation of cyclin-dependent kinase substrates. Nature 434, 104-108.

Mendenhall, M.D., and Hodge, A.E. (1998). Regulation of Cdc28 cyclin-dependent protein kinase activity during the cell cycle of the yeast Saccharomyces cerevisiae. Microbiol Mol Biol Rev 62, 1191-1243.

Peters, J.M. (2006). The anaphase promoting complex/cyclosome: a machine designed to destroy. Nat Rev Mol Cell Biol 7, 644-656. 
Pringle, J.R., Adams, A.E., Drubin, D.G., and Haarer, B.K. (1991). Immunofluorescence methods for yeast. Methods Enzymol 194, 565-602.

Richardson, H., Lew, D.J., Henze, M., Sugimoto, K., and Reed, S.I. (1992). Cyclin-B homologs in Saccharomyces cerevisiae function in S phase and in G2. Genes Dev 6, 2021-2034.

Rudner, A.D., and Murray, A.W. (2000). Phosphorylation by Cdc28 activates the Cdc20-dependent activity of the anaphase-promoting complex. J Cell Biol 149, 1377-1390.

Schneider, B.L., Yang, Q.H., and Futcher, A.B. (1996). Linkage of replication to start by the Cdk inhibitor Sic1. Science 272, 560-562.

Schwab, M., Lutum, A.S., and Seufert, W. (1997). Yeast Hct1 is a regulator of Clb2 cyclin proteolysis. Cell 90, 683-693.

Schwob, E., and Nasmyth, K. (1993). CLB5 and CLB6, a new pair of B cyclins involved in DNA replication in Saccharomyces cerevisiae. Genes Dev 7, 1160-1175.

Schwob, E., Bohm, T., Mendenhall, M.D., and Nasmyth, K. (1994). The B-type cyclin kinase inhibitor p4OSIC1 controls the $\mathrm{G} 1$ to $S$ transition in S. cerevisiae. Cell 79, 233-244.

Seufert, W., Futcher, B., and Jentsch, S. (1995). Role of a ubiquitin-conjugating enzyme in degradation of S- and M-phase cyclins. Nature 373, 78-81.

Shirayama, M., Toth, A., Galova, M., and Nasmyth, K. (1999). APC(Cdc20) promotes exit from mitosis by destroying the anaphase inhibitor Pds1 and cyclin Clb5. Nature 402, 203-207.

Surana, U., Amon, A., Dowzer, C., McGrew, J., Byers, B., and Nasmyth, K. (1993). Destruction of the CDC28/CLB mitotic kinase is not required for the metaphase to anaphase transition in budding yeast. Embo J 12, 1969-1978.

Tashiro, E., Tsuchiya, A., and Imoto, M. (2007). Functions of cyclin D1 as an oncogene and regulation of cyclin D1 expression. Cancer Sci 98, 629-635.

Thornton, B.R., Chen, K.C., Cross, F.R., Tyson, J.J., and Toczyski, D.P. (2004). Cycling without the cyclosome: modeling a yeast strain lacking the APC. Cell Cycle 3, 629-633.

Verma, R., Annan, R.S., Huddleston, M.J., Carr, S.A., Reynard, G., and Deshaies, R.J. (1997). Phosphorylation of Sic1p by G1 Cdk required for its degradation and entry into $S$ phase. Science 278, 455-460.

Visintin, R., Prinz, S., and Amon, A. (1997). CDC20 and CDH1: a family of substrate-specific activators of APC-dependent proteolysis. Science 278, 460-463.

Voges, D., Zwickl, P., and Baumeister, W. (1999). The 265 proteasome: a molecular machine designed for controlled proteolysis. Annu Rev Biochem 68, 1015-1068.

Wasch, R., and Cross, F.R. (2002). APC-dependent proteolysis of the mitotic cyclin Clb2 is essential for mitotic exit. Nature 418, 556-562.

Willems, A.R., Lanker, S., Patton, E.E., Craig, K.L., Nason, T.F., Mathias, N., Kobayashi, R., Wittenberg, C., and Tyers, M. (1996). Cdc53 targets phosphorylated G1 cyclins for degradation by the ubiquitin proteolytic pathway. Cell 86, 453-463.

Yeong, F.M., Lim, H.H., Wang, Y., and Surana, U. (2001). Early expressed Clb proteins allow accumulation of mitotic cyclin by inactivating proteolytic machinery during $\mathrm{S}$ phase. Mol Cell Biol 21, 5071-5081.

Zachariae, W., Schwab, M., Nasmyth, K., and Seufert, W. (1998). Control of cyclin ubiquitination by CDK-regulated binding of Hct1 to the anaphase promoting complex. Science 282, 17211724. 


\section{Footnotes}

We thank Patrick Dieckhoff, Melanie Bolte and Wibke Meyer for help in some of the experiments, Kim Nasmyth for providing Cdc28 antibodies, Fred Cross and Markus Künzler for yeast strains. We are grateful to Özgür Bayram for critical comments on the manuscript and Alexander Gierse, Institute of Technical Chemistry, Hannover, for help with the FACS analysis. This work was supported by the Deutsche Forschungsgemeinschaft, the Fonds der Chemischen Industrie und the Volkswagen-Stiftung. 


\title{
CHAPTER 3
}

THE C-TERMINAL REGION OF MEIOSIS-SPECIFIC KINASE IME2 MEDIATES PROTEIN INSTABILITY

AND IS REQUIRED FOR NORMAL SPORE FORMATION IN BUDDING YEAST

\begin{abstract}
The cyclin-dependent kinase Cdk1 and the related kinase Ime2 act in concert to trigger progression of meiotic cell cycle in the yeast Saccharomyces cerevisiae. These kinases share several functions and substrates during meiosis, but their regulation seems to be clearly different. In contrast to Cdk1, no cyclins seem to be involved in the regulation of Ime2 activity. Ime2 is itself a highly unstable proteins. Here, we were interested to elucidate the relevance of Ime2 instability for meiosis. By constructing a set of deletions in the IME2 gene, we found that small deletions did not affect Ime2 instability. In contrast, deletion of a C-terminal region of 242 amino acids resulted in a highly stabilised protein. Thus, the C-terminal domain of Ime2 mediates protein instability. The stabilised, truncated Ime2 protein is highly active and its expression in dividing cells caused a cell cycle arrest and efficient phosphorylation of Cdh1, a coactivator of the anaphase-promoting complex. Replacement of the IME2 gene with the truncated IME2 $\triangle C 242$ in diploid strains did not interfere with meiotic nuclear divisions, but caused abnormalities in spore formation, as manifested by the appearance of many asci with a reduced spore number such as triads and dyads. The truncated Ime2 caused spore number reduction in a dominant manner. These data suggest that downregulation of Ime2 kinase activity mediated by the C-terminal domain is required for the efficient production of 4-spore asci in S. cerevisiae.
\end{abstract}




\section{Introduction}

Cyclin-dependent kinases (Cdks) have fundamental roles for triggering progression of the eukaryotic cell cycle. The activity of these kinases depends on the association with unstable regulatory proteins known as cyclins, which mediate oscillation of the kinase activity during the cell cycle. In the budding yeast Saccharomyces cerevisiae, the kinase Cdk1 (also known as Cdc28) is the sole essential Cdk for cell cycle progression (Mendenhall and Hodge, 1998; Bloom and Cross, 2007). Different cyclins associate with Cdk1, the G1 cyclins Cln1-3, the S-phase cyclins Clb5 and Clb6 and the G2/ mitotic cyclins Clb1-4.

Cdk1 activity is also required for the meiotic cell cycle (Guttmann-Raviv et al., 2001; Honigberg, 2004). Meiosis is a specialised cell division allowing diploid cells the exchange of genetic material and the generation of haploid offspring. In the meiotic cell cycle, one round of DNA replication is followed by two rounds of chromosome segregation. Following the meiotic divisions of S. cerevisiae, four haploid spores are produced within an ascus.

In addition to Cdk1, the related protein kinase Ime2 is also essential for progression through meiosis (Yoshida et al., 1990). The expression of the IME2 gene is restricted to meiosis (Smith and Mitchell, 1989). The function of this protein kinase is essential for various processes during meiosis, such as the timely execution of DNA replication, the efficient expression of early and middle meiotic genes and for meiotic nuclear divisions (Mitchell et al., 1990; Benjamin et al., 2003; Kassir et al., 2003). It was proposed that Ime2 assists Cdk1 and that it can take over some functions of Cdk1 during meiosis (Guttmann-Raviv et al., 2001; Honigberg, 2004). Consistent with this idea, it was found that Ime2 fulfils the functions of the G1-specific Cdk1 prior to premeiotic DNA replication, rendering the G1 cyclins Cln1-3 dispensable for the meiotic cell cycle (Dirick et al., 1998).

Recently, it was demonstrated that Cdk1 and Ime2 phosphorylate their substrates on different consensus sequences. Whereas Cdk1 phosphorylates its substrates within the S/T-P-x-K/R motifs, Ime2 motifs were identified as R-P-x-S/T (Holt et al., 2007; Moore et al., 2007). Despite these differences, the protein kinase Ime2 seems to have many overlapping function with Cdk1. Indeed, Cdk1 and Ime2 have a number of common substrates. Like Cdk1, Ime2 is involved in phosphorylation of the CDK inhibitor Sic1, but phosphorylates Sic1 on different sites (Sawarynski et al., 2007). Remarkably, Ime2 activity is essential, but not sufficient for triggering Sic1 proteolysis, suggesting that a common function of Cdk1 and Ime2 is needed for this process (Dirick et al., 1998; Sedgwick et al., 2006). 
In addition to trigger Sic1 degradation, Ime2 has further roles in DNA replication, such as phosphorylation of the replication protein Rpa1 (Clifford et al., 2004). Furthermore, components of the pre-replicative complex (pre-RC) were identified as targets of Ime2, and thereby this kinase may contribute to prevent DNA rereplication during meiosis (Holt et al., 2007).

Cdh1, a coactivator of the anaphase promoting complex/cyclosome (APC/C), is a further common target of both Cdk1 and Ime2. The IME2 gene was identified in a genetic screening for factors inhibiting proteolysis of the APC/C substrate Clb2, a mitotic cyclin (Bolte et al., 2002). In vivo studies showed that ectopic expression of IME2 caused phosphorylation of Cdh1. Recently, it was demonstrated that Ime2 phosphorylates Cdh1 in vitro (Holt et al., 2007). Thus, Ime2 seems to be involved in APC/C inactivation prior to pre-meiotic S-phase. It is conceivable that Ime2 contributes to the highly versatile regulation of APC/C activity during meiosis (Irniger, 2006).

The data from Holt et al. (Holt et al., 2007) provided a clue why the regulation of meiosis may benefit from the presence of two different kinases with different phosphorylation motifs in their substrates. It was demonstrated that the accessibility of Cdk1 and Ime2 phosphorylation sites by phosphatases is different. Cdc14, a phosphatase required for exit from mitosis and meiosis I, efficiently removed phosphates from Cdk1 sites of Cdh1, but poorly from Ime2 sites. It was concluded that Ime2-mediated phosphorylation helps to restrict the activity of Cdc14 and therefore to maintain sufficient kinase activity to prevent an intervening S-phase between the meiotic divisions. These findings suggest that Ime2 is of importance to ensure the specific demands of the meiotic cell cycle.

Ime2 kinase activity increases in early meiosis, then decreases and subsequently rises to its highest levels during meiotic divisions (Benjamin et al., 2003). Whereas Cdk1 is known to be regulated primarily by the oscillation of its cyclin partners, little is known about regulation of Ime2 kinase activity. In contrast to CDKs, no regulatory subunits corresponding to cyclins have been identified for Ime2.

One possible regulatory mechanism of Ime2 appears to be phosphorylation. Residues Thr242 and Tyr-244 in the activation loop are phosphorylated and this is dependent on the kinase Cak1 and on autophosphorylation (Schindler et al., 2003; Schindler and Winter, 2006). This modification is important for the function of Ime2 during meiosis.

Phosphorylation of Ime2 was also detected in the C-terminal region (Schindler and Winter, 2006). This region is not required for Ime2 function, but rather represents a regulatory domain with apparently inhibitory roles (Kominami et al., 1993). Phosphorylation of Ser-520 and Ser-625 was detected by mass spectrometry (Schindler and Winter, 2006). Mutations of these sites had 
moderate effects on sporulation, but displayed synthetic phenotypes with mutations in genes impaired in the exit form meiosis I.

The C-terminal region was also identified as a binding site for regulatory proteins, at least under specific nutritional conditions. It was found that in media containing nitrogen in combination with a non-fermentable carbon source, the GTPase Gpa2 binds this region and thereby inhibits the kinase activity (Donzeau and Bandlow, 1999).

Modulation of protein stability may represent a further possible mechanism for the regulation of Ime2 activity. In contrast to the stable Cdk1, Ime2 was found to be itself an unstable protein. Pulse labeling experiments showed that Ime2 is rapidly degraded in cells undergoing meiosis (Guttmann-Raviv et al., 2002). A further study showed that Ime2 was rapidly degraded in response to low amounts of glucose and that this degradation is mediated by the ubiquitin ligase Skp1/Cullin/F-box protein (SCF), associated with the F-box protein Grr1 (Purnapatre et al., 2005). Ime2 was also shown to be highly unstable when expressed in dividing cells (Bolte et al., 2002),

Up to now, it is unknown whether the intrinsic instability of Ime2 has any role during the sporulation program of yeast. To address this question, we were interested to determine the consequence of the expression of a stabilised version of Ime2.

To enable such tests, we first identified Ime2 elements responsible for its instability. The instability of Ime2 in dividing cells allowed us to analyse Ime2 proteolysis by simple promoter shutoff experiments. By constructing a set of deletions, we found that only upon removal of a large region comprising most of the C-terminal regulatory domain, Ime2 was distinctly stabilised. Expression of this stable, highly active version of Ime2 in diploid cells did not interfere with meiotic divisions, but resulted in the accumulation of asci with reduced spore number, such as triads and dyads. Thus, the C-terminal region plays an important role for Ime2 instability and for the efficient formation of 4-spore asci. 


\section{Materials and Methods}

Yeast strains and growth conditions. Yeast strains used in this study are derivates of either the W303 strain or, for sporulation experiments, derivates of the SK1 strains. All strains used in this study are listed in Table 1. Cell were grown either in YEP (1\% yeast extract, $2 \%$ peptone) complete medium or minimal medium lacking the appropriate amino acid for plasmid selection. Media contained either $2 \%$ glucose or $2 \%$ raffinose as carbon source. For induction of the GAL1 promoter, cells were pregrown in media containing raffinose, and then galactose was added to a final concentration of $2 \%$. For promoter shut-off experiments, cells were filtered and transferred into glucose-containing medium. Cells were arrested in G1 phase by the addition of alpha-factor to a final concentration of $5 \mu \mathrm{g} / \mathrm{ml}$. Cells were incubated for at least 2,5 hours, until more than $90 \%$ of cells were unbudded.

Table I. Saccharomyces cerevisiae strains used in this study.

\begin{tabular}{|c|c|c|c|}
\hline Strain & $\begin{array}{r}\text { Relevant genotype } \\
\end{array}$ & ound & Source \\
\hline S001 & $\begin{array}{l}\text { W303-1A wild-type strain } \\
\text { MATa, ade2-1, trp1-1. leu2-3,112, his3-11,15, } \\
\text { ura3, can1-100, GAL, psi+ }\end{array}$ & W303 & R. Rothstein \\
\hline S003 & MATa, his1 & W303 & R. Rothstein \\
\hline S004 & MAT $\alpha$, his1 & W303 & R. Rothstein \\
\hline S396 & MATa, GAL-IME2-HA6-TRP1 (5x) & W303 & Bolte et al., 2002 \\
\hline S436 & MATa, swe1:LEU2 & W303 & Sia et al., 1996 \\
\hline S474 & MATa , GALL-HA-CDH1-TRP1, bar1::HisG & $\begin{array}{l}\text { W303 } \\
1998\end{array}$ & Zachariae et al., \\
\hline S617 & $\begin{array}{l}\text { MATa, GALL-HA-CDH1-TRP1, } \\
\text { GAL-IME2AC242-URA3, bar1::HisG }\end{array}$ & W303 & this work \\
\hline S510 & MATa, grr1::URA3, GAL-IME2-HA6-TRP1 & $\begin{array}{l}\text { W303 } \\
2005\end{array}$ & Purnapatre et al., \\
\hline S497 & SK1 wild-type strain, diploid & SK1 & M. Knop \\
\hline S577 & MATa, GAL-IME2 $\triangle P E S T-H A 6-T R P 1$ & W303 & this work \\
\hline S608 & 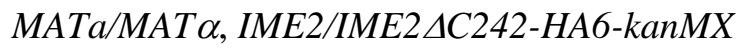 & SK1 & this work \\
\hline S610 & $\begin{array}{l}\text { MATa/MAT } \alpha, \text { IME2 } \triangle C 242-H A 6-k a n M X \\
\text { /ime2::kanMX }\end{array}$ & SK1 & this work \\
\hline S611 & MATa/MAT $\alpha$, ime2::kanMX /ime2::kanMX & SK1 & this work \\
\hline S613 & MATa/MAT $\alpha$, IME2 /ime2::kanMX & SK1 & this work \\
\hline S635 & $\begin{array}{l}\text { MATa/MAT } \alpha, \text { IME2 } \triangle C 242-H A 6-k a n M X / \\
\text { IME2 } \triangle \text { C242-HA6-kanMX }\end{array}$ & SK1 & this work \\
\hline S718 & MATa/MAT $\alpha$, IME2/IME2-MYC9-TRP1 & SK1 & this work \\
\hline
\end{tabular}


Table II. Plasmids used in his study

\begin{tabular}{|c|c|c|}
\hline Plasmid & Description & \\
\hline YCplac22 & centromeric plasmid, TRP1 marker & Gietz et al.(1988) \\
\hline YIplac204 & integrative plasmid, TRP1 marker & Gietz et al. (1988) \\
\hline pBluescript II KS & cloning vector & Fermentas \\
\hline Pym 1 & tagging plasmid & Knop et al. (1999) \\
\hline pME2116 & GAL-IME2-HA6 in YCplac22 & Bolte et. al (2002) \\
\hline FS100 & GAL-IME2 $\triangle P E S T-H A 6$ in YIplac204 & this work \\
\hline FS101 & GAL-IME2 $11-67-H A 6$ in YCplac22 & this work \\
\hline FS102 & GAL-IME2 $468-135-H A 6$ in YCplac22 & this work \\
\hline FS103 & GAL-IME2 $\Delta 136-201-H A 6$ in YCplac22 & this work \\
\hline FS104 & GAL-IME2 $\triangle 202-264-H A 6$ in YCplac22 & this work \\
\hline FS105 & GAL-IME2 $4265-337-H A 6$ in YCplac22 & this work \\
\hline FS106 & GAL-IME2 $4338-404-H A 6$ in YCplac22 & this work \\
\hline FS107 & GAL-IME2 $4405-466-H A 6$ in YCplac22 & this work \\
\hline FS108 & GAL-IME2 $4467-533-H A 6$ in YCplac22 & this work \\
\hline FS109 & GAL-IME2 $\triangle 534-600-H A 6$ in YCplac22 & this work \\
\hline FS110 & GAL-IME2 $\triangle 601-646-H A 6$ in YCplac22 & this work \\
\hline FS111 & GAL-IME2 $4405-533-H A 6$ in YCplac22 & this work \\
\hline \multirow[t]{2}{*}{ FS112 } & GAL-IME2 $\triangle 405-646-H A 6$ & \\
\hline & (GAL-IME2 $\triangle C 242-H A 6)$ in YCplac22 & this work \\
\hline \multirow[t]{2}{*}{ FS113 } & IME2 $\triangle C 242-H A 6$ and $k a n M X$ & \\
\hline & in pBluescript II KS & this work \\
\hline \multirow[t]{2}{*}{ FS114 } & IME2-HA6 and kanMX & \\
\hline & in pBluescript II KS & this work \\
\hline \multirow[t]{2}{*}{ FS115 } & IME2 $4467-533-H A 6$ and $k a n M X$ & \\
\hline & in pBluescript II KS & this work \\
\hline
\end{tabular}


Table III. Oligonucleotides used in this study

\begin{tabular}{|c|c|}
\hline Oligonucleotide & Sequence $5^{\prime}$ to $3^{\prime}$ \\
\hline Mel1 & CCGGTCACTTAAGCTCGAGC \\
\hline Mel3 & GGCGGAAGCTTTATGACCATGATTACGCC \\
\hline Mel4 & CCCGGGCTGCAGAAAGAAATTCGTAATAATTTGGCC \\
\hline Mel5 & CCCGGGCTGCAGATCATCATTATCTTCTTCAACG \\
\hline IME2 del 1 & CССССССТGCAGGAATAAGAAGTAATACAAACCG \\
\hline IME2 del 2 & СССССССТGСАGTTTAСССАATATGTTCGATAAAGG \\
\hline IME2 del 3 & СССССССТGCAGAATAAAGAССТСАAАAАTTTGTATCA \\
\hline IME2 del 4 & СССССССТGCAGGATAAGAATATTTTCAGGTTTTAAAT \\
\hline IME2 del 5 & СССССССТGCAGTTTGGAATAGTAACСАСТTCTTAAT \\
\hline IME2 del 6 & СССССССТGСAGCAAGTTTAATTTATGGACСАAАTTA \\
\hline IME2 del 7 & СССССССТGCAGTTCTGTATTAGTCACATTGCСTC \\
\hline IME2 del 8 & СССССССТGСAGAАATTСТАССАAAGTTAGTTTTTСТT \\
\hline IME2 del 9 & СССССССТGCAGAАTTTTCATTATCATTTGTCAACTGC \\
\hline IME2 del 10 & СССССССТGCAGGGCATCAСССАAАACATTATCA \\
\hline IME2 del 11 & СССССССТGCAGCAACATGATATAAGGGGTACTTTA \\
\hline IME2 del 12 & СССССССТGCAGTCTGAAAATTACСАATTACATA \\
\hline IME2 del 13 & CССССССТGCAGACACСAAGTACCCAGTATTTTGA \\
\hline IME2 del 14 & CCCСССCTGCAGCCTTTGGATATTTGGGCATTCG \\
\hline IME2 del 15 & CССССССТGCAGAAATTGCСТTATGTAGAAGGTTCA \\
\hline IME2 del 16 & CССССССТGCAGCAAGCATTGATTTTTGCAGGTATA \\
\hline IME2 del 17 & CССССССТGCAGTTAAACGAATTCGTTGAAGAAGATA \\
\hline IME2 del 18 & СССССССТGCAGATAAATAAAGATGAAGCAGACAACA \\
\hline IME2 del 19 & СССССССТGCAGTCTTTAGGCGATTCGTTTAATTCA \\
\hline IME2 del 20 & CCСССССТGCAGGGCCGCATCTTTTACCCATAC \\
\hline FAT1 & CCCCCCGGTACCATGGTTGAAAAACGTAGTAG \\
\hline FAT2 & CCCCCCGTCGACCATGATTACGCCAAGCTT \\
\hline FAT3 & CCCCCCGTCGACGACATGGAGGCCCAGAAT \\
\hline FAT4 & CCCCCCGCGGCCGCTGGATGGCGGCGTTAGTA \\
\hline \multirow[t]{2}{*}{ FAT5 } & ATACAGACGTAATAAAAGAAGAGTACTAAGCTTAACTTAATAGG \\
\hline & TCATTTGGTACCATGGTTGAAAAACGTAGTAG \\
\hline \multirow[t]{2}{*}{ FAT6 } & ATATAACTATATAACTGTGCCTAACGATTCGTCAGTCAAATGACAAA \\
\hline & TTAGCGGCCGCTGGATGGCGGCGTTAGTA \\
\hline
\end{tabular}

Sporulation experiments. Sporulation of yeast SK1 strains was performed as previously described (Buonomo et al., 2000). In brief, single colonies were picked from YEP plates containing $2 \%$ glycerol and streaked to YEPD plates. Patches were grown for 48 hours and then inoculated in YEP containing $2 \%$ potassium acetate. After 13,5 hours, cells were filtered, washed and transferred to sporulation medium ( $2 \%$ potassium acetate). Sporulation was monitored by counting nuclei of DAPI stained cells. 
Plasmid construction. Plasmids used in this study are listed in Table II. Construction of the GALIME2-HA6 fusion was previously described (Bolte et al., 2002). The gene fusion was cloned as a Kpn1-HindIII fragment into centromeric plasmid YCplac22 (Gietz and Sugino, 1988). The version lacking the PEST-rich sequence was constructed by a PCR amplification of the GAL promoter and Nterminal region of IME2 using primers Mel1 and Mel5. The received PCR product was cut with KpnI and Pstl and cloned into the Kpnl-Pstl digested vector YIplac204. In a second step the newly generated vector was reopened with Pstl-HindIII and a Pstl-HindIII fragment including the C-terminal part of IME2 and an HA tag was cloned. The latter fragment was amplified with the primers Mel3 and Mel4.

A set of deletions in the IME2 gene, each lacking about 201 base pairs (60-70 amino acids, Fig. 2A) were constructed using a plasmid containing the GAL-IME2-HA6 gene fusion (pME2116). Fragments for the deletion set were amplified from plasmid pME2116 and subsequently cloned into the vector YCplac22. Ten PCR fragments with different lengths comprised the GAL-promoter and N terminal region of IME2. These fragments were amplified by the use of the oligonucleotide Mel1 and different oligonucleotides (Ime2del 1-10; Table 3) from the IME2 open reading frame. The PCR products were digested with Kpnl and Pstl and cloned into YCplac22. Ten additional fragments comprised variable lengths of the C-terminal part of the IME2 open reading frame and the HA6 epitope. These fragments were amplified by the use of the oligonucleotide Mel3 and ten different oligonucleotide (Ime2del 11-20; Table III) from the IME2 open reading fame. These PCR products were digested with Pstl and HindIII and cloned into YCplac22. Based on the twenty IME2 fragments, a deletion was gained by fusion of one of the $\mathrm{N}$ terminal fragment with one of the $\mathrm{C}$ terminal fragment at the Pstl site (Fig. 2A). The combination of the fragments resulted in a deletion of approximately 200 base pairs. With this procedure, 10 plasmids, FS101-110 were obtained. Furthermore, two additional constructs with larger deletions of the IME2 open reading frame were created, a $387 \mathrm{bp}$ and a 726 bp deletion in the $3^{\prime}$ region of the IME2 gene. These constructs were also cloned into the vector YCplac22.

Plasmid FS116 (GAL-IME2 $\triangle C 242$ with no HA tag) was constructed by removing the HA6 from plasmid by digestion with the enzymes $X b a 1$ and $K p n 1$, blunt-ending with Klenow enzyme, religation and subcloning of the construct into Ylplac211.

For constructing a SK1 strain carrying the truncated IME2 $\triangle C 242-H A 6$ gene instead of the normal IME2 gene, a DNA fragment containing the IME2 $\triangle C 242-H A 6$ sequence was amplified from the plasmid FS112 using the primers FAT1 and FAT2. The PCR fragment digested with Acc65 and Sall was subcloned into an Acc65-Sall digested pBluescript II KS vector. A kanMX6 module (kanamycinresistance gene) was amplified from plasmid Pym1 (Knop et al., 1999) using the primers FAT3 and 
FAT4 and subsequently introduced behind the IME2 $\triangle C 242$ gene. For homologous integration the IME2 $\triangle C$-HA-KanMX6 module was amplified with primers FAT5 and FAT6 and transformed into the SK1 strain according to Knop et al. (Knop et al., 1999). Integration was verified by PCR and immunoblotting. Full-length IME2-HA6 and IME2 $4467-533-H A 6$ was cloned into an integrative plasmid similarly as described for the IME2 $\triangle C 242$ plasmid.

Removal of the C-terminal 242 amino acids of Ime2 was also performed by a direct tagging method (Knop et al., 1999), adding the HA6 tag after amino acid 403. For this purpose plasmid Pym1 was PCR amplified.

The ime2 deletion strain in the SK1 background was constructed by amplification of the disruption cassette from the EUROSCARF ime2 deletion strain, transformation into the SK1 strain, selection on kanamycin plates and verification of transformants by PCR.

Immunoblotting and immunofluorescence.Cell extracts were prepared as described (Surana et al., 1993). Yeast cells were broken with glass beads. The enhanced chemiluminescence detection system (Amersham) was used for the detection of specific proteins. Antibodies were used in 1:1000 (anti-HA and anti-Myc) or 1:2000 (anti-Cdc28) concentrations. For indirect immunofluorescence, cells were fixed in $3.7 \%$ formaldehyde. Spheroplasts were prepared as described (Pringle et al., 1991). DAPI (4',6-diamidino-2-phenylindole) staining and anti-tubulin antibodies (YOL 1/34, 1:60 dilution) were used for visualisation of nuclei and spindles, respectively. 


\section{Results}

Ime2 instability in dividing cells is independent of the PEST-rich region and the F-box protein Grr1. Ime2 is an unstable protein in meiotic cells (Guttmann-Raviv et al., 2002). We have earlier shown that Ime2 is also a highly unstable protein, when expressed in dividing cells (Bolte et al., 2002).

Ime2 contains a PEST-rich region in its C-terminal regulatory region. This region was implicated in mediating Ime2 proteolysis under conditions of low glucose concentrations in meiosis (Purnapatre et al., 2005). We tested whether the PEST-rich element is needed for the instability of Ime2 in dividing cells. Therefore, we constructed a plasmid containing an HA6-tagged version of Ime2 lacking the PEST-rich region, corresponding to amino acids 479-499. This truncated IME2 gene was expressed from the inducible GAL1 promoter. Protein stability was analysed in strains containing either GAL1-IME2 $\triangle P E S T-H A 6$ or, as a control, in GAL1-IME2-HA6 strains by promoter shut-off experiments. Strains were incubated in the presence of galactose for one hour and then transferred to glucose media. We found that Ime2 without the PEST region is as unstable as the fulllength Ime2 (Fig. 1 A). Thus, other sequences than the PEST rich region are responsible for the rapid proteolysis of Ime2 in dividing cells.

Previously, the F-box protein Grr1, a component of the ubiquitin-ligase SCF-Grr1, has been implicated in Ime2 degradation in response to low glucose concentrations. To test whether the instability of Ime2 in dividing cells also depends on Grr1, we tested the stability of Ime2 in grr1 deletion strains by promoter shut-off experiments. The expression of GAL-IME2-HA6 was transiently induced by the addition of galactose and then repressed by transfer of cells to glucose medium. By immunoblotting using an anti-HA antibody we found that Ime2 was highly unstable in wild-type and in grr1 mutants (Fig. 1B). Thus, Grr1 is not essential for the rapid destruction of Ime2.

We conclude that Grr1 and the PEST rich region are dispensable for Ime2 instability in dividing cells. 
A

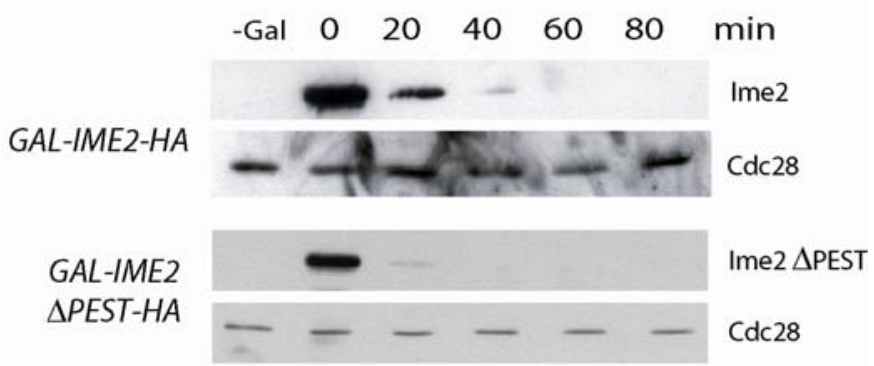

B

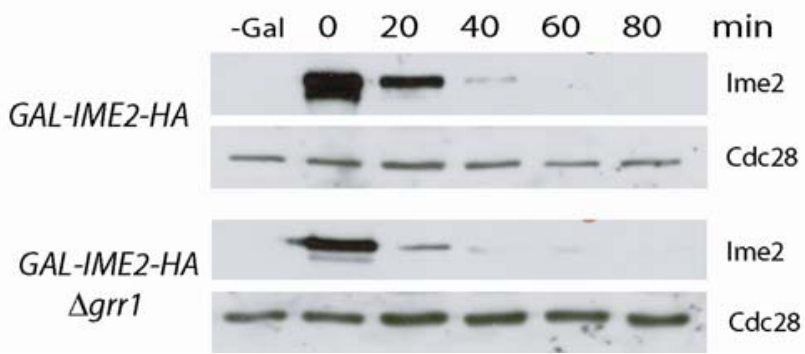

Fig.1 Ime2 instability is independent of the PEST-rich region and of the F-box Protein Grr1

(A) Strains expressing either GAL-IME2-HA6 or GAL-IME2 $\triangle P E S T-H A 6$ (encoding Ime2 with a deletion of the PEST-rich region 479-499) were pre-grown in YEP+Raf medium. Galactose (2\% end concentration) was added for 1 hour. Then, cells were filtered and transferred to glucose medium ( 0 min. time point) to shut off the GAL1 promoter. Samples taken at the indicated time points after the transfer were analysed by immunoblotting using the anti- HA-antibody. Cdc28 was used as loading control-

(B) Wild-type and grr1 deletion strain (grr1::LEU2), both containing the GAL-IME2-HA6 construct were treated as described for strains in (A).

\section{Small deletions have little influence on stability, but a large C-terminal deletion distinctly}

stabilises Ime2. To test the relevance of Ime2 instability for sporulation, we aimed to obtain a stabilised and active version of Ime2. For this purpose, we first wanted to identify the regions in Ime2 responsible for protein instability. We created a set of deletions each comprising about 200 base pairs of the IME2 coding sequence (Fig. 2A). Each deletion construct lacking 60-70 amino acids was expressed from the GAL1 promoter and fused at its C-terminal region with a HA6 tag. The resulting 10 deletion constructs, each cloned in a centromeric plasmid, were transformed into yeast cells. The stability was tested by promoter shut-off experiments. 
A

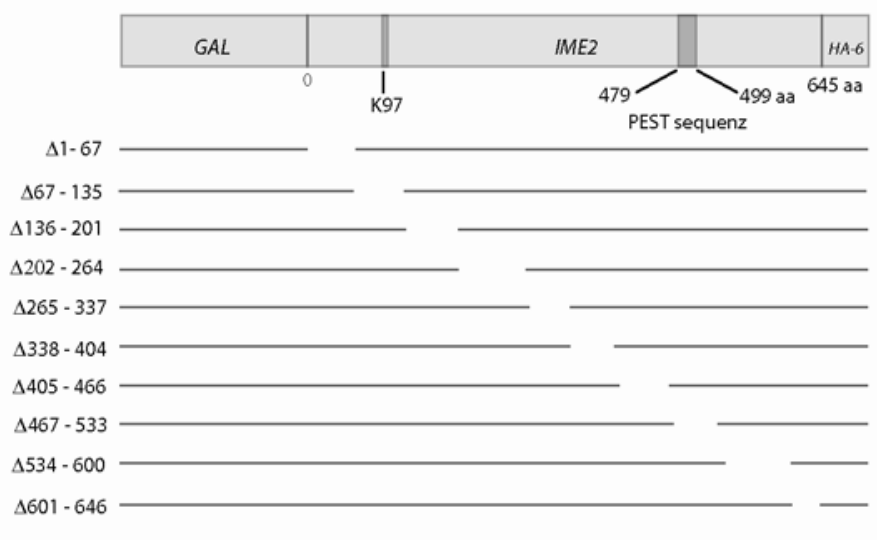

$\triangle 405-533$

$\Delta 405-646$
B
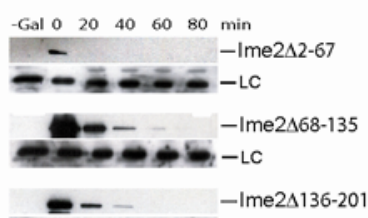

- -----1

$-I m e 2 \triangle 202-264$

$-0-0-\mathrm{LC}$

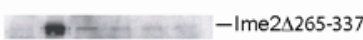

$---1--\mathrm{LC}$

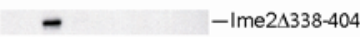

$---\cdots-10$

$-\quad-\operatorname{me} 2 \triangle 405-466$

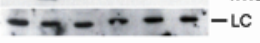

- - Ime2 $\triangle 467-533$

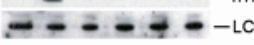

- $\quad-\operatorname{me} 2 \Delta 534-600$

$-0-0-\mathrm{LC}$

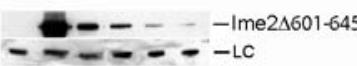

C

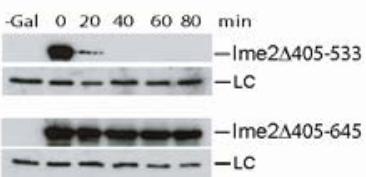

Fig.2 Deletion of the $\mathbf{2 4 2}$ amino acid region, but not deletion of smaller regions, cause stabilisation of Ime2

(A) Map of the deletion constructs of the IME2 gene (K97: catalytic site),

(B) Strains carrying different CEN-plasmids with GAL-IME2-HA6 deletion constructs were grown in minimal medium without tryptophan and containing raffinose. After galactose addition, protein stability was analysed by promoter shutoff experiments. Fur this purpose, strains were filtered and transferred into minimal medium containing glucose. Ime2 protein was detected using the anti-HA antibody. Cdc28 used as loading control (LC). For unknown reasons, no Ime2 protein was detected for the deletion $\Delta 202-264$. (C) Strains containing larger C-terminal deletions were analysed as in (B).

We found that none of the truncated Ime2 proteins was distinctly stabilised (Fig. 2B). Most of the proteins were similarly unstable as the full-length protein and only a weak stabilisation was observed for deletions of C-terminal regions.

We created two additional constructs with larger deletions in the C-terminal region, which is known to have regulatory functions. A deletion of a 174 amino acid region had no discernible effect 
on Ime2 instability, but a deletion of the 242 amino acid C-terminal region (amino acids 405-646) resulted in a significantly stabilised protein (Fig. 2C).

We conclude that the C-terminal part of Ime2 mediates instability of Ime2. Since small deletions did not affect Ime2 instability, it appears that multiple degradation signals with redundant functions are present in the C-terminal region.

\section{Expression of Ime2 lacking the C-terminal region is lethal and causes a cell cycle arrest.}

We next tested whether the truncated, stabilised Ime2 is functional. For this purpose, we tested whether expression of the C-terminally truncated IME2 version, termed IME2 $\triangle C 242$, influences growth of yeast cells. Expression of this gene on a centromeric plasmid had significant effects on cell division in galactose medium. The truncated Ime2 was more toxic than the full-length gene, suggesting that it was highly active (Fig. $3 \mathrm{~A}$ ). This increased activity may be due to an accelerated accumulation of the protein compared to full-length Ime2 protein. Indeed, the Ime $2 \Delta C 242$ protein accumulated to higher levels than full-length Ime2 (Fig. 3B). Upon incubation in liquid medium containing galactose, the expression of IME2 $\triangle C 242$ resulted in a uniform cell cycle arrest (Fig. $3 C$ ). Most cells were unbudded, reminiscent of the arrest described for strong overexpression of fulllength IME2 in multi-copy integration strains (Bolte et al., 2002).

Plasmids with shorter deletions in Ime2 did not cause a similar decrease in the viability of yeast strains (not shown). To exclude that the distinct phenoytpe upon IME2 $\triangle C 242$ expression is not artificially caused by the HA6 tag, we constructed a truncated Ime2 lacking the HA6 tag. Expression of this variant was also highly toxic for yeast strains (data not shown). Thus, stabilised Ime $2 \Delta C 242$ is a highly active variant of Ime2.

Inspection of cells expressing IME2 $\triangle C 242$ revealed that most cells arrested as unbudded cells with short mitotic spindles (Fig. 3D). This is a similar phenotype as the expression of five copies of GAL-IME2 (Bolte et al., 2002). This arrest in a metaphase-like state was dependent on the morphogenesis checkpoint protein Swe1. In swe1 mutants, GAL-IME2 $\triangle C 242$ frequently arrested with elongated spindles, which is also seen in cells expressing full-length IME2 (Fig. 3E and (Bolte et al., 2002)). Thus, the expression of the truncated IME2 on a centromeric plasmid causes a cell cycle arrest similarly to a vast overexpression of IME2. 
A AAL-IME2 GAL-MEE2NC242

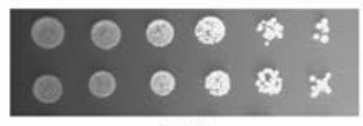

Gucose

D

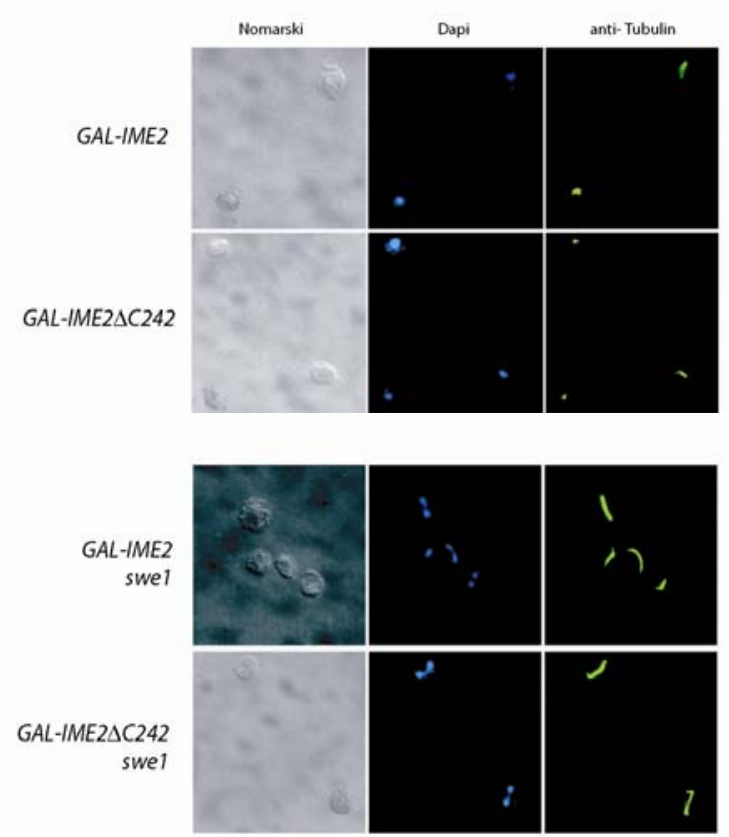

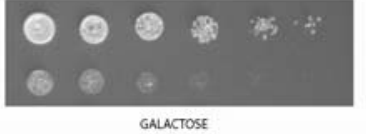

GAL-IME2 $\triangle$ C242-HA

$\begin{array}{llllll}0 & 20 & 40 & 60 & 80 & \text { minutes }\end{array}$

GAL-IME2 $\triangle$ C242-HA

GAL-IME2-HA

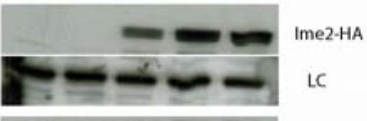

- Ime2-HA

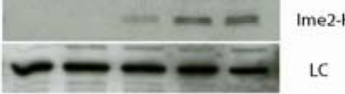

5X GAL-IME2-HA

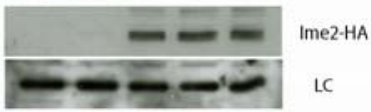

C

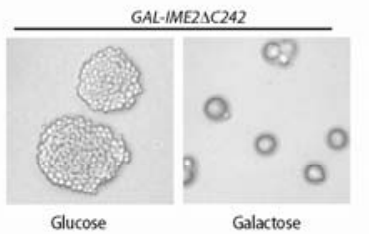

$E$

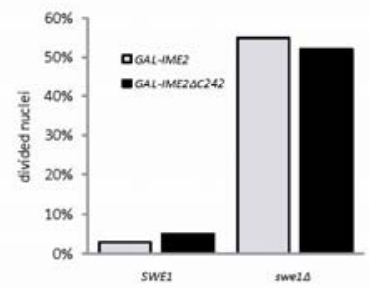

Fig.3 Ectopic expression of IME2 $\triangle C 242$ is lethal and causes a distinct cell cycle arrest

(A) Serial dilutions (1:5) of yeast strains containing centromeric plasmids with GAL-IME2-HA6 and GALIME2AC242-HA6.

(B) Accumulation of Ime2 and Ime2 $\triangle$ C242 proteins. Strains containing GAL-IME2-HA6 or GAL-IME2 $A C 242-H A 6$ on centromeric plasmid and a strain containing 5 copies of GAL-IME2 (S396) were pre-grown in minimal medium lacking tryptophan and containing raffinose. Galactose was added and then samples for immunoblotting were collected at indicated time points. HA and Cdc28 (loading control, LC) antibodies were used.

(C) Photographs of cells grown for 24 hours on either glucose or galactose plates.

(D) Cell cycle arrest of wild-type (SWE1) or swe1 mutants expressing GAL-IME2 or GAL-IME2 $\triangle$ C242 grown for 4 hours in the presence of galactose.

(E) Percentage of cells with divided nuclei of wild-type (SWE1) or swe1 mutants expressing GAL-IME2 or GALIME2 $\triangle$ C242. 


\section{Expression of IME2 $\triangle C 242$ promotes phosphorylation of APC-Cdh1 and accumulation of}

cyclin Clb2. We next tested the functionality of Ime2 $\Delta \mathrm{C}$ with respect to its function as an inhibitor of APC/C. The coactivator Cdh1 is phosphorylated upon IME2 expression in vivo (Bolte et al., 2002) and Cdh1 was identified as a direct substrate of Ime2 (Holt et al., 2007).

To test, whether the truncated Ime2 is able to phosphorylate Cdh1 in vivo, we expressed IME2 $\triangle C 242$ in a strain containing a HA3-tagged version of Cdh1 (Zachariae et al., 1998). The presence of Ime2 $\Delta C 242$ caused a distinct shift of Cdh1 to a slower migrating form (Fig. 4A).

We also found that expression of IME2 $\triangle C 242$ triggers an efficient accumulation of $\mathrm{Clb2}$ in pheromone arrested $\mathrm{G} 1$ cells (Fig. 4B). In contrast, full-length Ime2 or Ime2 variants containing small deletions did only cause a weaker or no distinct accumulation of cyclin $\mathrm{Clb2}$.

We conclude that the truncated Ime2 efficiently triggers Cdh1 phosphorylation and inactivation of APC-Cdh1. These data underline the findings that Ime $2 \Delta C 242$ is a hyperactive version of the Ime2 protein kinase. They also indicate a clear correlation between Ime2 stabilisation and Ime2 hyperactivation.

A

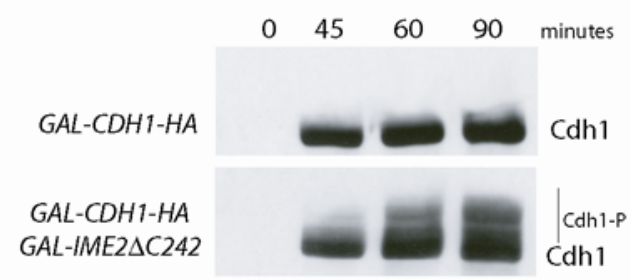

B

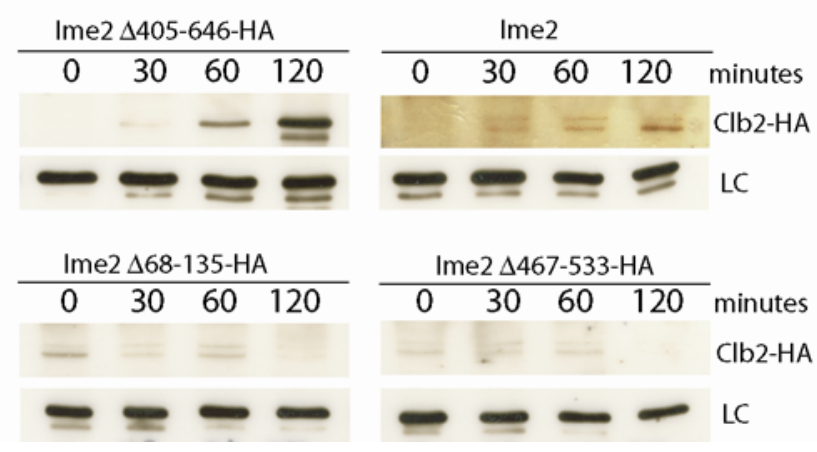


Fig. 4 Ime2 $\Delta$ C causes Cdh1 phosphorylation and Clb2 stabilisation in G1 cells

(A) A strain containing GALL-HA3-CDH1 as well as a strain containing GALL-HA3-CDH1 and GAL-IME2, both bar1 mutants, were arrested in G1 phase with the pheromone $\alpha$-factor. Galactose was added to induce expression from the GAL1 promoter. Samples for immunoblotting were collected at the indicated time points after galactose addition. Anti-HA antibodies and Cdc28 antibodies (loading control, LC) were used.

(B) A strain containing the GAL-CLB2 construct was transformed with centromeric plasmids containing different GAL-IME2-HA6 constructs. Transformants, all bar1 mutants, were grown on minimal medium lacking tryptophan and arrested with $\alpha$-factor.

The Ime2 $\Delta$ C242 protein interferes with normal spore formation. The findings that the Cterminal deletion resulted in a stable and highly active variant of Ime2 allowed us now to test the influence of a stabilised Ime2 on the progression through meiosis. We therefore replaced the IME2 gene by the truncated IME2 $\triangle C$-HA6 construct in the efficiently and rapidly sporulating strain SK1.

Meiosis and spore formation of homozygous IME2 $\triangle C 242 / I M E 2 \triangle C 242$ strains was compared to a wildtype SK1 strains. Meiosis was initiated by a transfer of cells into acetate medium and nuclear divisions were monitored by DAPI staining. We found that both strains underwent meiotic divisions with a similar kinetics, as manifested by the accumulation of cells with 2 or 4 nuclei (Fig. 5A). Thus, meiotic divisions appear to be unaffected by the removal of the C-terminal region of Ime2.

However, the expression of the stabilised Ime2 interfered with the formation of 4-spore asci. Cells contained predominantly two or three spores instead of four spores in the majority of asci of wild-type strains (Fig. 5B). Microscopic examination of two-spore asci showed that two nuclei were packed into spores whereas the other two nuclei were nacked inside the cell (Fig. 5C).

Shortening of the Ime2 by a different method, by a direct tagging method (Knop et al., 1999), adding the HA tag after amino acid 404 caused a similar defect in spore formation as the construction of a IME2-HA6 fusion construct (not shown).

We found similar effects of the truncated Ime2 in another strain background, W303. This strain sporulates slower and less efficiently than SK1. By replacing the IME2 gene with the truncated version, we observed that 4-spore were only rarely produced in homozygous mutants. In contrast, dyads and triads were dominant (not shown). Thus, the defect in spore formation is not restricted to the SK1 strain background.

To provide further evidence that the dyad formation of strains containing the truncated Ime2 correlates with stabilisation of Ime2, we used strains carrying a short deletion in the Ime2 Cterminal region. A Ime2 version containing the $\Delta 467-533$ deletion, which does not cause Ime2 
stabilisation (Fig. 2), was introduced into the SK1 strain. A homozygous strain lacking this short sequence, including PEST-rich region, displayed no apparent abnormalities in either meiotic divisions or in spore formation compared to wild-type strains (data not shown). No increase in dyad formation compared to wildtype strains was observed.

A
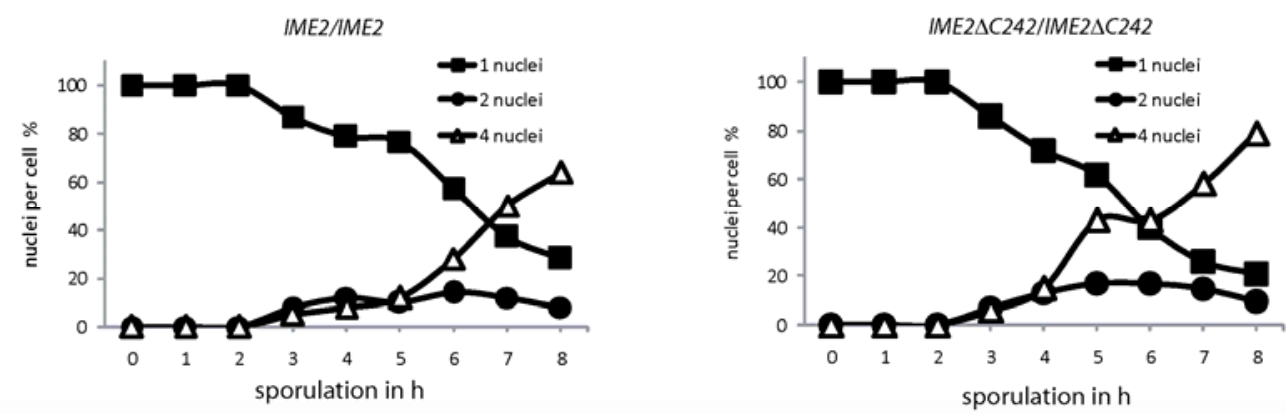

B

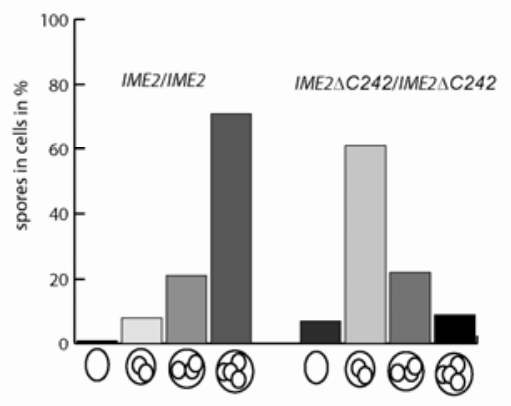

C

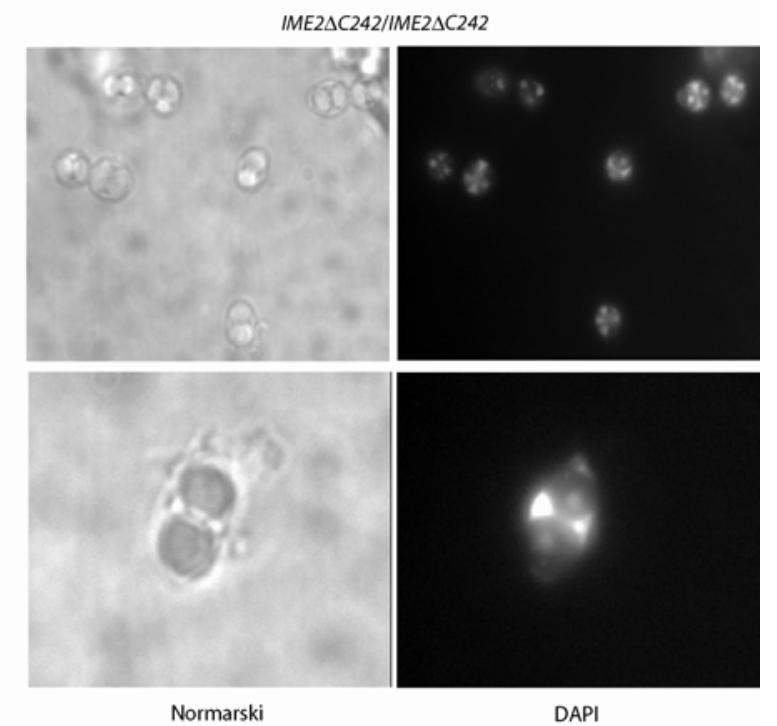

Fig. 5 Truncated Ime2 results in formation of asci with reduced spore number

A wild-type SK1-strain and a homozygous IME2 $\triangle C 242 / I M E 2 \triangle C 242$ strain were induced for sporulation by transfer to $2 \%$ potassium acetate medium.

(A) Percentage of nuclei per cell, counted after visualization of DNA with DAPI.

(B) Counting of spores per cell after 48 hours with light microscope.

(C) Immunofluorescence microscopy of cells 12 hours after induction of sporulation. 
Spore in dyads are viable and haploid. The appearance of four nuclei in sporulating strains with truncated Ime2 suggests that meiotic cell divisions occur normally in the presence of this Ime2 version, and this should result in the production of haploid nuclei. We next tested whether indeed haploid spores are produced in dyads.

For this purpose, we analysed dyades of IME2 $\triangle C 242 / I M E 2 \triangle C 242$ homozygous diploids strains. 88 dyads of this strain were dissected by a micromanipulator. These experiments revealed that more than 80 percent of spores in dyads were viable. Each of the viable segregants was able to mate with only one of the two mating type tester strains, MATa oder MAT $\alpha$ indicating that virtually all spores are haploid (Fig. 6). These results indicate that most spores in dyads are viable and virtually all of them are haploid. Thus, cells with a truncated Ime2 undergo efficient meiotic divisions and produce viable haploid spores, but fail to produce asci with normal spore number.

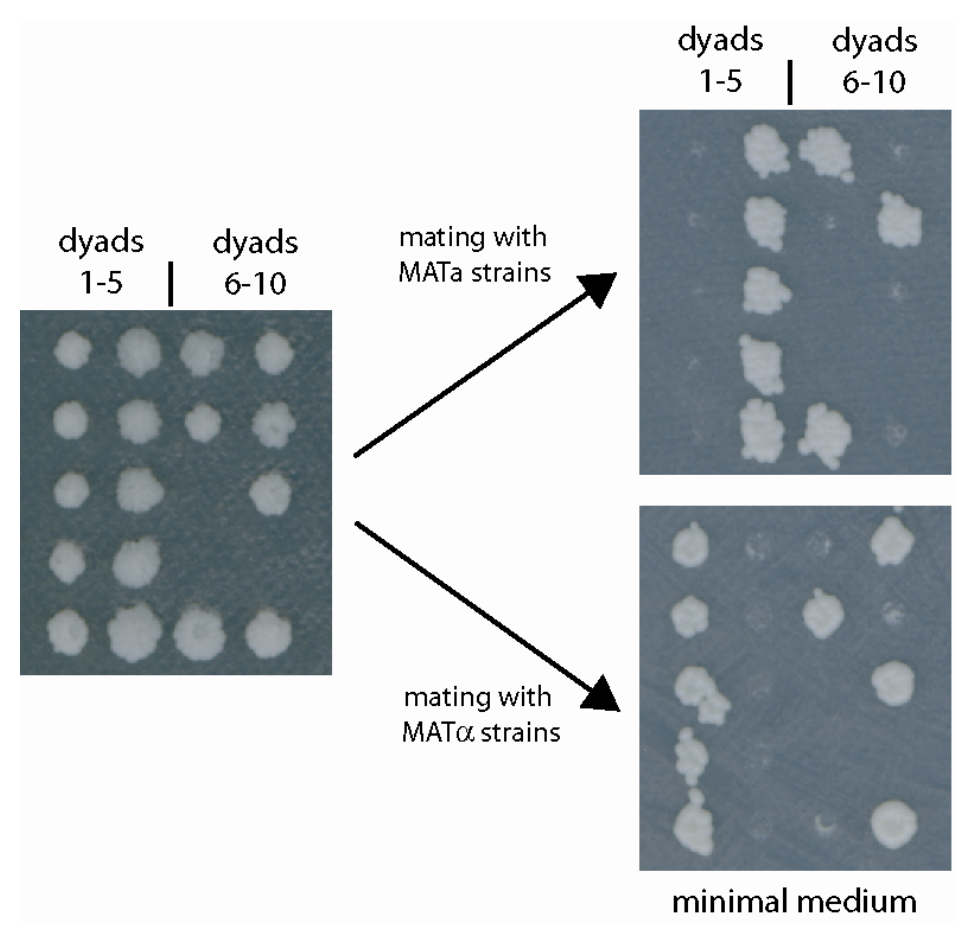

Fig. 6 Spores of dyads of IME2 $\triangle C 242 / I M E 2 \triangle C 242$ strains are viable and haploid

Dyads were dissected on YEPD, and segregants were grown for 3 days. Patches were subsequently replicaplated on minimal medium, on which either of the mating type test strains (S003: MATa, S004: MATa) have been spread. Cells were grown for 3 days at $30^{\circ} \mathrm{C}$. Only mating allowed the growth on minimal medium. 
Ime2 $\Delta$ C242 causes spore number reduction in a dominant manner. We next tested whether the increased dyad formation may be a dominant effect of truncated Ime2 or rather caused by loss of function due to the removal of the C-terminal region. For this purpose, sporulation experiments with heterozygous strains containing both a normal and a truncated IME2 allele were performed. The IME2/IME2 $\triangle C 242$ strain displayed a reduction of tetrads, whereas the production of dyads and triads increased (Fig. 7). However, the effect on spore number reduction was less distinct as in the homozygous diploid strain.

It could be assumed that the reduction in spore number of the heterozygous strain may be rather a loss of function because both copies of IME2 may be required for normal spore formation. To exclude this possibility, we tested sporulation of a diploid strain containing only one copy of IME2. We found that an IME2/Aime2 heterozygous strains sporulated efficiently and produced mostly tetrads in a similar manner as wild-type cells (Fig. 7). Thus, one functional copy of Ime2 is sufficient for sporulation, suggesting that dyad formation of the IME2/IME2 $\triangle C 242$ strain is not a consequence of haplo-insufficiency.

In addition, IME2 $4242 C / \Delta i m e 2$ heterozygous diploids were analysed. These cells formed mostly triads and dyads, but also a moderate number of tetrads. The number of dyads in homozygous IME2 $\triangle C 242$ strains (with two copies of the truncated IME2) is higher than in heterozygous strains with only a single copy, suggesting a gene dosis effect.

A dominant effect of IME2 $\triangle C 242$ was also found in the W303 background (data not shown). These results indicate that Ime $2 \Delta C 242$ increases triad and dyad formation, at least partially, in a dominant manner. The findings that the phenotype is most pronounced in the homozygous IME2 $\triangle C 242 / I M E 2 \triangle C 242$ strains indicate that the spore number reduction seems to occur in a dosedependent manner. 


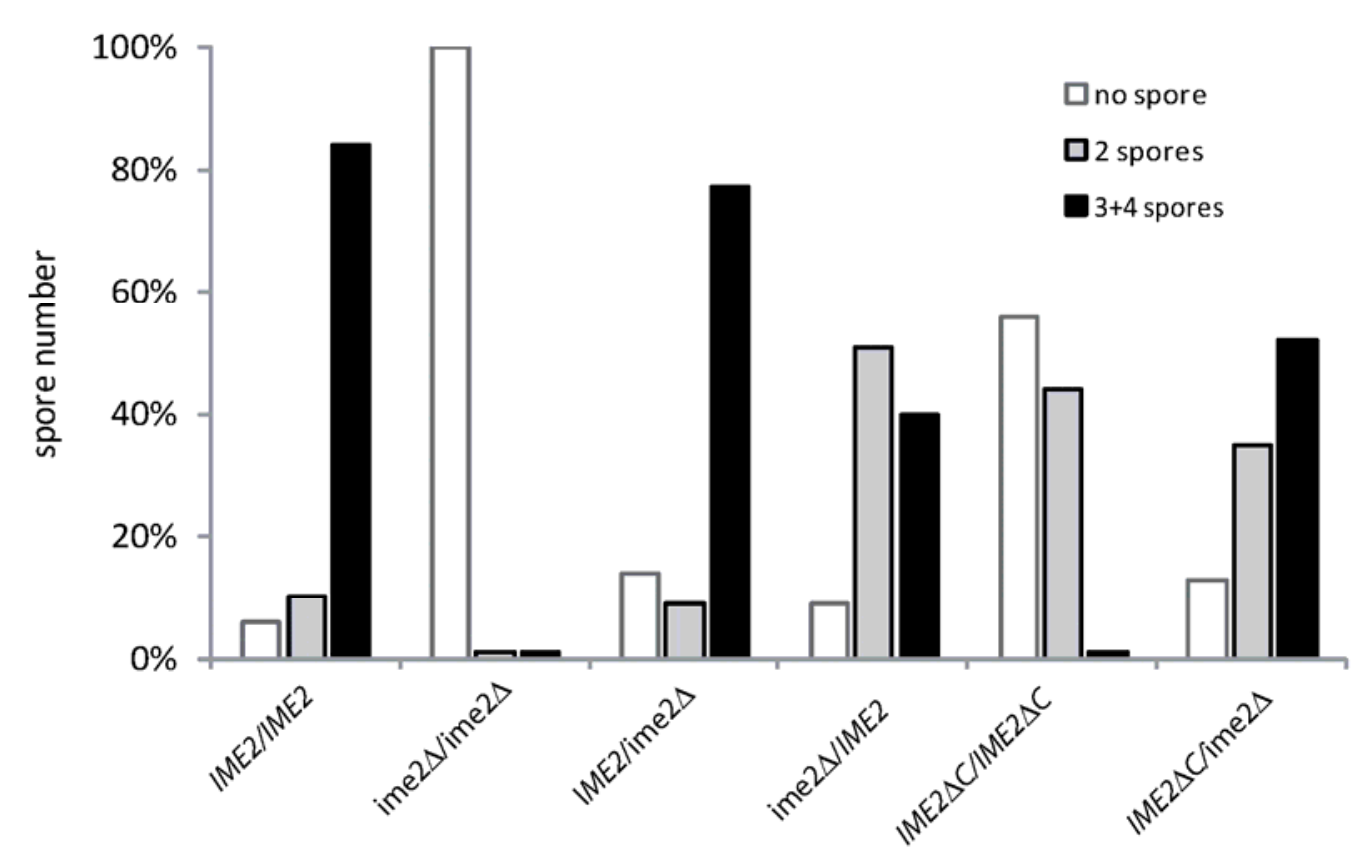

Fi.7 Expression of truncated Ime2 causes spore number reduction in a dominant manner Heterozygous strains IME2/IME2 $\triangle C 242$, IME2/ime2 $\Delta$ and IME2 $\triangle C 242 / i m e 2 \Delta$ were sporulated as described in Fig. 6 . The number of spores per cell was counted after 48 hours.

Phosphorylation of Ime2 $\Delta$ C242 is reduced compared to full-length Ime2. Ime2 was shown to be phosphorylated during meiosis, as manifested by the appearance of slower migrating forms, particularly during the time of meiotic divisions (Benjamin et al., 2003). We were interested to compare Ime2 and Ime2 $\Delta$ C242 phosphorylation during meiosis. Heterozygous Ime2/Ime2-Myc9 and Ime2/Ime2 $\Delta \mathrm{C} 242-\mathrm{HA} 6$ strains were transferred to acetate medium and samples for immunoblotting were collected every hour during the sporulation experiment. Cells underwent meiotic divisions with a similar kinetics (data not shown). Immunoblotting showed that protein levels increased in both strains of full-length and truncated Ime2 during meiosis. However, the shift to a slower migrating form seen in wild-type cells after 7 hours was only modestly detectable for the Ime2 $\triangle \mathrm{C} 242-\mathrm{HA} 6$ protein, suggesting that this protein was phosphorylated to a distinctly lesser extent. These results underline the model that phosphorylation of Ime2 during late stages of meiosis occur predominantly in its C-terminal region. Our findings that the truncated Ime2 fulfills all functions for meiotic divisions suggest that Ime2 phosphorylation of the C-terminal region is not required for meiotic divisions. Instead, C-terminal modification could be relevant for proper spore formation and the failure to phosphorylate this region could result in a hyperactive protein. 


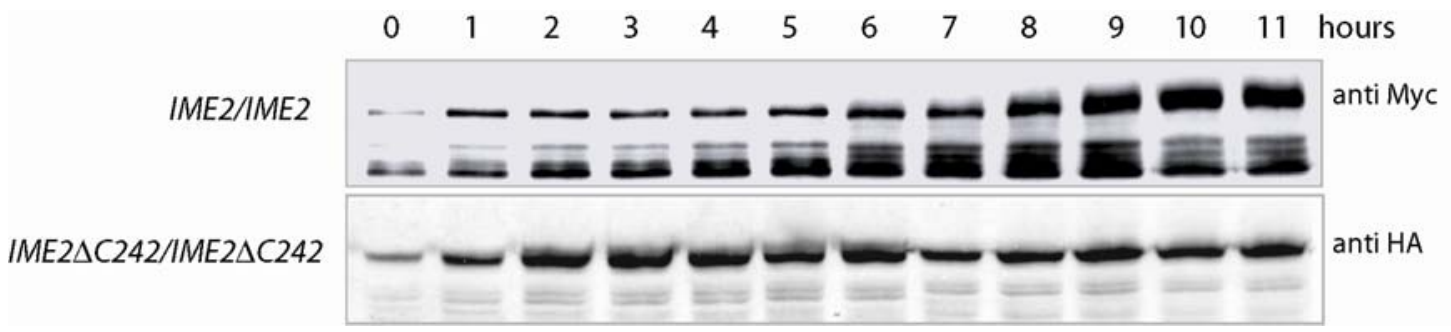

Fig. 8 Phosphorylation of Ime2 $\Delta$ C242 is reduced compared to the full-length protein

Heterozygous IME2/IME2-MYC9 and IME2/IME2 $\triangle C 242-H A 6$ strains were induced to enter meiosis by transfer to acetate medium. Samples were collected at the indicated time points after transfer. Immunoblotting were performed with anti- Myc or anti-HA antibodies, respectively. 


\section{Discussion}

Ime2 instability is mediated by the C-terminal regulatory region of Ime2. The protein kinase Ime2 is in combination with the cyclin-dependent kinase Cdk1 a key regulator of meiosis in Saccharomyces cerevisiae. In contrast to Cdk1, which is regulated by unstable cyclins, Ime2 is itself an unstable protein (Bolte et al., 2002; Guttmann-Raviv et al., 2002; Purnapatre et al., 2005). It is therefore conceivable that Ime2 instability may have a role in the regulation of this kinase. In this study, we have performed a deletion analysis to identify sequence elements responsible for Ime2 instability and to test how the expression of a stabilised variant of this protein kinase affects the sporulation program of budding yeast.

Our deletion analysis demonstrates that a large C-terminal deletion, Ime2 $\Delta \mathrm{C} 242$, strongly stabilised Ime2. Thus, the C-terminal region contains motifs required for protein instability. The findings that none of the deletions of smaller than 60-70 amino acids causes stabilisation of Ime2 suggests that the $\mathrm{C}$-terminal region contains multiple redundant degradation signals.

Previous studies implied that the C-terminal region is not essential for Ime2 kinase activity and for sporulation (Kominami et al., 1993). By expression of IME2 $\triangle C 242$ in dividing cells, we have underlined these findings and shown that this truncated version is a hyperactive version of Ime2. Lethality of cells expressing IME2 $\triangle C 242$ is more pronounced than for full-length Ime2. Ime2 $\triangle C 242$ is capable of phosphorylating Cdh1, a substrate of Ime2 in meiosis (Holt et al., 2007), and of causing a stabilisation of cyclin Clb2. Smaller deletions in Ime2, which did not lead to protein stabilisation, did not result in hyperactivated version of Ime2. Thus, there seems to be a correlation between stabilisation and hyperactivation of this protein kinase.

The C-terminal region has been implicated in regulation of the kinase and it was suggested that it might be an inhibitory domain (Kominami et al., 1993; Donzeau and Bandlow, 1999). We have shown here that the $\mathrm{C}$-terminal region negatively affects Ime2 by targeting it for rapid degradation.

What elements in the C-terminal region may mediate protein instability? Previously, Honigberg and coworkers have shown that Ime2 is degraded in meiotic cells in the presence of low glucose levels and that Ime2 proteolysis is dependent on the PEST-rich region in the C-terminal domain of Ime2 (Purnapatre et al., 2005). Instability is mediated by the ubiquitin ligase SCF-Grr1.

It is however unknown, whether SCF-Grr1 and the PEST triggers Ime2 degradation only under this specific conditions, such as low glucose, or also in a normal meiotic cell cycle. We found that a deletion of the PEST-rich region in Ime2 did not cause a discernible phenotype in meiotic cells. 
Our data show that Ime2 is degraded in dividing cells independently of Grr1 and the PESTrich element. A possible explanation for this discrepancies may be that in addition to the PEST rich region, other additional degradation signals could target Ime2 for proteolysis in dividing cells.

Possibly, Ime2 degradation is different between dividing cells and in cells entering into meiosis in the presence of low glucose levels. Instability of Ime2 during the cell division cycle may be mediated by an additional mechanism. Rapid degradation of Ime2 may help to ensure that this kinase cannot accumulate in normally growing cells. It is known that abnormal Ime2 accumulation interferes with a proper progression of the cell cycle ((Bolte et al., 2002) and Fig.3). The presence of Ime2 in dividing cells leads to distinct growth defects, such as the inhibition of budding and a cell cycle arrest. These phenotypes are most pronounced in cells expressing stabilised Ime2. To prevent such a disastrous outcome, it is conceivable that cells may use multiple redundant mechanisms to prevent any Ime2 accumulation during a normal cell division cycle.

Role of the C-terminal region for spore formation. Analysis of strains containing the truncated, active Ime2 version showed that stabilised Ime2 $\Delta$ C242 does not display discernible defects in the progression through meiosis. These findings imply that instability of Ime2 is not required for meiotic divisions and that the regulatory $\mathrm{C}$-terminal domain is not essential for downregulating Ime2 during meiotic divisions.

From our present data, we cannot rule out the possibility, that stabilised Ime2 could induce an accelerated progression through meiotic division. Indeed, we often observed that two nuclei appeared earlier in IME2 $\triangle C 242$ strain than in the wild-type strain (not shown). However, these observations were very different between individual experiments and do not allow to draw a clear conclusion.

While the C-terminal region has no pronounced effects on meiotic divisions, we have shown here that it has an important role in spore formation. The truncated version prevents the efficient production of asci with four spores. Instead, predominantly triads and dyads are produced. Ime2 version lacking short elements not leading to Ime2 stabilisation, such as the deletion of the PESTrich region, did not cause a detectable increase in dyad or triad formation.

Our data suggest that Ime2 inhibits spore production, and that its removal is required for the packing of each nucleus into spores. We addressed the question, whether this effect is due to a gain or loss of function. To distinguish between these possibilities, various heterozygous strains were analysed. We found that the C-terminally truncated Ime2 had, at least partial, dominant effect. In contrast, diploid strain with only one single copy of the IME2 gene show no reduction in the formation of 4-spore asci, and therefore this effect is not due to haplo-insufficiency. 
Interestingly, we found repeatedly that homozygous strains with two alleles of IME2 $\triangle C 242$ caused a more pronounced reduction of spore number than heterozygous IME2/IME2 $\triangle C 242$ and IME2 $\triangle C 242 / i m e 2 \Delta$ strains suggesting that truncated Ime2 affects spore number reduction in a dose-dependent manner.

Our data indicate that Ime2 inactivation is a prerequisite for the efficient formation of 4-spore asci.

The findings that Ime2 reaches its highest level in late periods of meiosis seems to be inconsistent with the model that Ime2 protein has to be degraded for proper spore formation. However, it is possible that a specific fraction of Ime2 needs to be degraded during meiotic divisions to enable production of 4-spore asci.

In budding yeast, spore formation is initiated by the formation of a prospore membrane at spindle pole bodies (Moreno-Borchart and Knop, 2003). Meiotic SPB are characterized by a specific structure, the meiotic plaques. Prospore formation requires the presence of the three proteins Mpc54, Mpc70 and Spc74 (Taxis et al., 2005). A low abundance of one of these proteins interferes with formation of the prospore membran. This might represent a link to nutritional conditions. It has been found that limitation of carbon source promotes the formation of asci with reduced spore number (Taxis et al., 2005). Spore number control is a mechanism for yeast cells to adjust spore production to environmental conditions, such as the availability of nutrients.

Possibly the persistence of Ime2 activity at spindle pole bodies may interfere with the formation of the prospore membrane. It will be interesting to test whether stabilised Ime2 may affect the association of one of the Mpc54, Mpc70 or Spc74 proteins with spindle pole bodies.

Despite the correlation between Ime2 instability and defects in normal asci formation, it is possible that Ime2 inactivation may be induced by mechanisms other than Ime2 instability, for example post-translational modification or binding of inhibitory proteins.

It is known that the C-terminal part of Ime2 is phosphorylated and this modification may affect Ime2 activity. It was previously found that the mutation of two serines in the regulatory Cterminal region resulted in a moderate accumulation of cells containing two spores (Schindler and Winter, 2006). These data may indicate that phosphorylation of the C-terminal domain is important for controlling spore number. However, it was not tested in this study whether the spores in strains with these mutations are haploid and viable. These mutations caused synthetic defects with several mutants defective in the exit from MI (Schindler and Winter, 2006). It remains unknown whether loss of phosphorylation causes defects in packing of nuclei into spores or rather defects in the completion of meiosis I.

Our findings that the C-terminal is not required for meiotic divisions rather indicate that phosphorylation of this region may have only a prominent role in spore formation. Phosphorylation 
could either directly inhibit the catalytic activity, modulate intracellular Ime2 localisation or function as degradation signal.

Phosphorylation may serve as degradation signals, as found for targets of the SCF ubiquitin ligase. Only phosphorylated substrates are recognised by the F-box subunit of SCF (Cardozo and Pagano, 2004). SCF-Grr1 has been proposed to mediate Ime2 proteolysis in response to the presence of low amounts of glucose (Purnapatre et al., 2005). Whether this ubiquitin-ligase triggers Ime2 instability during meiosis is at present unknown.

It is also possible that the C-terminal region may enable the binding of inhibitory proteins downregulating Ime2 kinase activity in late meiosis. The GTPase Gpa2 binds the C-terminal domain in response to the presence of nitrogen and thereby inhibits Ime2 activity (Donzeau and Bandlow, 1999). Inhibitory proteins could bind Ime2 in late meiosis and induce kinase inactivation. It is rather unlikely that Gpa2 plays an important role in late meiosis, because its expression is repressed during the sporulation program (Chu et al., 1998). Further experimental approaches will be required to elucidate by which mechanism Ime2 is inactivated in late meiosis.

Ime2 related proteins in other eukaryotes. Ime2 is a conserved protein kinase among eukaryotes. Orthologs of Ime2 have been identified in other fungi such as Schizosaccharomyces pombe (Abe and Shimoda, 2000), Candida albicans (Ni et al., 2004) and Ustilago maydis (Garrido and Perez-Martin, 2003; Garrido et al., 2004). Ime2 also displays similarity to human kinases, such as male germ cell associated kinase (MAK) and intestine cell kinase (ICK) (Fu et al., 2005; Fu et al., 2006). Yeast Ime2, S. pombe Mde1 and Pit1, Ustilago maydis Crk1 and the human MAK and ICK are all characterized by a TXY motif, a characteristics of MAP kinases, in their activation loop.

Interestingly, S. pombe mde1 pit1 double mutants completed meiosis, but produced asci with reduced spores and thus, inactivation of these genes has a similar phenotype as the hyperactivation of Ime2. In U. maydis, Crk1 is involved in the induction of sexual development (Garrido and Perez-Martin, 2003), whereas in A. nidulans, the Ime2 homolog appears to be an inhibitor of sexual development (F. Sari, Ö. Bayram, G. Braus and S. Irniger, manuscript in preparation).

All of these Ime2-related kinases are involved in regulating sexual development, but the studies of various fungal mutants indicate that the regulatory function of these protein kinases may be highly diverse between organisms. Furthermore, in contrast to the highly conserved kinase domain, the C-terminal region show little homology among these organisms. It is therefore likely that also the regulation of these kinases will turn out to be highly diverse. 


\section{Footnotes}

We are grateful to Tülin Ersahin and Sevim Dalva for help in some of the experiments. We thank Özgür Bayram for critical comments on the manuscript, Saul Honigberg and Michael Knop for providing yeast strains and plasmids, and Michael Knop for technical advice for the sporulation experiments. This work was supported by the Fonds der Chemischen Industrie und the VolkswagenStiftung. 


\section{References}

Abe, H., and Shimoda, C. (2000). Autoregulated expression of Schizosaccharomyces pombe meiosisspecific transcription factor Mei4 and a genome-wide search for its target genes. Genetics 154, 1497-1508.

Benjamin, K.R., Zhang, C., Shokat, K.M., and Herskowitz, I. (2003). Control of landmark events in meiosis by the CDK Cdc28 and the meiosis-specific kinase Ime2. Genes Dev 17, 1524-1539.

Bloom, J., and Cross, F.R. (2007). Multiple levels of cyclin specificity in cell-cycle control. Nat Rev Mol Cell Biol 8, 149-160.

Bolte, M., Steigemann, P., Braus, G.H., and Irniger, S. (2002). Inhibition of APC-mediated proteolysis by the meiosis-specific protein kinase Ime2. Proc Natl Acad Sci U S A 99, 43854390.

Buonomo, S.B., Clyne, R.K., Fuchs, J., Loidl, J., Uhlmann, F., and Nasmyth, K. (2000). Disjunction of homologous chromosomes in meiosis I depends on proteolytic cleavage of the meiotic cohesin Rec8 by separin. Cell 103, 387-398.

Cardozo, T., and Pagano, M. (2004). The SCF ubiquitin ligase: insights into a molecular machine. Nat Rev Mol Cell Biol 5, 739-751.

Chu, S., DeRisi, J., Eisen, M., Mulholland, J., Botstein, D., Brown, P.O., and Herskowitz, I. (1998). The transcriptional program of sporulation in budding yeast. Science 282, 699-705.

Clifford, D.M., Marinco, S.M., and Brush, G.S. (2004). The meiosis-specific protein kinase Ime2 directs phosphorylation of replication protein A. J Biol Chem 279, 6163-6170.

Dirick, L., Goetsch, L., Ammerer, G., and Byers, B. (1998). Regulation of meiotic S phase by Ime2 and a Clb5,6-associated kinase in Saccharomyces cerevisiae. Science 281, 1854-1857.

Donzeau, M., and Bandlow, W. (1999). The yeast trimeric guanine nucleotide-binding protein alpha subunit, Gpa2p, controls the meiosis-specific kinase Ime2p activity in response to nutrients. Mol Cell Biol 19, 6110-6119.

Fu, Z., Schroeder, M.J., Shabanowitz, J., Kaldis, P., Togawa, K., Rustgi, A.K., Hunt, D.F., and Sturgill, T.W. (2005). Activation of a nuclear Cdc2-related kinase within a mitogen-activated protein kinase-like TDY motif by autophosphorylation and cyclin-dependent protein kinaseactivating kinase. Mol Cell Biol 25, 6047-6064.

Fu, Z., Larson, K.A., Chitta, R.K., Parker, S.A., Turk, B.E., Lawrence, M.W., Kaldis, P., Galaktionov, K., Cohn, S.M., Shabanowitz, J., Hunt, D.F., and Sturgill, T.W. (2006). Identification of yinyang regulators and a phosphorylation consensus for male germ cell-associated kinase (MAK)-related kinase. Mol Cell Biol 26, 8639-8654.

Garrido, E., and Perez-Martin, J. (2003). The crk1 gene encodes an Ime2-related protein that is required for morphogenesis in the plant pathogen Ustilago maydis. Mol Microbiol 47, 729743.

Garrido, E., Voss, U., Muller, P., Castillo-Lluva, S., Kahmann, R., and Perez-Martin, J. (2004). The induction of sexual development and virulence in the smut fungus Ustilago maydis depends on Crk1, a novel MAPK protein. Genes Dev 18, 3117-3130.

Gietz, R.D., and Sugino, A. (1988). New yeast-Escherichia coli shuttle vectors constructed with in vitro mutagenized yeast genes lacking six-base pair restriction sites. Gene 74, 527-534. 
Guttmann-Raviv, N., Martin, S., and Kassir, Y. (2002). Ime2, a meiosis-specific kinase in yeast, is required for destabilization of its transcriptional activator, Ime1. Mol Cell Biol 22, 20472056.

Guttmann-Raviv, N., Boger-Nadjar, E., Edri, I., and Kassir, Y. (2001). Cdc28 and Ime2 possess redundant functions in promoting entry into premeiotic DNA replication in Saccharomyces cerevisiae. Genetics 159, 1547-1558.

Holt, L.J., Hutti, J.E., Cantley, L.C., and Morgan, D.O. (2007). Evolution of Ime2 phosphorylation sites on Cdk1 substrates provides a mechanism to limit the effects of the phosphatase Cdc14 in meiosis. Mol Cell 25, 689-702.

Honigberg, S.M. (2004). Ime2p and Cdc28p: co-pilots driving meiotic development. J Cell Biochem 92, 1025-1033.

Irniger, S. (2006). Preventing fatal destruction: inhibitors of the anaphase-promoting complex in meiosis. Cell Cycle 5, 405-415.

Kassir, Y., Adir, N., Boger-Nadjar, E., Raviv, N.G., Rubin-Bejerano, I., Sagee, S., and Shenhar, G. (2003). Transcriptional regulation of meiosis in budding yeast. Int Rev Cytol 224, 111-171.

Knop, M., Siegers, K., Pereira, G., Zachariae, W., Winsor, B., Nasmyth, K., and Schiebel, E. (1999). Epitope tagging of yeast genes using a PCR-based strategy: more tags and improved practical routines. Yeast 15, 963-972.

Kominami, K., Sakata, Y., Sakai, M., and Yamashita, I. (1993). Protein kinase activity associated with the IME2 gene product, a meiotic inducer in the yeast Saccharomyces cerevisiae. Biosci Biotechnol Biochem 57, 1731-1735.

Mendenhall, M.D., and Hodge, A.E. (1998). Regulation of Cdc28 cyclin-dependent protein kinase activity during the cell cycle of the yeast Saccharomyces cerevisiae. Microbiol Mol Biol Rev 62, 1191-1243.

Mitchell, A.P., Driscoll, S.E., and Smith, H.E. (1990). Positive control of sporulation-specific genes by the IME1 and IME2 products in Saccharomyces cerevisiae. Mol Cell Biol 10, 2104-2110.

Moore, M., Shin, M.E., Bruning, A., Schindler, K., Vershon, A., and Winter, E. (2007). Arg-Pro-X$\mathrm{Ser} / \mathrm{Thr}$ is a consensus phosphoacceptor sequence for the meiosis-specific Ime2 protein kinase in Saccharomyces cerevisiae. Biochemistry 46, 271-278.

Moreno-Borchart, A.C., and Knop, M. (2003). Prospore membrane formation: how budding yeast gets shaped in meiosis. Microbiol Res 158, 83-90.

Ni, J., Gao, Y., Liu, H., and Chen, J. (2004). Candida albicans Cdc37 interacts with the Crk1 kinase and is required for Crk1 production. FEBS Lett 561, 223-230.

Pringle, J.R., Adams, A.E., Drubin, D.G., and Haarer, B.K. (1991). Immunofluorescence methods for yeast. Methods Enzymol 194, 565-602.

Purnapatre, K., Gray, M., Piccirillo, S., and Honigberg, S.M. (2005). Glucose inhibits meiotic DNA replication through SCFGrr1p-dependent destruction of Ime2p kinase. Mol Cell Biol 25, 440450.

Sawarynski, K.E., Kaplun, A., Tzivion, G., and Brush, G.S. (2007). Distinct activities of the related protein kinases Cdk1 and Ime2. Biochim Biophys Acta 1773, 450-456.

Schindler, K., and Winter, E. (2006). Phosphorylation of Ime2 regulates meiotic progression in Saccharomyces cerevisiae. J Biol Chem 281, 18307-18316.

Schindler, K., Benjamin, K.R., Martin, A., Boglioli, A., Herskowitz, I., and Winter, E. (2003). The Cdkactivating kinase Cak1p promotes meiotic $S$ phase through Ime2p. Mol Cell Biol 23, 87188728. 
Sedgwick, C., Rawluk, M., Decesare, J., Raithatha, S., Wohlschlegel, J., Semchuk, P., Ellison, M., Yates, J., 3rd, and Stuart, D. (2006). Saccharomyces cerevisiae Ime2 phosphorylates Sic1 at multiple PXS/T sites but is insufficient to trigger Sic1 degradation. Biochem J 399, 151-160.

Smith, H.E., and Mitchell, A.P. (1989). A transcriptional cascade governs entry into meiosis in Saccharomyces cerevisiae. Mol Cell Biol 9, 2142-2152.

Surana, U., Amon, A., Dowzer, C., McGrew, J., Byers, B., and Nasmyth, K. (1993). Destruction of the CDC28/CLB mitotic kinase is not required for the metaphase to anaphase transition in budding yeast. Embo J 12, 1969-1978.

Taxis, C., Keller, P., Kavagiou, Z., Jensen, L.J., Colombelli, J., Bork, P., Stelzer, E.H., and Knop, M. (2005). Spore number control and breeding in Saccharomyces cerevisiae: a key role for a self-organizing system. J Cell Biol 171, 627-640.

Yoshida, M., Kawaguchi, H., Sakata, Y., Kominami, K., Hirano, M., Shima, H., Akada, R., and Yamashita, I. (1990). Initiation of meiosis and sporulation in Saccharomyces cerevisiae requires a novel protein kinase homologue. Mol Gen Genet 221, 176-186.

Zachariae, W., Schwab, M., Nasmyth, K., and Seufert, W. (1998). Control of cyclin ubiquitination by CDK-regulated binding of Hct1 to the anaphase promoting complex. Science 282, 17211724. 


\title{
CHAPTER 4
}

\section{THE IME2 RELATED PROTEIN KINASE INHIBITS SEXUAL DEVELOPMENT IN ASPERGILLUS NIDULANS}

\begin{abstract}
Protein kinases are central regulators of both mitotic and meiotic cell cycle. In the yeast Saccharomyces cerevisiae, the meiosis-specific IME2 gene encoding a serine/threonine protein kinase is essential for the meiotic cell cycle and sporulation. A survey of the Aspergillus nidulans genome revealed a putative IME2 homolog, conclusively named imeB. The ImeB protein has $40 \%$ identity to the yeast IME2 gene in the N-terminal part of the protein. ImeB contains a highly conserved protein kinase domain comprising a mitogen activated protein (MAP) kinase like TXY motif which is also present in Ime2. ImeB mRNA is upregulated during both sexual and asexual development and we showed that ImeB is localised to the nucleus. To elucidate the role of $i m e B$ in A. nidulans, we constructed an $i m e B$ deletion strain. imeB mutants show slower growth, but have an increased number of sexual fruiting bodies, cleisthothecia, on plates. Moreover, in contrast to wild type cells, imeB mutants produce vast amounts of Hülle cells in submerged cultures, suggesting that ImeB may be a negative regulator of sexual development in A. nidulans. By analyzing the expression of a Hülle cell specific gene, the $\alpha-1,3$-glucanase encoding mutA in imeB mutants, we showed that the Hülle cells are physiologically active and viable. Overexpression of imeB also results in slower growth and in a fluffy phenotype without any conidia or cleistothecia in the darkness. The fluffy phenotype can be explained by a lack of BrlA, since we showed that imeB overexpressing strains lack any blrA transcript. Transcript levels of developmental regulators $s t u A, n s d D$, and veA are upregulated in imeB mutant strains. Analysis of the TXY motif,TTY, showed that a mutation of the whole TTY motif or a mutation of any single aminoacid of the motif leads to the same phenotype observed in $i m e B$ mutant strains. Our findings suggest that ImeB is a member of the MAP kinase family and has roles for both during the asexual and the sexual development.
\end{abstract}




\section{Introduction}

Different environmental conditions force the fungus Aspergillus nidulans to change its developmental way of life. Thus it decides early in development to propagate either by forming asexual or the more robust sexual spores. The asexual development starts with the appearance of spore carrying structures, conidiophores, after 3 days of germination (Pöggeler et al., 2006). Conidiophores are the carrier structures of the asexual spores called conidia which are dispersed to form new colonies (Braus et al., 2002). One typical stimuli for conidiophore formation is an air interphase. Also factors such as light or aeration play an important role in conidiophore development.

Several key regulators of the asexual development were identified and characterised. The transcription factor blrA represents an upstream regulator of conidiophore formation, because $b r / A$ null mutants block the generation of conidiophore vesicles (Clutterbuck, 1969). Together with two other downstream factors $a b a A$ and wetA, brlA defines a central regulatory pathway cooperating together to determine the order of gene activation during conidiophore development and spore maturation (Boylan et al., 1987).

Other regulators seem to have mediator roles since medA and stuA both exhibit clear effects on asexual as well as sexual differentiation. Mutations in the medA gene leads to abnormal conidiophores with branching metulae (Clutterbuck, 1969). On the other hand medA is needed for cleistothecia formation during sexual development. The stuA gene product has also duties in both sexual and asexual development (Miller et al., 1991).

The homothallic fungus $A$. nidulans has also the ability to propagate sexually even in the absence of a partner in a process called selfing (Braus et al., 2002). Once sexual progeny is induced, A. nidulans hyphae aggregate to so called "nest" and later differentiate to globose, multinucleate Hülle cells. This nest like structures serve as a cavity for cleistothecia, the sexual structures where meiosis takes place (Pöggeler et al., 2006).

While asexual sporulation and the genetical basis of the process was intensely investigated during the past decades (Adams et al., 1998) first regulators of sexual development were revealed only in the last few years. One example is the GATA- type transcription factor $n s d D$ necessary for sexual development of $A$. nidulans. (Han et al., 2001) showed that $n s d D$ mutants fail to produce sexual fruiting bodies. Recently, two other transcription factors, $\operatorname{ros} A$ and $\operatorname{nos} A$, were $\operatorname{described}$ as regulators of sexual development. While RosA blocks formation of fruiting body (Vienken et al., 2005), NosA is needed for maturation of sexual structures (Vienken and Fischer, 2006). This opposite function of both factors seem to be genetically linked, because RosA represses NosA expression (Vienken and Fischer, 2006). 
In the yeast, Saccharomyces cerevisiae, meiosis is driven by a protein kinase named Ime2. Ime2 is a serine/threonine protein kinase functionally related to $\mathrm{Cdk} 1$, the sole cyclin dependant kinase (CDK) required for mitosis and meiosis in budding yeast. In contrast to Cdk1, Ime2 does not require cyclins for activity (Hui et al., 2002). Early in meiosis Ime2 controls the onset of meiotic Sphase by targeting Sic1, the Cdk1 inhibitor, for degradation (Dirick et al., 1998) thus enabling the G1-S transition. Additionally, freeing Cdk1 allows the binding to $\mathrm{M}$ phase cyclins, $\mathrm{Clb5}$ and $\mathrm{Clb6}$, which in complex triggers meiotic DNA replication (Stuart and Wittenberg, 1998). In later phases of meiosis, Ime2 induces transcription of NDT80, a transcription factor controlling the expression of 150 middle genes (Chu et al., 1998; Guttmann-Raviv et al., 2002). Other late functions of Ime2 include the phosphorylation of Ndt80 and other target substrates (Benjamin et al., 2003). Not only target proteins of Ime2, but also Ime2 itself is modified by phosphorylation. Previous studies showed that Ime2 is phosphorylated in early and hyperphosphorylated during middle sporulation (Benjamin et al., 2003; Schindler et al., 2003). Presumably, phosphorylation of Ime2 is mediated by Cak1 in the activation loop (Schindler and Winter, 2006). The activation loop of Ime2 contains a TXY motif, which is also found in mitogen activated protein kinases (MAPKs). It could be shown that mutations in the TXY motif leads to a decrease of Ime2 activity (Schindler et al., 2003) and defects in sporulation.

Ime2 is a highly conserved kinase having homologs in mouse, rat, and human. The requirement of Ime2 for meiosis in higher organisms could not be shown until know. In a search BLAST the cdk-related kinase 1 (Crk1) from Ustilago maydis could be identified as a homolog of Ime2, which showed $35 \%$ sequence similarity in the $\mathrm{N}$-terminal kinase domain. One prominent task of Crk1 is to balance positive and negative environmental signals thus leading to changes in morphology and cell cycle (Garrido and Perez-Martin, 2003). In human, male germ cell-associated kinases (MAK) and intestinal cell kinases (ICK) were designated as putative homologs of budding yeast Ime2 (Fu et al., 2006). (Ma et al., 2006) could prove a sex specific task for human MAK kinases showing that human MAK kinases are targeted by androgene, a steroid hormon stimulating the development of masculine characteristics.

The genome sequence of $A$. nidulans revealed a putative Ime2 homolog with a highly conserved catalytic domain, which we designated ImeB. The ImeB protein sequence shares $40 \%$ similarity to that of $S$. cerevisiae, Ime2, comprising the well characterized mitogen activated protein kinase like TXY motif. To analyze ImeB function in $A$. nidulans we deleted the imeB wild type locus via homologous gene replacement. We could show that a lack of ImeB leads to an increase of both sexual fruiting bodies on solid media and fruiting body nursing Hülle cells in liquid culture, which hints to a repressor function in sexual development. Conidiophore formation was totally blocked in 
ime $B$ overexpressing cells under conditions promoting sex, but was unaffected when grown asexually. The investigation of the divergent roles of ImeB in A. nidulans is the scope of this study. 


\section{Materials and Methods}

Strains and culture conditions. A.nidulans strains used in this work are listed in Table 1. The FGSC A4 served as wild-type for the imeB deletion, AGB 152 was used for overexpression and GFP experiments. Generated plasmids were reproduced in E.coli DH5a (Woodcock et al., 1989). E. coli strains were grown in LB media ( $1 \%$ tryptone, $0.5 \%$ yeast extract, $1 \% \mathrm{NaCl}$ ) adding $100 \mu \mathrm{g} \mathrm{m} \mathrm{l}^{-1}$ ampicillin for plasmid selection. A. nidulans minimalmedia $\left(0.52 \mathrm{~g} \mathrm{I}^{-1} \mathrm{KCl}, 0.52 \mathrm{~g} \mathrm{I}^{-1} \mathrm{MgSO}_{4}, 1.52 \mathrm{~g} \mathrm{I}^{-1}\right.$ $\mathrm{KH}_{2} \mathrm{PO}_{4}, 0.1 \%$ trace elements, $\mathrm{pH} 6.5$ ) was prepared according to (Käfer, 1965) supplementing either with pyrithiamine (TAKARA; $0.05 \mu \mathrm{g} \mathrm{ml}^{-1}$ ) or uracil/uridin (5mM) or phleomycin (INVIVO GEN; $30 \mu \mathrm{g}$ $\mathrm{ml}^{-1}$ ) as required. Either 1\% D-glucose or Gylcerol/Ethanol used as carbon source, and as nitrogen source $10 \mathrm{mM}$ ammonium was supplemented. Sexual development of $A$. nidulans strains was induced by wrapping plates with parafilm, covering with aluminium foil, and inoculating in the dark. For development-specific RNA isolation, $A$. nidulans liquid cultures were pregrown for $18 \mathrm{~h}$ and subsequently mycelia was harvested (miracloth, Calbiochem) and transferred to solid media.

Table 1. Strains used in this study

\begin{tabular}{|c|c|c|}
\hline Strain & Genotype & Source \\
\hline FGSC A4 & Glasgow wild-type & FGSC \\
\hline AGB 152 & pyroA4, pyrG89, veA & (Busch et al., 2003) \\
\hline AGB 320 & imeB $\Delta:: p t r A$ & this study \\
\hline AGB 321 & imeBA::ptrA transformed with $p M E 3293$ & this study \\
\hline AGB 322 & AGB 320 backcrossed with FGSC $A 4$ & this study \\
\hline AGB 323 & $\begin{array}{l}\text { AGB152 transformed with } p M E 3294 \\
\text { alcA::imeB, veA, pyroA4 }\end{array}$ & this study \\
\hline AGB 324 & $\begin{array}{l}\text { AGB } 152 \text { transformed with } p M E 1565 \\
\text { alcA }(p) \text {, pyroA4 }\end{array}$ & this study \\
\hline AGB 325 & $\begin{array}{l}\text { AGB152 transformed with pME } 3295 \\
\text { alcA(p)::imeB::egfp, pyroA4 }\end{array}$ & this study \\
\hline AGB 326 & $\begin{array}{l}\text { AGB } 320 \text { transformed with pME } 3296 \\
\text { imeB }:: \text { ptrA, gpdA::nat }{ }^{R}, \text { mutA }(p):: s g f p\end{array}$ & this study \\
\hline ABG 327 & $\begin{array}{l}\text { AGB } 320 \text { transformed with pME } 3297 \text { (T219-ALA) } \\
\text { imeBA::ptrA }\end{array}$ & this study \\
\hline AGB 328 & $\begin{array}{l}\text { AGB } 320 \text { transformed with pME } 3298 \text { (T220-ALA) } \\
\text { imeBA::ptrA }\end{array}$ & this study \\
\hline AGB 329 & $\begin{array}{l}\text { AGB } 320 \text { transformed with pME } 3299 \text { (Y221-ALA) } \\
\text { imeBA::ptrA }\end{array}$ & this study \\
\hline AGB 330 & $\begin{array}{l}\text { AGB } 320 \text { transformed with pME } 3300 \text { (TTY-ALA) } \\
\text { imeBA::ptrA }\end{array}$ & this study \\
\hline
\end{tabular}


Table 2. Plasmids used in this study

\begin{tabular}{|c|c|c|}
\hline Plasmid & Contruction & Source \\
\hline pBluescript KS & Cloning vector & Invitrogen \\
\hline pMut-p-gfp & mutA promoter fused with sGFP in pBluescript KS- & (Wei et al., 2001) \\
\hline pCMB17apx & $\begin{array}{l}\text { alcA(p)::egfp,pyr4; for N-terminal fusion of GFP to } \\
\text { genes of interest }\end{array}$ & V. Efimov (Piscataway, NJ) \\
\hline pan8-1 & plasmid conferring phleomycin resistance & (Mattern et al., 1988) \\
\hline pME 1565 & $\begin{array}{l}\text { alcA-overexpression plasmid } \\
\text { pMCB32-MA1, pyrG }\end{array}$ & (Hoffmann et al., 2000) \\
\hline pME 3292 & 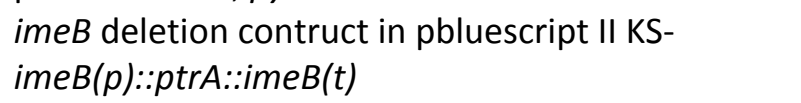 & this study \\
\hline pME 3293 & $\begin{array}{l}\text { ime } B \text { complementation construct } \\
\text { ime } B(p):: \text { ime } B:: i m e B(t) \text {, bleo; ime } B \Delta p \operatorname{tr} A\end{array}$ & this study \\
\hline pME 3294 & $\begin{array}{l}\text { imeB overexpression construct } \\
\text { alcA }(p):: \text { imeB::his } 2 B(t), p y r G \text { in } A G B 152\end{array}$ & this study \\
\hline pME 3295 & egfp::imeB in PCMB17apx, pyrG & this study \\
\hline pME 3296 & $\operatorname{mutA}(p):: s g f p$, NatR & this study \\
\hline pME 3297 & $\operatorname{ime} B(T 219 \rightarrow A L A)$ in pan8-1, bleo marker & this study \\
\hline pME 3298 & ime $B(T 220 \rightarrow A L A)$ in pan8-1, bleo marker & this study \\
\hline pME 3299 & imeB $(Y 221 \rightarrow A L A)$ in pan8-1, bleo marker & this study \\
\hline pME 3300 & ime $B(T T Y \rightarrow A L A)$ in pan8-1, bleo marker & this study \\
\hline
\end{tabular}

Table 3. Oligonucleotides used in this work

\begin{tabular}{ll}
\hline Designation & Sequence 5' $^{\prime}$ \\
\hline OZG38 & GGTACCGGTCGAGAAGAGTCAAGACTTAC \\
F39 & GGCCTGAGTGGCCCTTGTCTCCTTAACTTCTCTGCC \\
OZG40 & GAGTATCTCGGCCACTCAGGCCAATTGATTACGGGATCCCATTGG \\
OZG41 & CCGTGCGTAGGCCTAGATGGCCTCTTGCATCTTTGTTTGTATTATAC \\
F42B & CCCAAGCTTGGCCATCTAGGCCCTCATATCCCAATTCTCTGATT \\
F43B & CAACTTCAACCCCTTCCAGCCCCTTCTAGACC \\
Fat42gpdA & ATGGCTCCCAAGGTCGAATC \\
Fat43gpdA & CTATTGGGCATCAACCTTGGAG \\
F21gfp & GGGCGCGCCGACTGTCTGCTACGAACATCCC \\
F22gfp & GTTAATTAAGGTACCAGGAGTGATGCTGGG \\
Fat19 & ATGACTGTCTGCTACGAACATCCC \\
Fat20 & CTACCTGTAGGTGGAGCCTGTC \\
Fat15 & GTTAAATTCATTGAGCGTAT \\
Fat16 & GAGGGAAGTGAGAGCAGCCCC \\
Fat17b & CCCCGAATTCCCTCCGACTACGTAGTCAAGGGT \\
Fat18b & CCCCCTGCAGGGGCAGGATATCTGTTTCTGCTG \\
ImeB(T1-ALA) & GAACCTCTGGAGCGCGGTACCATCGTGTGGAAACGTATGTGGCGTAAGGTAACTTGG \\
ImeB(T2-ALA) & AATGCGTCTC \\
& GAACCTCTGGAGCGCGGTACCATCGTGTGGAAACGTAGGCGGTGTAAGGTAACTTGG \\
ImeB(Y-ALA) & AATGCGTCTC \\
ImeB(TTY-ALA) & GAACCTCTGGAGCGCGGTACCATCGTGTGGAAACGGCTGTGGTGTAAGGTAACTTGG \\
ImeB(TTYterm) & AATGCGTCTC \\
\hline & GAACCTCTGGAGCGCGGTACCATCGTGTGGAAACGGCGGCGGCGTAAGGTAACTTG \\
& GTTTCCACACGATGGTACCGCGC \\
\hline
\end{tabular}


Molecular techniques. E. coli strains were chemically transformed according to (Mandel and Higa, 1970). For A. nidulans protoplast mediated transformation was conducted (Punt and van den Hondel, 1992). For PCR experiments, standart protocols (Saiki et al., 1985) were applied using the MWG-Biotech primus96 cycler. Taq, Pfu (MBI Fermentas) or KOD (Novagen) or Platinum-Taq (Invitrogen) were used as thermostable polymerases. Sequencing was conducted in the Göttingen Genomics Laboratory. Genomic DNA was extracted from ground mycelia with liquid nitrogen (Kolar et al., 1988). RNA was isolated with TRIzol ${ }^{\mathrm{TM}}$ (Gibco BRL). Southern and Northern hybridizations were performed as described peviously (Southern, 1975; Brown and Mackey, 1997). Probes for hybridization were generated with the Stratagene Prime-It II kit. Hybridization membranes (PerkinElmer Life Sciences Inc) were radioactively labeled, washed and subsequently exposed to Kodak X-Omat films. Sequences were analysed and aligned with the Lasergene software DNAstar.

Plasmid constructions. All plasmids used in this work are summarized in Table 2 . Oligonucleotides are listed in Table 3 . Plasmids used for $A$. nidulans strain manipulation were constructed as follows:

Deletion of imeB and complementation. The wild type imeB locus was knocked out using the technique of homolog gene replacement. Therefore the deletion construct pME 3292 was generated by cloning the fragments imeB promoter (5 UTR; OZG38/F39), ptrA-cassette (from pTRII Takara; OZG40/OZG41) and imeB terminator (3 UTR; F42B/F43B) into the pBluescript KS (Invitrogen) vector stepwise. The deletion cassette was excised from pME 3292 with Kpnl and transformed into the FGSC A4 strain. A southern analysis (Southern, 1998) was applied to verify the disruption event using the primers Fat15/Fat16 for the probe. For complementation, a 5,2 kb fragment comprising the ime $B$ promoter $(1,6 \mathrm{~kb})$, imeB open reading frame and imeB terminator $(1,3 \mathrm{~kb})$ was amplified (Fat17b/Fat18b) with Platinum Taq DNA polymerase (Invitrogen). The PCR product was digested with EcoRI and cloned into the EcoRI linearized pan8-1 vector $\left(\mathrm{phleo}^{\mathrm{R}}\right)$. The created imeB complementation construct, pME 3293, was transformed into the imeB mutant strain yielding AGB 321. 
Overexpression of imeB. The imeB open reading frame was amplified (Fat19/Fat20) with KOD polymerase. The imeB PCR product was placed into the Smal site of the vector pMCB32-MA1. The overxpression vector contains the auxotrophy marker pyrG for selection and the $A$. nidulans alcA promoter which allows induction in the presence of ethanol. The alcA-imeB contruct, pME 3294, was transformed into the pyrG mutant strain AGB 152 yielding AGB 323.

GFP tagging of ImeB. The imeB open reading frame was amplified from genomic DNA. The primers F21gfp having an Ascl site at the 5'end and F22gfp having a Pacl site at the $3^{\prime}$ end were used for amplification. N-terminal tagging was achieved by digesting the pCMB17apx plasmid with Ascl-Pacl, thus opening the vector behind the alcA promoter. Subsequent cloning of the Ascl-Pacldigested PCR product into the opened vector generated the plasmid pME 3295. The imeB-eGFP construct was transformed into the pyrG mutant strain AGB 152 yielding the strain AGB 325.

Generation of mutA(p)::sGFP. The plasmid pME 3296, carrying the sGFP tagged mutanaseA promoter, was created by blunt ending the vector pMut(p)gfp with Ec/136II and subsequent ligation of a $g p d A(p)-n a t^{R}$ module. The $g p d A(p)-n a t^{R}$ module was amplified using Fat42gpdA and Fat43gpdA primers with KOD Polymerase giving blunt ended PCR products. The plasmid pME 3296 was transformed into the the imeB mutant strain ABG 320. The imeB mutant strain bearing the $\operatorname{mutA}(p):: s G F P$ construct was named AGB 326.

Mutations of the TTY motif. A two step fusion PCR was applied to generate mutations in the TTY motif using the high fidelity polymerase Phusion (Finnzymes). Tyrosin219 was exchanged by alanine using the primers F17b/ImeB (T1-ALA) for the first fragment and ImeB (TTYterm)/ F18b for the second fragment which were fused in a PCR reaction. The resulting product was ligated in a EcoRI digested pan8-1 vector (pME 3297). The same procedure was conducted to receive an exchange to alanine of Tyrosine220 (pME 3298; used primers: F17b, imeB (T2-ALA), ImeB (TTYterm), and F18b) and of Threonine221 (pME 3299; used primers: F17b, ImeB (Y-ALA), ImeB (TTYterm), and F18b) and of the whole motif (pME 3300; used primers: F17b, ImeB (TTY-ALA), ImeB (TTYterm), and F18b). All constructs were transformed into the imeB mutant strain AGB 320. Transformants were selected on phleomycin plates.

Microscopy. $1^{*} 10^{4}$ spores were grown on cover slips at $30^{\circ} \mathrm{C}$ either for light- or flourescence microscopy. GFP strains were observed with a Zeiss Axiovert S100 microscope using appropiate filter sets (AHF Analysetechnik AG, Germany). Digital pictures were captured with a Hammatsu Ocra-ER camera using the Openlab software (V5.0.) 


\section{Results}

Putative Aspergillus nidulans MAP kinase ImeB protein shows high similarity to meiosisspecific kinase Ime2 from yeast. The meiotic cell cycle of bakers yeast Saccharomyces cerevisiae is initiated by the activity of a protein kinase named Ime2. Not only initiation but also later meiotic events are regulated by Ime2, such as phosphorylation of Cdh1 and Ndt80, the latter a transcription factor responsible for the activation of $\sim 150$ middle meiotic genes (Bolte et al., 2002; Sopko et al., 2002). Aspergillus nidulans, like bakers yeast S.cerevisiae, belongs to ascomycetes, but is different in terms of morphology, reproduction and habits. A nidulans asexual development was intensly investigated during the last decades (Adams et al., 1998), but less is known about the sexual development. We attempted to identify regulators of $A$. nidulans sexual life cycle. Detailed inspection of $A$. nidulans genome reveals a yeast Ime2 similar protein encoding gene (AN6243.3) which was conclusively named as imeB (Fig.1). This gene contains automatically annotated three exons interrupted by two introns, the presence of which were also confirmed by sequencing the cDNA of the gene amplified from sexual cDNA library (Fig.2).

A. nidulans ImeB protein (782 aa) was aligned with yeast Ime2p and putative human germ line specific kinase (huGSK1) using Clustal W method (Fig.1 A). N-termini (first 400 aa) of the proteins are highly conserved whereas C-termini of the proteins do not have such a significicant homology. The $\mathrm{N}$-terminal parts of $A$. nidulans ImeB and S. cerevisiae Ime2 show $40 \%$ similarity. When blasted ImeB against the other organisms' protein database, a putative human germ line specific kinase (huGSK1) appeared to be similar to ImeB protein along with Xenopus laevis germ line specific kinase (not shown). Additionally all these proteins comprise TXY motif in their N-termini (Fig.1 B) which was described by (Payne et al., 1991). TXY motif is essential for the function of the TXY motif MAP kinases. 
A

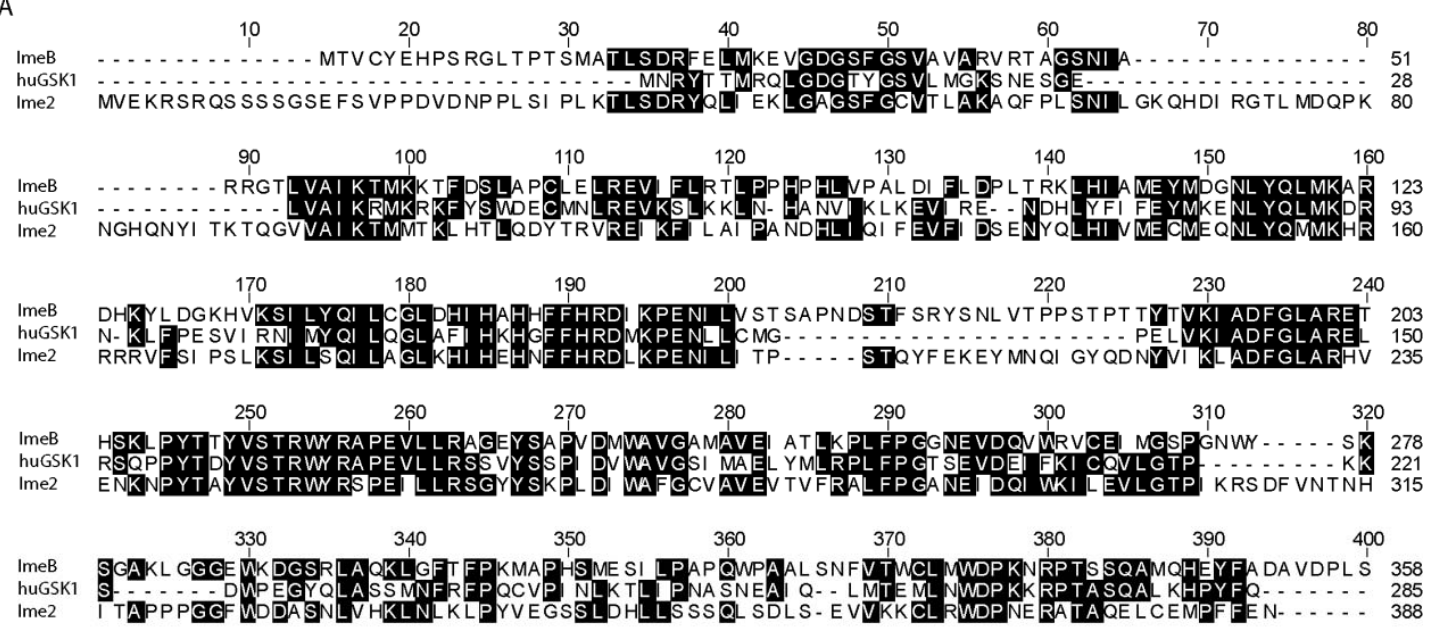

B

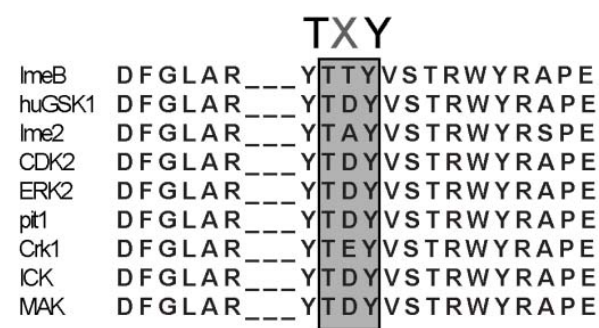

C

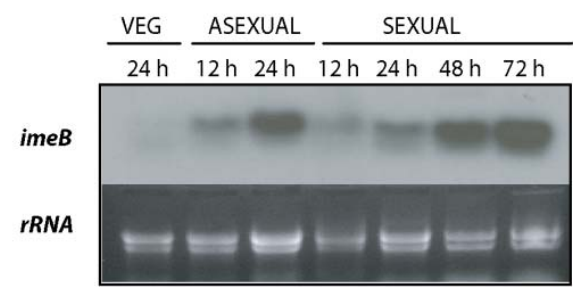

\section{Fig.1 BLAST search and expression pattern of imeB}

A) N-terminal alignment of A.nidulans ImeB with the homolog Ime2 from S.cerevisiae and GSK1 from Homo sapiens. Amino acids identical in at least two sequences were shaded. The alignment was done with DNAstar using Megalign (Clustal W). B) Conserved mitogen activated protein kinase (MAPK) motifs of selected protein kinases. Sequence alignment of the catalytic domain of ImeB (A. nidulans), huGSK1 (Homo sapiens), Ime2 (S. cerevisiae), CDK2 (Homo sapiens), ERK2 (Rattus norvegicus), pit1 (Schizosaccharomyces pombe), Crk1 (Ustilago maydis), ICK (Mus musculus), MAK (Mus musculus). The TXY motif located in the T-loops of the kinases are boxed. C) Expression pattern of $i m e B$ at different developmental stages. A wild type strain (FGSCA4) was pregrown in liquid culture for $24 \mathrm{~h}$, subsequently transformed onto solid medium to propagate either asexually or sexually. At indicated timepoints strains were harvested and a Northern analysis was conducted. A probe specific to the $5^{\prime}$ upstream region of the ImeB ORF was labeled with ${ }^{32} \mathrm{P}$ prior to hybridization. rRNA was stained with ethidium bromide as loading control.

Despite the fact that $A$. nidulans ImeB contains similar motifs to that of yeast Ime2 and conserved structurally, it does not complement the meiosis defect of a yeast ime $2 \Delta$ mutant, which shows that ImeB cannot replace the fnction of yeast Ime2 (data not shown). After observing the similarities of Ime2-like proteins, we asked the question whether imeB gene is expressed at all. Therefore we isolated RNA from different life stages of wild type $A$. nidulans strains and blotted with imeB probe (Fig.1C). Northern blot results showed that imeB is expressed at basal levels during 
vegetative growth (24 h) in liquid culture, early asexual (12 h) and sexual (12 and 24 h) developmental stages. However, its expression increases at the late asexual conidiation ( 24 and 48 h) and sexual development (48 and $72 \mathrm{~h}$ ).

These results suggest that Ime2-like protein kinases are conserved throughout the eukaryotic kingdom and are mostly related to meiosis that is always associated with sexual reproduction. Northern data also propose that imeB might bear some role related with either asexual conidiation or sexual fruiting body formation.

$\Delta$ imeB mutants show a slower growth phenotype. Protein alignments and northern analysis drew our attention to the function of $i m e B$ which might possibly have roles either in asexual or sexual differentiation. To address the cellular function of that conserved kinase protein, a deletion

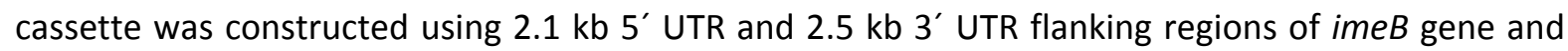
ptrA marker as selective agent. Transformation of deletion cassette into wild type (A4) strain yielded a number of transformants, southern analysis of which disclosed an imeB knock out strain. This strain was analysed and homologous gene replacement was confirmed by Southern blot analysis (Fig.2). Southern blot bands were in agreement with the theoretical map of imeB wild type and imeB deletion loci (Fig. 2).

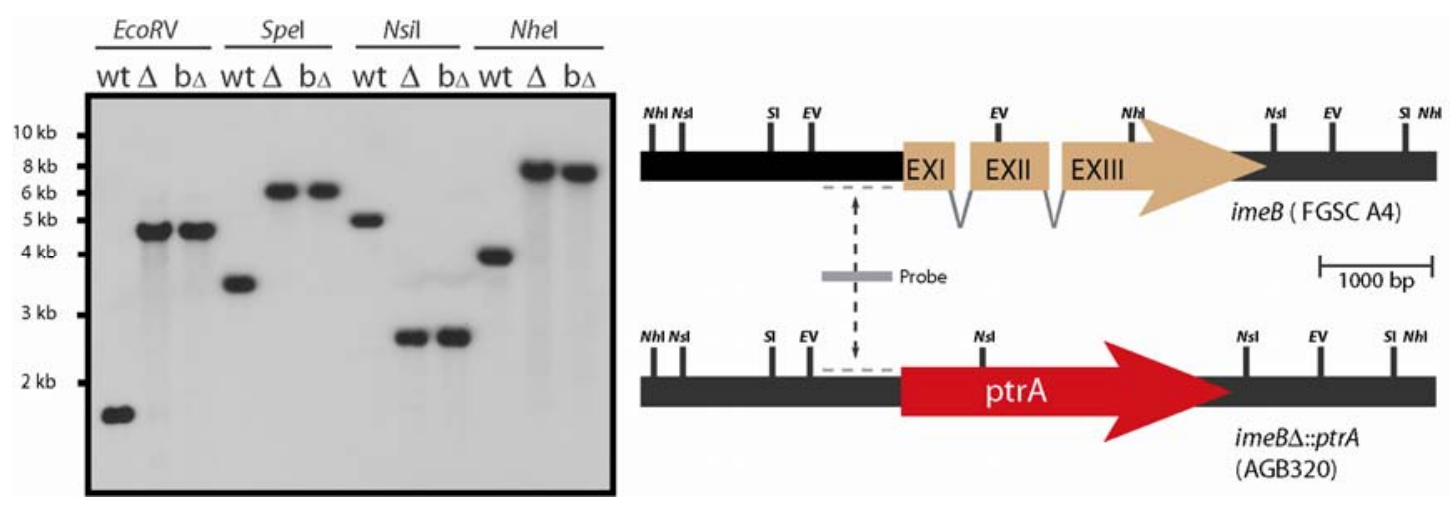

\section{Fig.2 Deletion of the imeB gene}

The imeB genome locus is illustrated. The imeB ORF consists of three exons and two introns (breaks). For gene disruption of the $i m e B$ ORF the dominant marker pyrithiamine (red) was used (right). Restriction enzyme sites are abbreviated: EV: EcoRV, SI: Spel, Nsl: Nsil, Nhl: Nhel. Southern autoradiograph of wild type (FGSC A4), $\Delta i m e B$ (AGB 320), and $\triangle i m e B$ backcrossed (AGB 321)(left). Strain names were abbreviated: wt: wild type, $\Delta$ : imeB mutant, $\mathrm{b} \Delta$ : imeB mutant backcrossed with FGSC A4. 
Our first results observed in imeB $\Delta$ strains was a slower growth rate (Fig. 3B) and highly increased sexual development (Fig. 3A, C) in the light that normally represses fruiting body formation through the red light receptor protein FphA phytochrome (Blumenstein et al., 2005) and velvet gene product VeA (Mooney et al., 1990; Kim et al., 2002). The slower growth phenotype of ime $B \Delta$ strains on agar plates (Fig. $3 \mathrm{~B}$ ) could also be observed when imeB $\Delta$ strains are grown in liquid (data not shown). Besides slower hyphae elongation a delay of spore germination was noticed. imeBA strains behaves as if it is blind to light where it produces amost a thousand fold more cleistothecia than wild type strain (Fig. 3C). However, when incubated in the darkness, wild type and mutant produce approximately the same number of cleistothecia indicating that the increased cleistothecia formation is specific only to the light grown plates. Cleistothecia produced by imeBA strain are fully fertile (data not shown). The phenotypes of the imeB $\Delta$ mutant can be complemented by integration of a $5 \mathrm{~kb}$ genomic fragment of $i m e B$ locus ectopically into the imeB $\Delta$ deletion strain (Fig. 3A, C).

All these results suggest that $i m e B$ is involved in the hyphal growth and regulation of sexual development. Deletion of $i m e B$ locus causes an abnormal increase in sexual development by loosing the sense of time and light. 

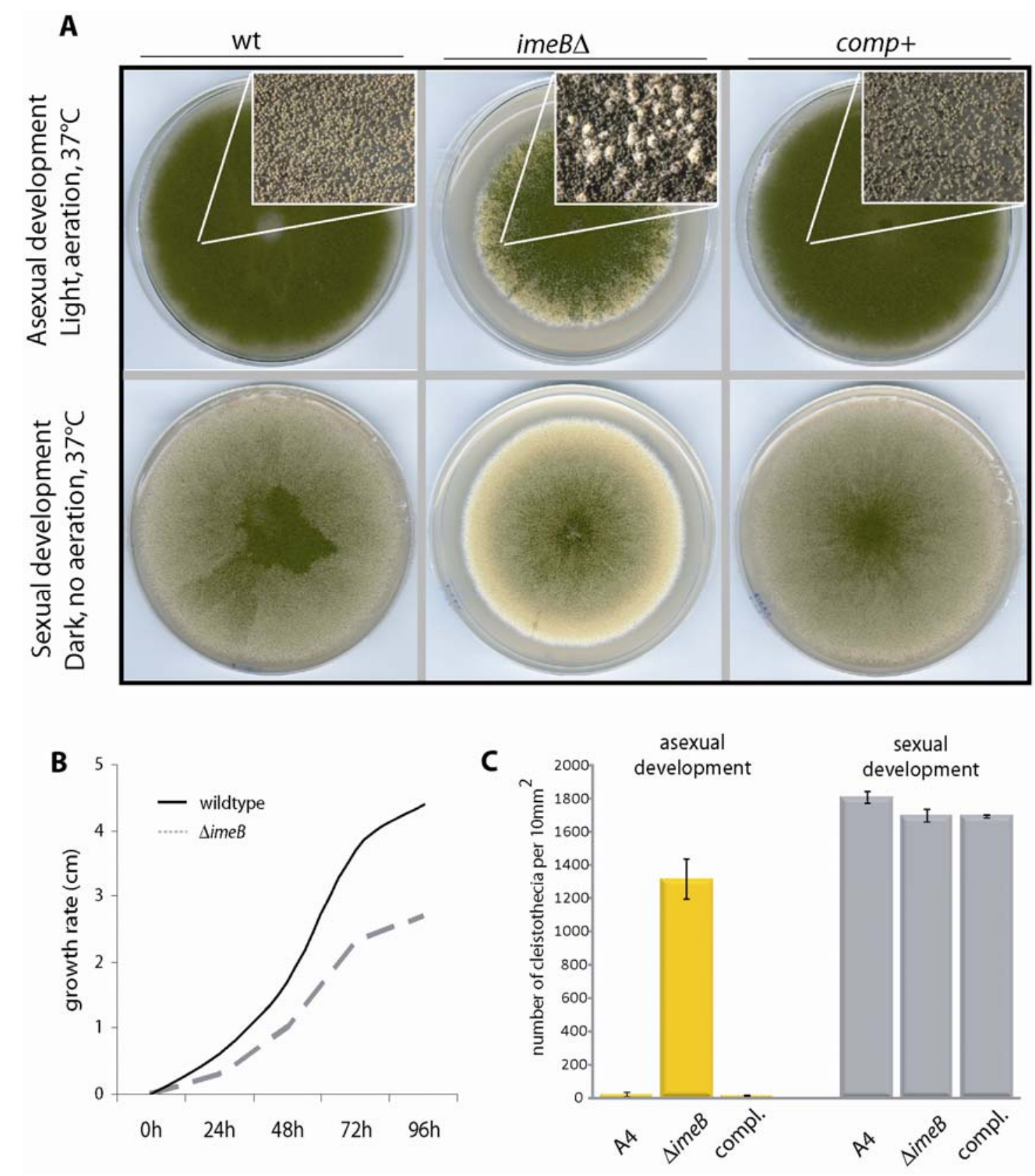

\section{Fig.3 $\triangle$ ime $B$ mutant phenotype on solid media}

A) A wild type (FGSC A4), the $\triangle i m e B$ (AGB 322), and the complementation strain (ABG 321) were point inoculated $\left(2 * 10^{3}\right.$ spores) on solid minimal media. Strains were grown at $37^{\circ} \mathrm{C}$ for 7 days in conditions promoting either asexual development or sexual development. Enlargement of the colonies (boxed) showing conidiophores and cleistothecia. B) Growth rates of a wild type (FGSC A4) and the $\triangle i m e B$ strain on solid minimal media were compared. Strains were point inoculated $\left(2 * 10^{3}\right.$ spores) and colony size was measured (in $\mathrm{cm}$ ) over a period of $96 \mathrm{~h}$. C) Number of cleistothecia were counted. From ten independent plates cleistothecia in a square of $10 \mathrm{~mm}^{2}$ were counted under a stereomicroscope. 
Deletion of imeB results in Hülle cell formation in submerged culture. Inspection of imeB deletion strain revealed some phenotypic defects not only on plates but also in submerged culture. We observed the formation of Hülle cells in liquid culture (Fig. 4A). Hülle cells, which are sexual development specific and covers the maturating fruiting bodies on the plates, are proposed to have some protecting and nursing functions (Braus et al., 2002). Production of Hülle cells, which does not take place under submerged culture, has been reported in the overexpressing strains of sexual development regulators such as veA and $n s d D$ (never sexual development) in liquid culture (Mooney et al., 1990; Han et al., 2001; Kim et al., 2002).

A

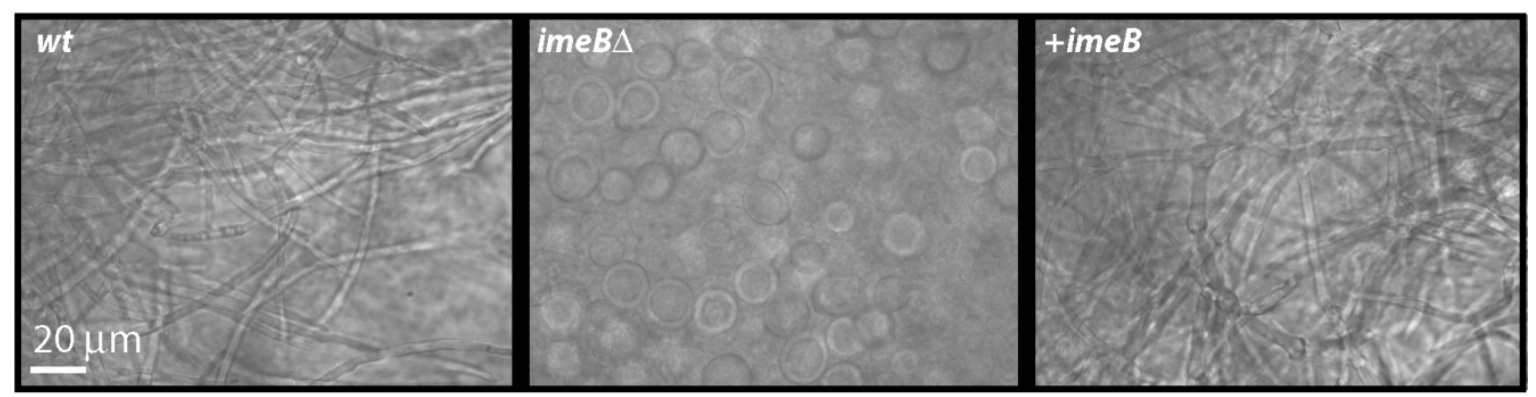

B

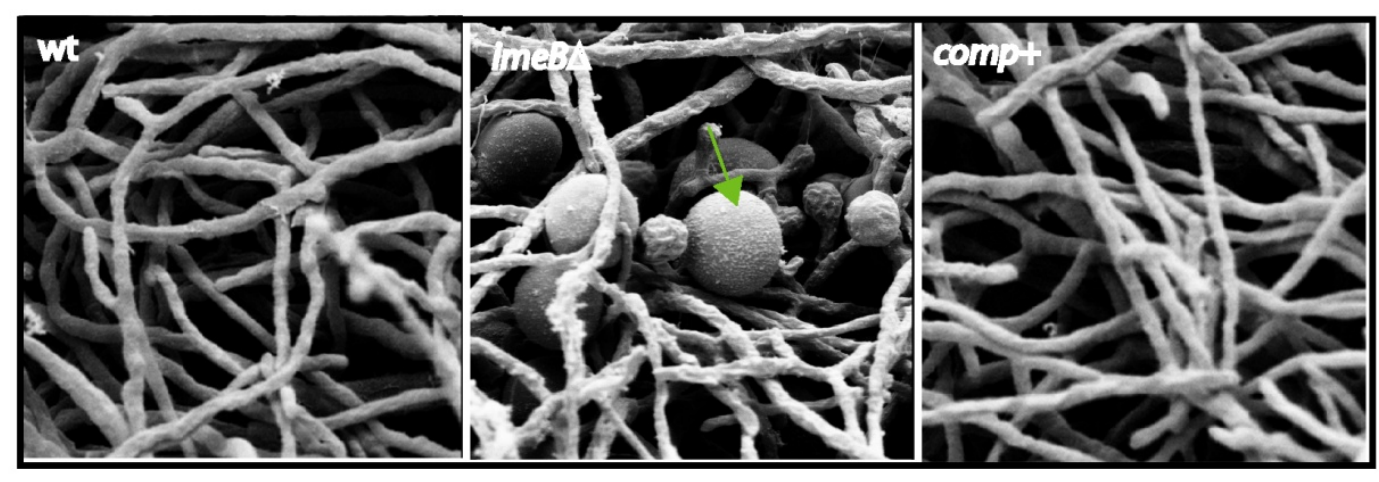

C

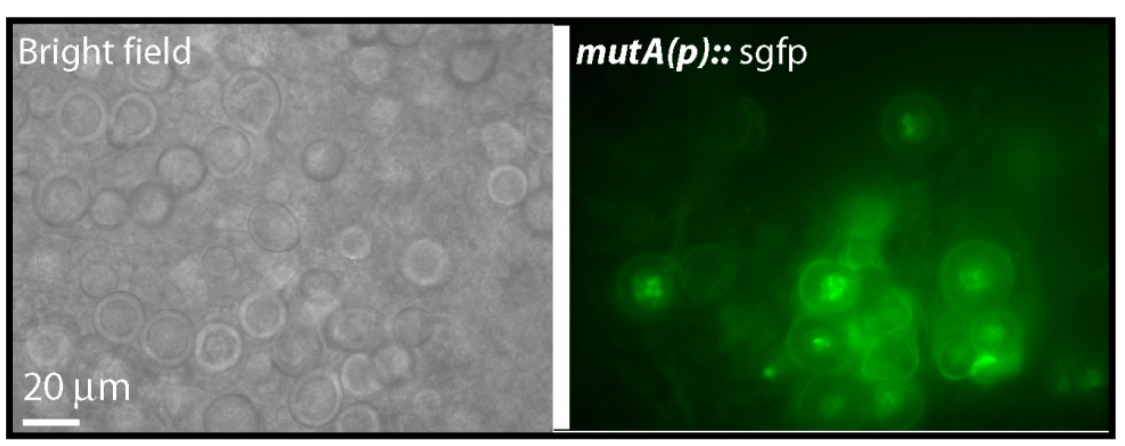


Fig.4 $\triangle$ imeB mutant phenotype in liquid culture

Phenotype of the $\triangle i m e B$ strain in submerged culture. A wild type (FGSC A4), an $\triangle i m e B$ (AGB 322), and an $\triangle i m e B$ complemented strain (AGB 321) were grown vegetatively at $37^{\circ} \mathrm{C}$. Phase contrast pictures were photographed after $48 \mathrm{~h}$ of vegetativ growth. C) Scanning electron microscopy of a wildtype, $\triangle i m e B$ mutant, and the complementation strain. Strains were grown in liquid minimal media for $48 \mathrm{~h}$. Arrow indicate Hülle cell. D) Phase contrast and flourescence pictures of an $\Delta i m e B$ strains bearing the mutA(p)::sgfp contruct (AGB 326). For ananlysis of physiologically active Hülle cells, the strain was inoculated in minimal media containing threonine $(100 \mathrm{mM})$ and glycerol $(2 \%)$ at $30^{\circ} \mathrm{C}$ for $24 \mathrm{~h}$.

Hülle cell formation of imeB $\Delta$ strain is more pronounced after prolonged incubation (48-72 h) in submerged culture. However very long incubation in liquid culture does not result in complete fruiting body formation. We also wanted to know wether the Hülle cells produced are physiologically active. For that purpose, mutA promoter driven s-gfp was expressed in the imeBA strain. The mutA gene is only expressed in Hülle cells, in another term it is specific to Hülle cells. Accordingly, mutA driven s-gfp expression can be visualized in Hülle cells if the cells are physiologically active. Expression of mutA (p)::s-gfp produces green fluorescence signal sepcifically from Hülle cells, which indicates that Hülle cells are physiologically functional (Fig. 4C). Hülle cell formation could be complemented with a $5 \mathrm{~kb}$ imeB genomic fragment (1.5 kb promoter and $1.5 \mathrm{~kb}$ terminator) cloned in a phleomycin resistance plasmid that ectopically integrated into the genome (Fig. 4A).

RNA levels of sexual regulators increase in an imeB $\Delta$ strain. The formation of Hülle cells under inappropriate conditions raised the questions on the conditions that cause to the production of Hülle cells, which are very specific for the sexual developmental programme in $A$. nidulans. When overexpressed, the sexual development controller veA (velvet $A$ ) and nsdD (never in sexual development $\underline{D}$ ) results in Hülle cell formation even in submerged culture (Han et al., 2001; Kim et al., 2002). Deletion of the $\mathrm{C}_{2} \mathrm{H}_{2}$ transcription factor rosA (repressor of sexual development $A$ ) causes Hülle cells to be produced in submerged conditions as well (Vienken et al., 2005). Since the deletion of $i m e B$ also results in Hülle cells formation and highly increased sexual development, we were interested to analyse mRNA levels of sexual regulators in imeB $\Delta$ strain. For this purpose, $w t, i m e B \Delta$ and complementation strains were grown in submerged culture until the time when first Hülle cells 
appear. At that time point (48 hours), RNAs were isolated and blotted with DNA probes from the stuA, nsdD, and veA genes (Fig. 5).
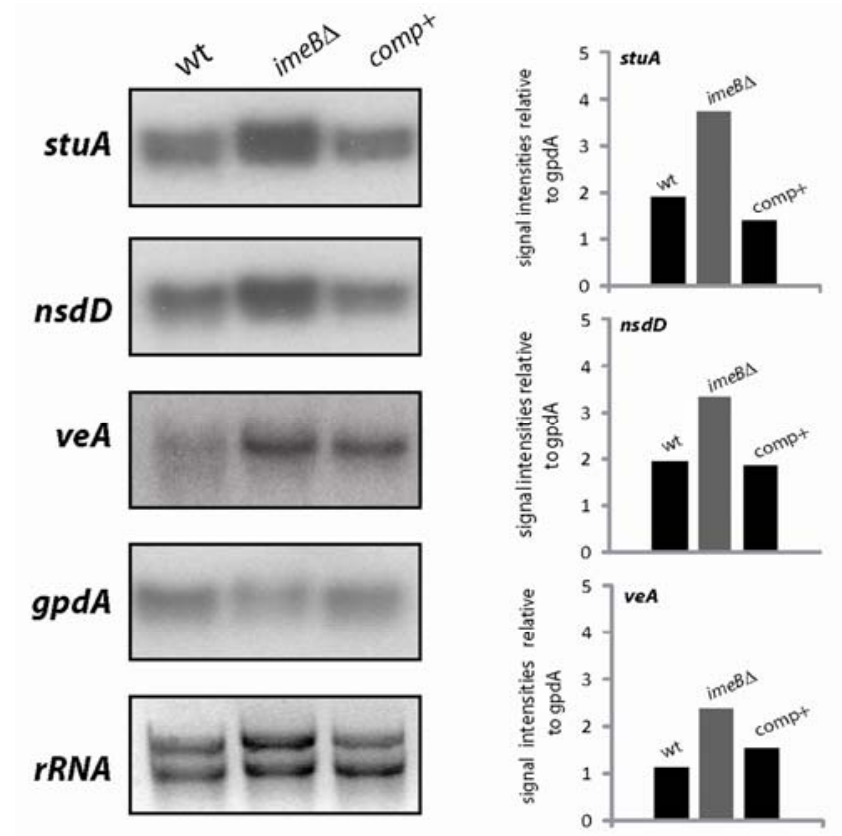

Fig.5 Northern Blot analysis of three developmental regulators

A wild type (FGSC A4), the $\triangle i m e B$ (AGB 322), and the complementation strain (ABG 321) were grown in submerged culture overnight. Taking gpdA transcript level as basis changes in expression of selected genes were measured. Ethidium bromide stained rRNA and the constitutively expressed gpdA served as loading control.

$n s d D$ is a transcriptional regulator of sexual development and stuA is an inducer of Hülle cell production (Wu and Miller, 1997; Han et al., 2001). nsdD and stuA transcripts level increased during 48 hours of growth, correlating to the observation of Hülle cells (Fig. 5). The light dependent sexual development regulator veA transcript did moderately increase. Quantified signal intensities relative to $g p d A$ signal also show that there is almost two fold increase of $n s d D$, stuA, and veA transcripts in the imeB $\Delta$ strain (Fig. 5 Right panel).

All together, these expression profile proposes that imeB negatively regulates the expression of sexual development regulators. Deletion of $i m e B$ results in a moderate upregulation of transcripts of these sexual fruit body formation regulators. 
Overexpression of imeB results in fluffy phenotype. To follow the phenotypical changes when ImeB is present at higher levels, we overexpressed the imeB gene replacing the endogenous promoter by the strong inducible alcohol dehydrogenase $(a / c A)$ promoter from $A$. nidulans. The resulting construct (pME 3294) was introduced ectopically into the $A$. nidulans wild type strain (AGB 152) as one single copy.

Overexpression of imeB under induction conditions (2\% Glycerol and 2\% Ethanol) showed no difference to wildtype in concern of sexual or asexual development if grown in light. However, when sexual development is induced, in the dark, overexpressing imeB displays many significant defects in growing behaviour. Unlike wild type, in imeB ovexpressing strains both the asexual and the sexual programm is blocked at very early stages of development showing cotton like colony morphology and an inability to form conidiophores or cleistothecia anymore (Fig.6 A). In literature this type of phenoytpe is implicated to a group of mutants called fluffy (Adams et al., 1998).

The possible toxic effect of the empty plasmid was excluded since a wild type strain bearing just the empty plasmid showed the same phenotype as the wild type strain. Out of 6 selected transformants 5 showed this fluffy phenotype suggesting that no essential gene was disrupted during the ectopic integration of the overexpression construct. One other gene leading to a fluffy phenotype when overexpressed is rosA (Vienken et al., 2005). To elucidate a possible interplay of ime $B$ and $\operatorname{ros} A$ a northern analysis was conducted. Upon ethanol induction there is no significant change of mRNA levels of $\operatorname{ros} A$ in imeB overexpression strains suggesting no direct influence on $\operatorname{ros} A$ transcription (Fig.6 B). The transcript level of the sexual regulator velvet (veA) are also similar during sexual or asexual development. The VeA protein is a light-dependent regulator determining the ratio between conidiation and sexual development. Despite the light-dependent fluffy phenotype observed in imeB overexpressing strains, transcripts of veA is not affected by high levels of ImeB. However, one target of ImeB may be $b r l A$, since the $b r l A$ transcript is absent in ime $B$ overexpressing strains during sexual development. During asexual development $b r l A$ is reduced compared to wild type. Probably, the observation that $i m e B$ overexpressing strains are phenotypically growing the same as the wildtype in light (Fig.6 B) may be due to the sufficient transcript level of $b r l A$. 


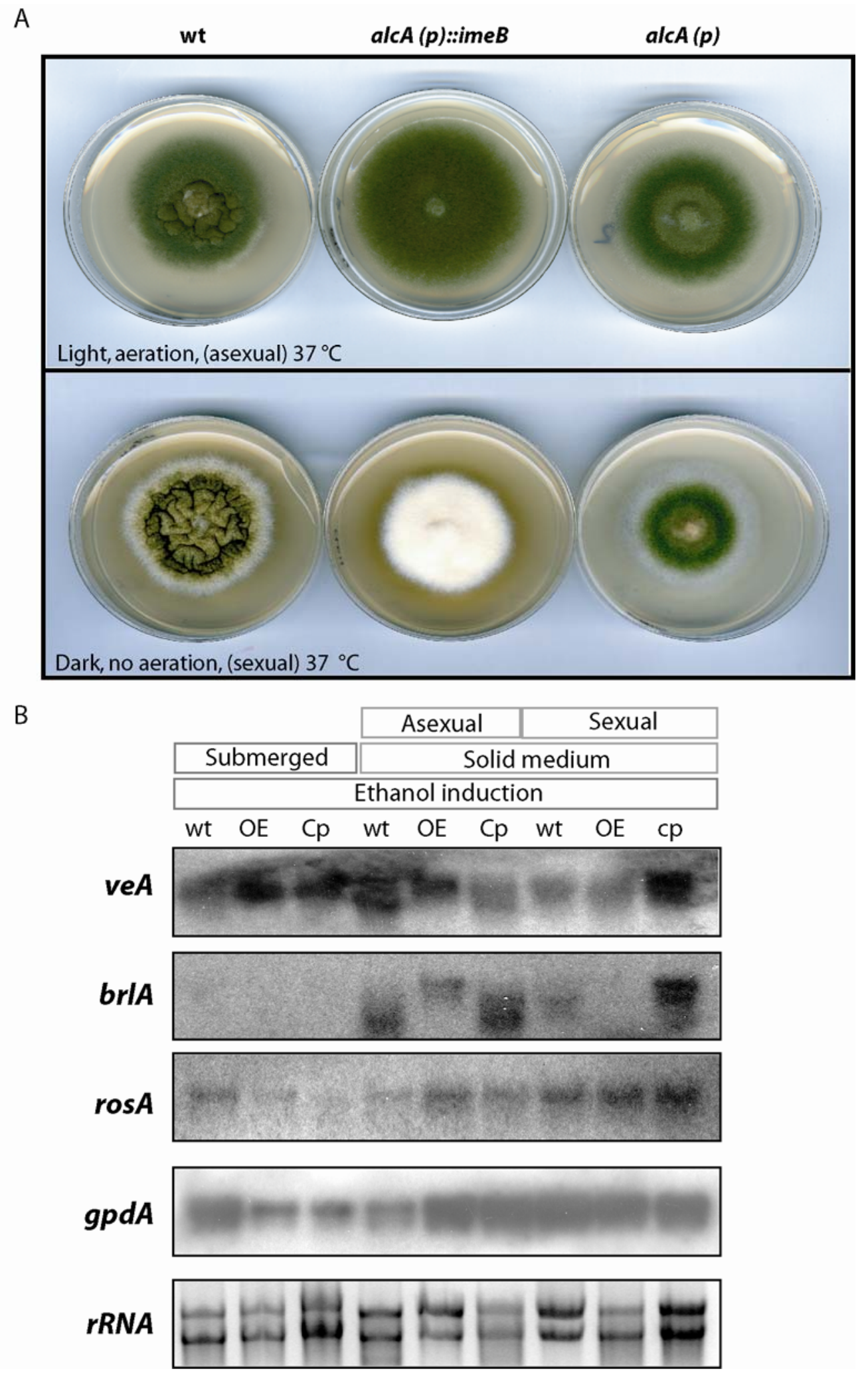


Fig.6 Growth of imeB overexpressing strains and transcripts of developmental regulators in imeB overexpressing strains

A) A wild type ( $A G B$ 152), an overexpression ( $A G B 323$, alcA(p)::imeB), and control plasmid carrying strain ( $A G B 324$, alcA plasmid without imeB) were grown at $37^{\circ} \mathrm{C}$ for 7 days in conditions promoting either asexual or sexual development. Strains were point inoculated $\left(2 * 10^{3}\right.$ spores) on solid minimal media containing $2 \%$ ethanol and $2 \%$ glycerol for induction of the constructs. B) Expression pattern of different developmental regulators of $A$. nidulans. Mycelia from strains used in (A) were pregrown in submerged cultures for $18 \mathrm{~h}$, transferred to solid minimal media, to induce either sexual or asexual developmental program. For overexpression, $2 \%$ glycerol and $2 \%$ ethanol were added both to liquid (pregrown) and solid media (induction). Total RNA was extracted for Northern Blot analysis. Probs used for hybridization were labeled with ${ }^{32} \mathrm{P}$. Ethidium bromide stained rRNA and the constitutively expressed gpdA served as loading controls. Strain names were abbreviated: wt: wild type, OE: imeB overexpressing strain, $\mathrm{cp}$ : wild type with control plasmid.

ImeB MAP kinase a constitutive nuclear protein. MAP kinases regulate gene expression by phosphorylating some transcription factors either activating or inactivating them. Therefore their nuclear localization is essential for their inhibitory or activatory functions. For identification of subcellular localization of the putative MAP kinase ImeB protein, imeB CDNA was cloned in plasmid pCMB17apx under the alcA promoter as an e-gfp fusion and co-transformed to strain AGB 152 together with histone mRFP fusion plasmid. alcA promoter, which is an inducible promoter used in Aspergillus genetics, is induced by different non fermentable carbon sources such as ethanol and glycerol (Lubertozzi and Keasling, 2006). For induction of alcA driven e-gfp::imeB cDNA construct, media was supplemented with glycerol as well as ethanol and strain was grown overnight and analysed under fluorescence microscope.

As can be seen from Figure 7, E-GFP::ImeB fusion protein is localized to the nucleus that is indicated by the co-localization of red fluorescence coming from histone mRFP construct. Nuclear localization of E-GFP::ImeB protein is constitutively nuclear either in germinating spores (Fig.7 upper panel) or in the older hypha (Fig.7 lower panel). Localization of E-GFP::ImeB fusion protein is not affected by illumination (data not shown). Localization experiments propose that ImeB protein is a constitutively nuclear protein that might regulate gene expression via various sexual development regulators. 


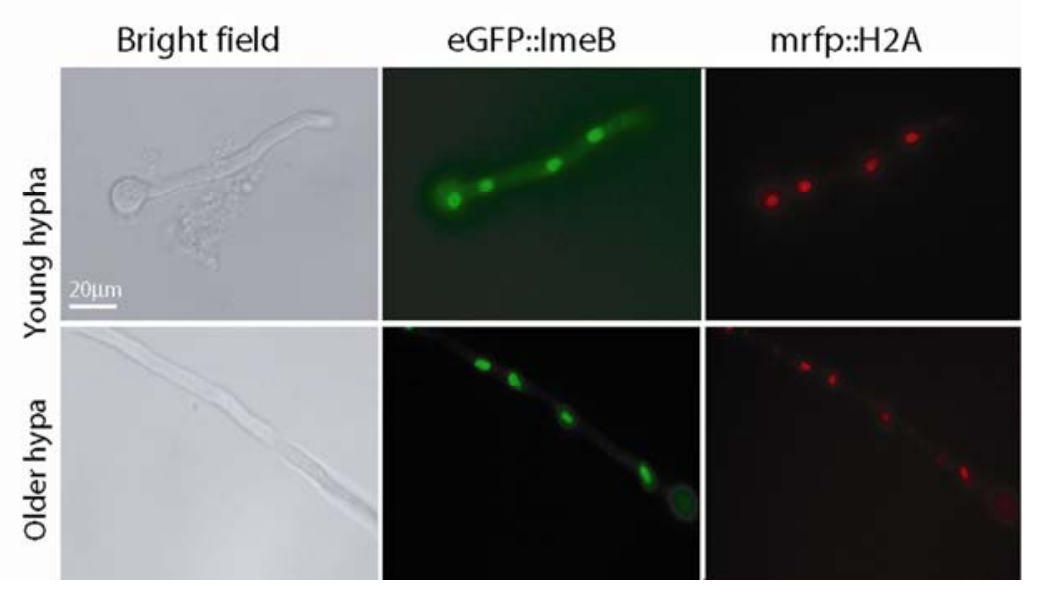

Fig.7 Subcellular localization of an imeB::egfp protein

An AGB 152 strain containing the imeB::eGFP (AGB 325) construct was grown for $7 \mathrm{~h}$ (young hypae) or $24 \mathrm{~h}$ (older hyphae) in liquid media containing $100 \mathrm{mM}$ threonine and $2 \%$ glycerol for induction of the constructs. An $m r f p:: H 2 A$ construct was used for nuclear staining.

TXY motif is required for function of ImeB. MAP kinases have a characteristic TXY motif embedded in the T-Loop of the protein. A dual phosphorylation on tyrosine and threonine is a prerequisite for kinase activation (Payne et al., 1991). To address the question whether the observed phenotype of imeB mutant strains is due to the lack of phosphorylation on the TTY motif we mutated stepwise each aminoacid of the ImeB TTY motif to alanine and accordingly the whole TTY motif to alanine. The single constructs (Table 2) were generated by fusion PCR and transformed into the imeB mutant strain (AGB 322). Successful integration of the constructs into the genome was verified by sequencing.

Mutation of each aminoacid of the TTY motif leads to the same phenotype observed in $\triangle i m e B$ before (Fig. 8 A) suggesting the eminent role of every single amino acid for ImeB function. Activation of the protein kinase ImeB requires both tyrosin219 and threonine221, presumably for activation by phosphorylation. Surprisingly, a lack of the third amino acid, tyrosin 220 embedded between the two phosphorylation sites, leads also to a loss of ImeB function. Accordingly, the same phenotype is obtained when the whole TTY motif is mutated, but which is not stronger than those of the single mutations. In contrast, the restoration of the $\triangle i m e B$ phenotype was achieved when we complemented with an $i m e B$ gene without any mutations (Fig.8 A). We adressed the question whether mutations in the TTY motif lead to the same phenotype observed in $\triangle i m e B$ mutant strains in liquid culture. Therefore, strains with mutated TTY motifs were inoculated in minimal submerged 
culture and propagated for 48 hours. Indeed, Hülle cells emerged after $48 \mathrm{~h}$ vegetative growth of these strains in a similar manner as for $\Delta i m e B$ mutant strains before (Fig. $8 \mathrm{~B}$ ).

The results of the ImeB TTY motif show that it is indispensable for ImeB activity for $A$. nidulans development.

A

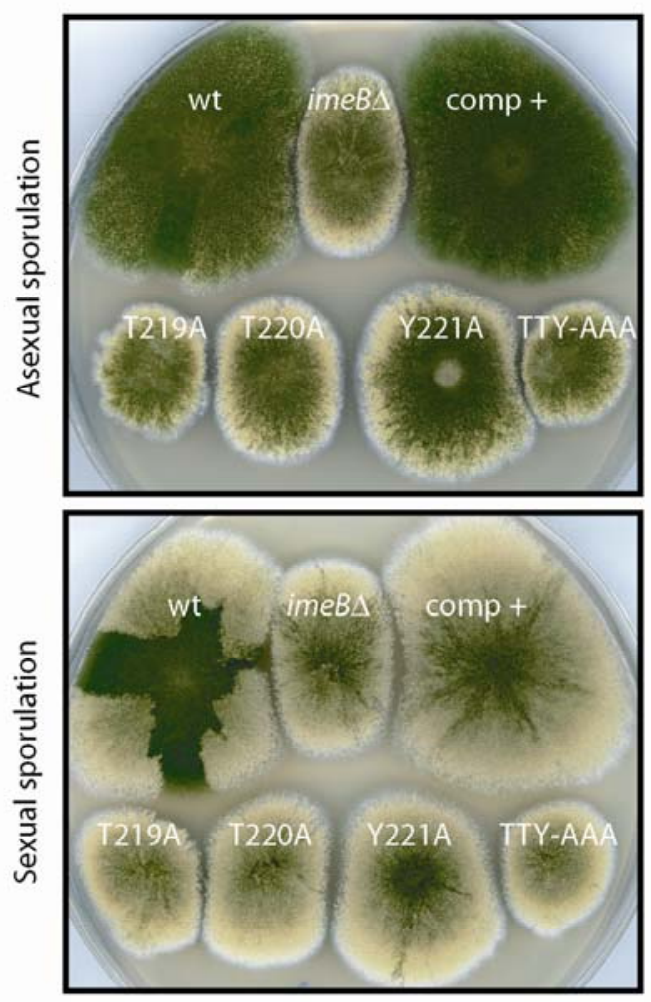

B

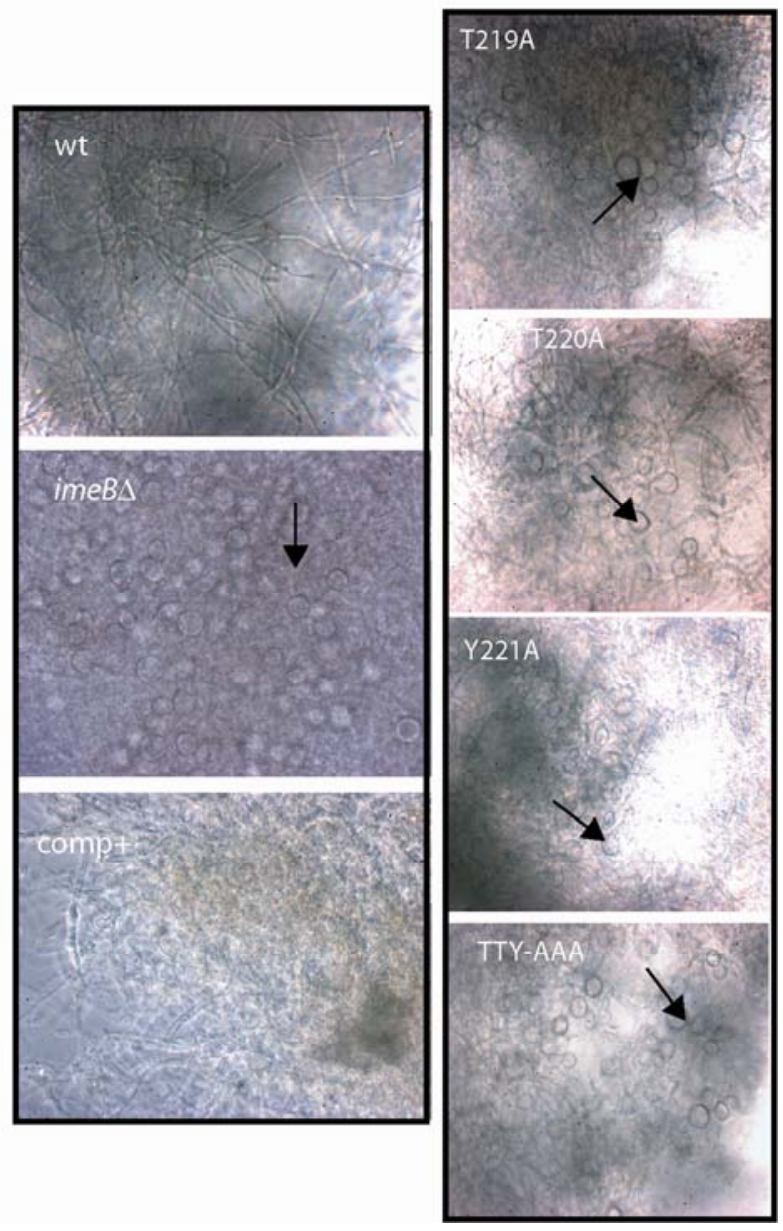

Fig.8 Characterization of the $A$. nidulans TTY motif

A) A wild type strain (A4), $\triangle i m e B$ mutant (AGB 322), the complementation strain (AGB 321) were point inoculated on solid minimal media. Additionally, strains, where the aminoacid T219 (AGB 327), T220 (AGB 328), Y221 (AGB 329), and TTY (AGB 330) are mutated to alanine, were point inoculated on the same agar plate. Strains on agar plates were propagated either asexually or sexually. B) Strains in (A) were cultured in liquid minimal media for $48 \mathrm{~h}$ vegetative growth. 


\section{Discussion}

To adopt to environmental changes fungi sense outer signals and transduce the information to the interior of the cell via several signal transduction pathways. More and more about players and the signaling mechanism in Aspergilli were revealed in the past few years (Bussink and Osmani, 1999; Kawasaki et al., 2002; Wei et al., 2003; Xue et al., 2004; Reyes et al., 2006). Here, we present an analysis of ImeB, a serin threonin protein kinase of Aspergillus nidulans. The ImeB protein sequence contains a TXY motif characteristic to MAP kinases. A BLAST search of ImeB disclosed an akin protein in the pathogenic fungi $A$. fumigatus, which was designated as the putative meiosis induction protein kinase Ime2 (Nierman et al., 2005). Indeed, alignment of ImeB and Ime2 (Fig.1) showed that both kinases are also homologs, but not orthologues since we found that ImeB expressed in yeast can not take over the function of Ime2 for meiosis (data not shown). Like in yeast, ImeB is also involved in sexual development in A. nidulans. However, it has an opposite role to yeast Ime2, it acts as a negativ regulator of sexual development.

We showed that imeB null mutants form masses of Hülle cells in liquid culture and vast amounts of cleistothecia on solid media. If one considers that imeB is transcribed to very low levels in submerged culture (Fig.1C) then it becomes obvious that even low amounts of ImeB is sufficient to act as a repressor of sexual development. Interestingly, in imeB mutants the production of sexual stuctures is only affected during asexual development, whereas in sexual development only the number of Hülle cells are increased but not the number of cleistothecia (Fig.3C). Even a prolonged incubation did not yielded more cleistothecia.

How may ImeB regulate development in A.nidulans? RosA, a transcription factor which acts as a negativ regulator of sexual development, may be a factor acting in the same pathway like ImeB. Like $\Delta i m e B, \Delta \operatorname{ros} A$ mutants form Hülle cells in liquid culture and show an increase of cleistothecia production (Vienken et al., 2005). Interestingly, $\Delta \operatorname{ros} A$ mutants show only an increase of cleistothecia production when propagated in the dark, whereas in light the amount of cleistothecia remains unaffected. This proposes that both, ImeB and RosA, are influencing the development of $A$. nidulans in a similar way, but one affects the asexual and the other the sexual progeny. The relationship between RosA and ImeB is even more strengthend when transcript levels of three transcription factor- $n s d D, v e A$, and stuA- with known roles in sexual development are compared. In liquid culture all three factors are upregulated in $\triangle i m e B$ and $\Delta \operatorname{ros} A$, respectively. The question whether the latter expression pattern is due to an interplay of ImeB and RosA or if they act 
independently remains unclear and needs to be studied further. A double knock out approach of $i m e B$ and $\operatorname{ros} A$ and the resulting phenotype would display the correlation between both proteins.

We have further found, that overexpression of imeB leads to a cotton like colony morphology (Fig6), a phenotype which is termed as fluffy in literature. The fluffy phenotype typically is correlated with a lack of conidiophores having profuse aerial hyphae. Also rosA overexpressing cells show a fluffy phenotype when asexually propagated, whereas in imeB overexpressing cells a fluffy phenotype could only be observed during sexual but not asexual development. These data indicate that ImeB overexpression inhibits development of asexual spores. Garrido and PerezMartin (2003) identified an Ime2-related protein, Crk1, in Ustilago maydis. They demonstrated that Crk1 is required for morphogenesis and environmental adaptation in U. maydis. Wild type U.maydis colonies under normal conditions form white aerial filaments, which gives a "fuzzy" phenotype. Interestingly, overexpression of crk1 drastically increases the amount of white aerial filaments the same as in $i m e B$ overexpressing strains. $\Delta c r k 1$ strains are unable to display such a fuzzy phenotype. Also a slower growth phenotype was reported for $\Delta c r k 1$ strains, a phenotype, which we observed for $\triangle i m e B$ mutants. In addition to these data, the sequence similarity, $40 \%$ in the $\mathrm{N}$-terminal part, of ImeB to Crk1 and Ime2 illustrates that all three proteins are related to each other.

One master regulator controlling the balance between asexual and sexual development is VeA. Although transcript levels of veA in imeB overexpressing cells, grown sexually, did not change (Fig.6B), it might be possible that $\mathrm{VeA}$ is modified by the protein kinase ImeB leading to a misfunction of VeA.

It seems as if bIrA is one target of ImeB. Elevated levels of ImeB result in a complete loss of the brlA transcript during sexual growth (Fig.6B). Since BrlA is one of the early regulators of conidiation, this might explain the lack of conidiation of $i m e B$ overexpressing cells when propagated sexually.

Hence, our data propose that ImeB carries out functions both in asexual and sexual development. Another evidence confirming this assumption is the expression pattern of imeB (Fig.1C) showing increased imeB transcript levels for both developmental modes. Not only early transcription of $i m e B$ but also the delayed spore germination (data not shown) leading to slower growth phenotype (Fig.3B) suggests an early function of ImeB in A. nidulans development. Probably, boosting cleistothecia production exhausts all reserves and delays mycelial growth.

Another regulator recently described as a transcription factor controlling fruit body formation is NosA. NosA is a $\mathrm{Zn}(\mathrm{II}) 2 \mathrm{Cys} 6$ transcription factor presumably performs its job late in sexual development, thus being responsible for cleistothecia maturation (Vienken and Fischer, 2006). To reveal a potential interplay of ImeB and NosA, we deleted imeB in the $\Delta$ nos $A$ mutant 
background. An imeB/nosA double knock (data not shown) also did not result in matured cleistothecia indicating that ImeB acts upstream of NosA without having any impact on NosA in concern of fruit body maturation.

Since ImeB is a protein kinase which possesses a mitogen activated kinase like TXY motif, we asked whether exclusively this motif, which resembles the acitvation domain of the kinase, is needed for blocking the sexual development of $A$. nidulans. We generated ImeB versions having mutations in the TXY motif and compared the resulting effects with those lacking the whole imeB gene. Strains which had mutations in the TXY motif showed the same phenotype as $\triangle i m e B$ mutants (Fig.7). This suggests, that mutations of the motif, or of even every single aminoacid of the TXY motif, leads to an inactivation of the kinase and is not able to block sex anymore. Recently, a MAK (male germ cell-ạssociated protein kinase) and ICK (intestinal cell kinase) were identified as human homologs of Ime2 in S.cerevisiae (Fu et al., 2006). Nevertheless, they illustrated that for activity of both proteins a dual phophorylation in the TXY motif is required.

In summary, the nuclear localized (Fig.4) protein kinase acts as a repressor of sexual development, but also has roles during asexual life cycle. We suggest, that ImeB is a MAP kinase which plays an eminent role in transducing environmental signals which presumably stimulate $A$. nidulans cells to block sexual development. It should be in the focus of further investigations to unravel all players of a new MAP kinase module which seems to control sex in A. nidulans. 


\section{References}

Adams, T.H., Wieser, J.K., and Yu, J.H. (1998). Asexual sporulation in Aspergillus nidulans. Microbiol Mol Biol Rev 62, 35-54.

Benjamin, K.R., Zhang, C., Shokat, K.M., and Herskowitz, I. (2003). Control of landmark events in meiosis by the CDK Cdc28 and the meiosis-specific kinase Ime2. Genes Dev 17, 1524-1539.

Blumenstein, A., Vienken, K., Tasler, R., Purschwitz, J., Veith, D., Frankenberg-Dinkel, N., and Fischer, R. (2005). The Aspergillus nidulans phytochrome FphA represses sexual development in red light. Curr Biol 15, 1833-1838.

Bolte, M., Steigemann, P., Braus, G.H., and Irniger, S. (2002). Inhibition of APC-mediated proteolysis by the meiosis-specific protein kinase Ime2. Proc Natl Acad Sci U S A 99, 43854390.

Boylan, M.T., Mirabito, P.M., Willett, C.E., Zimmerman, C.R., and Timberlake, W.E. (1987). Isolation and physical characterization of three essential conidiation genes from Aspergillus nidulans. Mol Cell Biol 7, 3113-3118.

Braus, G.H., Krappmann, S., and Eckert, S. (2002). Sexual development in ascomycetes: Fruit body formation in Aspergillus nidulans. In Molecular Biology of Fungal Development, Osiewacz, ed (New York: Marcel Dekker Inc), pp. 215-244.

Brown, T., and Mackey, K. (1997). Analysis of RNA by Northern and slot blot hybridization. In Current protocols in molecular biology (New York, NY: John Wiley and Sons Inc.), pp. 4.9.1 4.9.16.

Busch, S., Eckert, S.E., Krappmann, S., and Braus, G.H. (2003). The COP9 signalosome is an essential regulator of development in the filamentous fungus Aspergillus nidulans. Mol Microbiol 49, 717-730.

Busch, S., Schwier, E.U., Nahlik, K., Bayram, O., Helmstaedt, K., Draht, O.W., Krappmann, S., Valerius, O., Lipscomb, W.N., and Braus, G.H. (2007). An eight-subunit COP9 signalosome with an intact JAMM motif is required for fungal fruit body formation. Proc Natl Acad Sci U S A 104, 8089-8094.

Bussink, H.J., and Osmani, S.A. (1998). A cyclin-dependent kinase family member (PHOA) is required to link developmental fate to environmental conditions in Aspergillus nidulans. Embo J 17, 3990-4003.

Bussink, H.J., and Osmani, S.A. (1999). A mitogen-activated protein kinase (MPKA) is involved in polarized growth in the filamentous fungus, Aspergillus nidulans. FEMS Microbiol Lett 173, 117-125.

Chu, S., DeRisi, J., Eisen, M., Mulholland, J., Botstein, D., Brown, P.O., and Herskowitz, I. (1998). The transcriptional program of sporulation in budding yeast. Science $\mathbf{2 8 2}, \mathbf{6 9 9 - 7 0 5 . ~}$

Clutterbuck, A.J. (1969). A mutational analysis of conidial development in Aspergillus nidulans. Genetics 63, 317-327.

Dirick, L., Goetsch, L., Ammerer, G., and Byers, B. (1998). Regulation of meiotic S phase by Ime2 and a Clb5,6-associated kinase in Saccharomyces cerevisiae. Science 281, 1854-1857.

Fu, Z., Larson, K.A., Chitta, R.K., Parker, S.A., Turk, B.E., Lawrence, M.W., Kaldis, P., Galaktionov, K., Cohn, S.M., Shabanowitz, J., Hunt, D.F., and Sturgill, T.W. (2006). Identification of yinyang regulators and a phosphorylation consensus for male germ cell-associated kinase (MAK)-related kinase. Mol Cell Biol 26, 8639-8654.

Garrido, E., and Perez-Martin, J. (2003). The crk1 gene encodes an Ime2-related protein that is required for morphogenesis in the plant pathogen Ustilago maydis. Mol Microbiol 47, 729743.

Guttmann-Raviv, N., Martin, S., and Kassir, Y. (2002). Ime2, a meiosis-specific kinase in yeast, is required for destabilization of its transcriptional activator, Ime1. Mol Cell Biol 22, 20472056. 
Han, K.H., Han, K.Y., Yu, J.H., Chae, K.S., Jahng, K.Y., and Han, D.M. (2001). The nsdD gene encodes a putative GATA-type transcription factor necessary for sexual development of Aspergillus nidulans. Mol Microbiol 41, 299-309.

Hoffmann, B., LaPaglia, S.K., Kubler, E., Andermann, M., Eckert, S.E., and Braus, G.H. (2000). Developmental and metabolic regulation of the phosphoglucomutase-encoding gene, pgmB, of Aspergillus nidulans. Mol Gen Genet 262, 1001-1011.

Hui, C.M., Campistrous, A., and Stuart, D.T. (2002). Purification and some properties of Saccharomyces cerevisiae meiosis-specific protein kinase Ime2. Protein Expr Purif 26, 416424.

Käfer, E. (1965). Origins of translocations in Aspergillus nidulans. Genetics 52, 217-232.

Kawasaki, L., Sanchez, O., Shiozaki, K., and Aguirre, J. (2002). SakA MAP kinase is involved in stress signal transduction, sexual development and spore viability in Aspergillus nidulans. Mol Microbiol 45, 1153-1163.

Kim, H., Han, K., Kim, K., Han, D., Jahng, K., and Chae, K. (2002). The veA gene activates sexual development in Aspergillus nidulans. Fungal Genet Biol 37, 72-80.

Kolar, M., Punt, P.J., van den Hondel, C.A., and Schwab, H. (1988). Transformation of Penicillium chrysogenum using dominant selection markers and expression of an Escherichia coli lacZ fusion gene. Gene 62, 127-134.

Lubertozzi, D., and Keasling, J.D. (2006). Marker and promoter effects on heterologous expression in Aspergillus nidulans. Appl Microbiol Biotechnol 72, 1014-1023.

Ma, A.H., Xia, L., Desai, S.J., Boucher, D.L., Guan, Y., Shih, H.M., Shi, X.B., Devere White, R.W., Chen, H.W., Tepper, C.G., and Kung, H.J. (2006). Male Germ Cell-Associated Kinase, a MaleSpecific Kinase Regulated by Androgen, Is a Coactivator of Androgen Receptor in Prostate Cancer Cells. Cancer Res 66, 8439-8447.

Mandel, M., and Higa, A. (1970). Calcium-dependent bacteriophage DNA infection. J Mol Biol 53, 159-162.

Mattern, I.E., Punt, P.J., and Van den Hondel, C.A. (1988). A vector of Aspergillus nidulans conferring phleomycin resistance. Fungal Genetics Newsletter, 25.

Miller, K.Y., Toennis, T.M., Adams, T.H., and Miller, B.L. (1991). Isolation and transcriptional characterization of a morphological modifier: the Aspergillus nidulans stunted (stuA) gene. Mol Gen Genet 227, 285-292.

Mooney, J.L., Hassett, D.E., and Yager, L.N. (1990). Genetic analysis of suppressors of the veA1 mutation in Aspergillus nidulans. Genetics 126, 869-874.

Nierman, W.C., May, G., Kim, H.S., Anderson, M.J., Chen, D., and Denning, D.W. (2005). What the Aspergillus genomes have told us. Med Mycol 43 Suppl 1, S3-5.

Payne, D.M., Rossomando, A.J., Martino, P., Erickson, A.K., Her, J.H., Shabanowitz, J., Hunt, D.F., Weber, M.J., and Sturgill, T.W. (1991). Identification of the regulatory phosphorylation sites in pp42/mitogen-activated protein kinase (MAP kinase). Embo J 10, 885-892.

Pöggeler, S., Nowrousian, M., and Kück, U. (2006). Fruiting-Body Development in Ascomycetes. In The Mycota I Growth, Differentiation and Sexuality, K. Fischer, ed (Heidelberg: SpringerVerlag), pp. 325-355.

Punt, P.J., and van den Hondel, C.A. (1992). Transformation of filamentous fungi based on hygromycin B and phleomycin resistance markers. Methods Enzymol 216, 447-457.

Reyes, G., Romans, A., Nguyen, C.K., and May, G.S. (2006). Novel mitogen-activated protein kinase $\mathrm{MpkC}$ of Aspergillus fumigatus is required for utilization of polyalcohol sugars. Eukaryot Cell 5, 1934-1940.

Saiki, R.K., Scharf, S., Faloona, F., Mullis, K.B., Horn, G.T., Erlich, H.A., and Arnheim, N. (1985). Enzymatic amplification of beta-globin genomic sequences and restriction site analysis for diagnosis of sickle cell anemia. Science 230, 1350-1354.

Schindler, K., and Winter, E. (2006). Phosphorylation of Ime2 regulates meiotic progression in Saccharomyces cerevisiae. J Biol Chem 281, 18307-18316. 
Schindler, K., Benjamin, K.R., Martin, A., Boglioli, A., Herskowitz, I., and Winter, E. (2003). The Cdkactivating kinase Cak1p promotes meiotic $S$ phase through Ime2p. Mol Cell Biol 23, 87188728.

Sopko, R., Raithatha, S., and Stuart, D. (2002). Phosphorylation and maximal activity of Saccharomyces cerevisiae meiosis-specific transcription factor Ndt80 is dependent on Ime2. Mol Cell Biol 22, 7024-7040.

Southern, E.M. (1975). Detection of specific sequences among DNA fragments separated by gel electrophoresis. J Mol Biol 98, 503-517.

Stuart, D., and Wittenberg, C. (1998). CLB5 and CLB6 are required for premeiotic DNA replication and activation of the meiotic S/M checkpoint. Genes Dev 12, 2698-2710.

Vienken, K., and Fischer, R. (2006). The Zn(II)2Cys6 putative transcription factor NosA controls fruiting body formation in Aspergillus nidulans. Mol Microbiol 61, 544-554.

Vienken, K., Scherer, M., and Fischer, R. (2005). The Zn(II)2Cys6 putative Aspergillus nidulans transcription factor repressor of sexual development inhibits sexual development under low-carbon conditions and in submersed culture. Genetics 169, 619-630.

Wei, H., Requena, N., and Fischer, R. (2003). The MAPKK kinase SteC regulates conidiophore morphology and is essential for heterokaryon formation and sexual development in the homothallic fungus Aspergillus nidulans. Mol Microbiol 47, 1577-1588.

Wei, H., Scherer, M., Singh, A., Liese, R., and Fischer, R. (2001). Aspergillus nidulans alpha-1,3 glucanase (mutanase), mutA, is expressed during sexual development and mobilizes mutan. Fungal Genet Biol 34, 217-227.

Woodcock, D.M., Crowther, P.J., Doherty, J., Jefferson, S., DeCruz, E., Noyer-Weidner, M., Smith, S.S., Michael, M.Z., and Graham, M.W. (1989). Quantitative evaluation of Escherichia coli host strains for tolerance to cytosine methylation in plasmid and phage recombinants. Nucleic Acids Res 17, 3469-3478.

Wu, J., and Miller, B.L. (1997). Aspergillus asexual reproduction and sexual reproduction are differentially affected by transcriptional and translational mechanisms regulating stunted gene expression. Mol Cell Biol 17, 6191-6201.

Xue, T., Nguyen, C.K., Romans, A., and May, G.S. (2004). A mitogen-activated protein kinase that senses nitrogen regulates conidial germination and growth in Aspergillus fumigatus. Eukaryot Cell 3, 557-560.

\section{Footnotes}

We thank Sybille Traupe, Armgard Janczikowski for help in some of the experiments. We also thank Özgür Bayram for the cooperation in this project. This work was supported by the Deutsche Forschungsgemeinschaft, the Fonds der Chemischen Industrie and the Volkswagen-Stiftung. 


\section{Conclusions \& Outlook}

Cell cycle and development are processes which can be studied in simple eukaryotic model organisms. The unicellular yeast Saccharomyces cerevisiae was used in this work to analyse a regulatory protein of the cell cycle, the S-phase cyclin $\mathrm{Clb5}$, and a main regulator of the meitotic cell cycle, the protein kinase Ime2. The filamentous fungus Aspergillus nidulans was applied to characterise the role of protein kinase related to Ime2, ImeB, for the complex developmental program of ascomyctes. The model organism Aspergillus nidulans is one representative of filamentous fungi, which was used during the last decades to investigate developmental processes. For sure, this lead to a better understanding of other, pathogenic fungi, such as the close relative Aspergillus fumigatus, which is a human pathogen and can even cause death of humans.

\section{Clb5 proteolysis during the cell cycle in S. cerevisiae}

The first project of this work revealed some novel insights into the degradation mechanisms of the S-phase cyclin Clb5. It was unknown for some time, why a deletion of the destruction box motif of Clb5 did not cause any defects in the cell cycle, as found for other cyclins in many different organisms. By pulse-labelling experiments, which allow the precise determination of the half-life of proteins, we could show that two different pathway contribute to trigger Clb5 to the 26S proteasome. The first degradation pathway is mediated by the APC/C and is cell-cycle regulated, whereas the second one does not depend on APC/C and is apparently constitutively active during the cell cycle.

We have further shown that these two mechanisms have redundant roles for triggering $\mathrm{Clb5}$ degradation. From our data, it can be concluded that the degradation of $\mathrm{Clb5}$ by two independent modes is a safety mechanisms to prevent cell death in the case that one of these pathways does not work properly. This model is supported by the findings that overexpression of CLB5 leads to a rapid cell death. It is conceivable that these redundant pathways are of particular importance for Clb5, but not for other cyclins such mitotic cyclins, whose overexpression causes a reversible cell cycle arrest, but not cell death.

Despite the new data presented here, there remain many open questions which need to be addressed in the future. For example, it is unclear, how Clb5 is degraded by the APC/C-independent pathway. The SCF ubiquitin ligase does not contribute to this pathway, but it appears to be dependent on the $26 \mathrm{~S}$ proteasome. How is $\mathrm{Clb5}$ then targeted to the proteasome? Does this 
pathway involve ubiquitination or not? If yes, which are then the responsible ubiquitin-conjugating enzymes and ubiquitin ligases? Yeast cells have at least 12 ubiquitin-conjugating enzymes and the analysis of $\mathrm{Clb5}$ stability in mutants of these genes may reveal new hints about this degradation pathway.

It will be also highly interesting whether the functional homolog of $\mathrm{Clb} 5$ in human, cyclin $\mathrm{A}$, is also subject to an APC/C-independent mechanisms like the yeast cyclin. Studies with cyclin A may also reveal novel degradation mechanisms for human cyclins.

\section{Role of Ime2 instability for the sporulation program in S. cerevisiae}

Since several years it is known that in yeast, Ime2 and the cyclin-dependent kinase Cdk1 act together to trigger progression through meiosis. Whereas much is known about the regulation of cyclin-dependent kinases, little information is available about how Ime2 kinase activity may be regulated during meiosis. The previous finding that Ime2 is a highly unstable protein prompted us to investigate the degradation of this kinase in detail. We could show that the C-terminal region, which was already known to have regulatory functions, acts as an instability element. There is evidence that the C-terminal region contains multiple degradation signals with overlapping functions. Indeed small deletions in this region did not stabiled Ime2.

Sporulations experiments revealed that a stabilised version of Ime2 efficiently blocks the formation of normal asci. As consequence, asci with a reduced spore, frequently dyads, were produced. Our data clearly showed that Ime2 has to be inactivated to allow the formation of normal 4-spore asci.

The key issue for future experiments is certainly to identify the mechanisms, how Ime2 regulates the formation of prospore membrane. Is Ime2 probably localised to meiotic plaques of the spindle pole bodies, the location from where the prospore membrane is formed? Or does Ime2 inhibit the association of specific proteins with the meiotic plaques.

A further interesting question is also, whether phosphorylation of the C-terminal region is a prerequisite for degradation of Ime2. For this purpose, phosphorylation sites need to be identified, for example by mass spectrometry. Then, the respective amino acids can be mutated to alanin and protein stability can be tested.

Future experiments may also enable the identification of factors which trigger Ime2 degradation. By genetic screenings, it should be possible to identify mutants which are defective in Ime2 proteolysis. Then it will be of particular interest to find out, whether and how these factors regulate Ime2 during meiotic cell cycle. 
Role of ImeB, the homolog of yeast Ime2, in regulation of development in Aspergillus nidulans

After identification of a putative yeast Ime2 homolog in A. nidulans, it was challenging to elucidate the role of this protein kinase in this more complex fungus, which is able to develop highly differentiated structures.

Indeed, we could appoint functions in regulation of asexual and sexual development for ImeB. $\triangle i m e B$ mutants showed an increase of cleistothecia formation on solid surfaces and even an induction of sex in liquid culture where normally wild type is hindered in sexual development. One hint for entering sex of $\triangle i m e B$ mutant cells in liquid culture is the formation of Hülle cells. Nevertheless, $\triangle i m e B$ mutants are not able to complete sexual development and form mature cleistothecia in liquid culture. Not only in sex but also in asexual development ImeB seems to have functions, since a lack of ImeB slowers the growth rate of $A$. nidulans and overexpression of ImeB inhibits condiophore formation.

At present it is unclear, what could be downstream targets of ImeB. Normally, MAP kinase regulate transcription factors. We think that the developmentally reglalted transcription factors RosA and NosA could be putative targets of ImeB. The veA protein is also a likely candidate. Future experiments by in vitro phosphorylation assays using purified ImeB kinase and candidate proteins should be helpful in identifying targets of ImeB.

At present, we have initiated a further analysis for genetic interactions with other regulatory genes of sexual development. Preliminary results are described in the following section.

\section{Interplay of ImeB with the two developmental regulators RosA and NosA}

RosA and NosA are two regulators recently identified, which seem to have roles exclusively during sexual development. Our data suggest that there might be a direct or indirect interplay between ImeB and RosA or NosA, respectively. To follow this assumption we generated $\triangle i m e B / \triangle \operatorname{ros} A$ and $\triangle i m e B / \Delta n o s A$ double knock out strains and searched for phenotypical differences to those which were observed in single mutant strains. For analysis, strains were grown on solid surface for 7 days eihter asexually or sexually (Fig.1). 


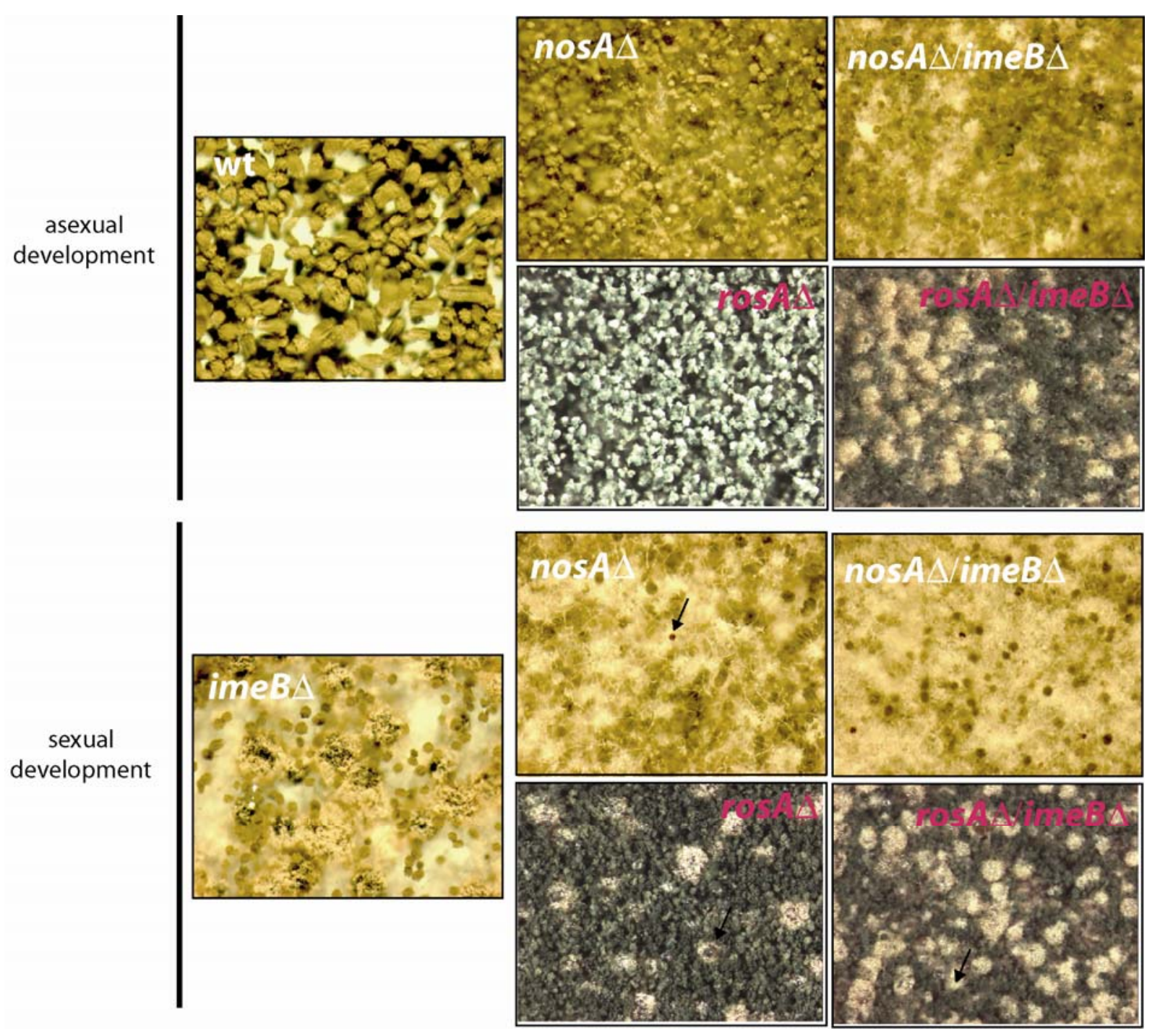

Fig. 1 Phenotypes of $\triangle i m e B / \Delta \operatorname{ros} A$ and $\triangle i m e B / \Delta$ nosA double knock out strains on solid minimal media A wild type, the $\triangle i m e B$ mutant, $\triangle \operatorname{ros} A, \triangle \operatorname{nos} A$, and the two double knock out strains $\triangle i m e B / \triangle \operatorname{ros} A$ and $\triangle i m e B / \triangle$ nos $A$ were point inoculated on solid minimal media and grown for 7 days at $37^{\circ} \mathrm{C}$ either asexually or sexually. Pictures were photographed under stereomicrosope. Arrows indicate cleistothecia.

The single knock out strains, $\triangle$ nos $A$ and $\triangle \operatorname{ros} A$, does not produce cleistothecia when grown asexually the same as the wild type. Only an abnormal conidiophore morphology with less conidia could be observed in both strains. The group of Reinhard Fischer also showed that $\Delta$ rosA mutants do not form cleistothecia when grown asexually, but when grown sexually the strain has a slightly increased number of cleistothecia in comparison to wild type. The double-knock out strain $\triangle i m e B / \Delta n o s A$ showed at many sites on agar surface unordered, packed mycelia which are designated as "nest" in literature. The $\triangle i m e B / \Delta \operatorname{ros} A$ strain produces masses of Hülle cells, which later is supposed to support cleistothecia formation. Actually, both double knock out strains did not form cleistothecia, even after prolonged incubation. This data supports the idea, that the effect of 
absence of ImeB is dominant and induces sex in A. nidulans, but not strong enough to complete sexual development if one of the regulators, RosA or NosA, is missing. It also indicates that ImeB has early functions in sexual development. On the other hand, if propagated in the dark the phenotypical effects of a $\triangle i m e B / \triangle n o s A$ double knock-out is similar to the phenotype described for $\triangle n o s A$ single knock out before. In both cases, the maturation of cleistothecia is hindered and the formation of microcleistothecia is observed. In the dark, the phenotype of a $\triangle i m e B / \Delta \operatorname{ros} A$ mutant is similar to $\triangle \operatorname{ros} A$ mutant strain showing a slightly increase of cleistothecia number. Taken together, the effect of an imeB knock out in $\triangle \operatorname{ros} A$ or $\triangle$ nosA mutant strains is true only when propagated asexually, but not when grown sexually. These results indicate an interplay between ImeB and of these two regulators only in a developmental specific manner.

Hülle cells production is a sign of sexual development, but is only induced when $A$. nidulans strains grows on plates. Thus wild type strains will not form Hülle cells in liquid culture. To elucidate the strength of the sexual induction we cultured $\triangle i m e B, \triangle n o s A, \triangle \operatorname{ros} A$, and double knock out strains in liquid minimal media for $48 \mathrm{~h}$ (Fig.2).

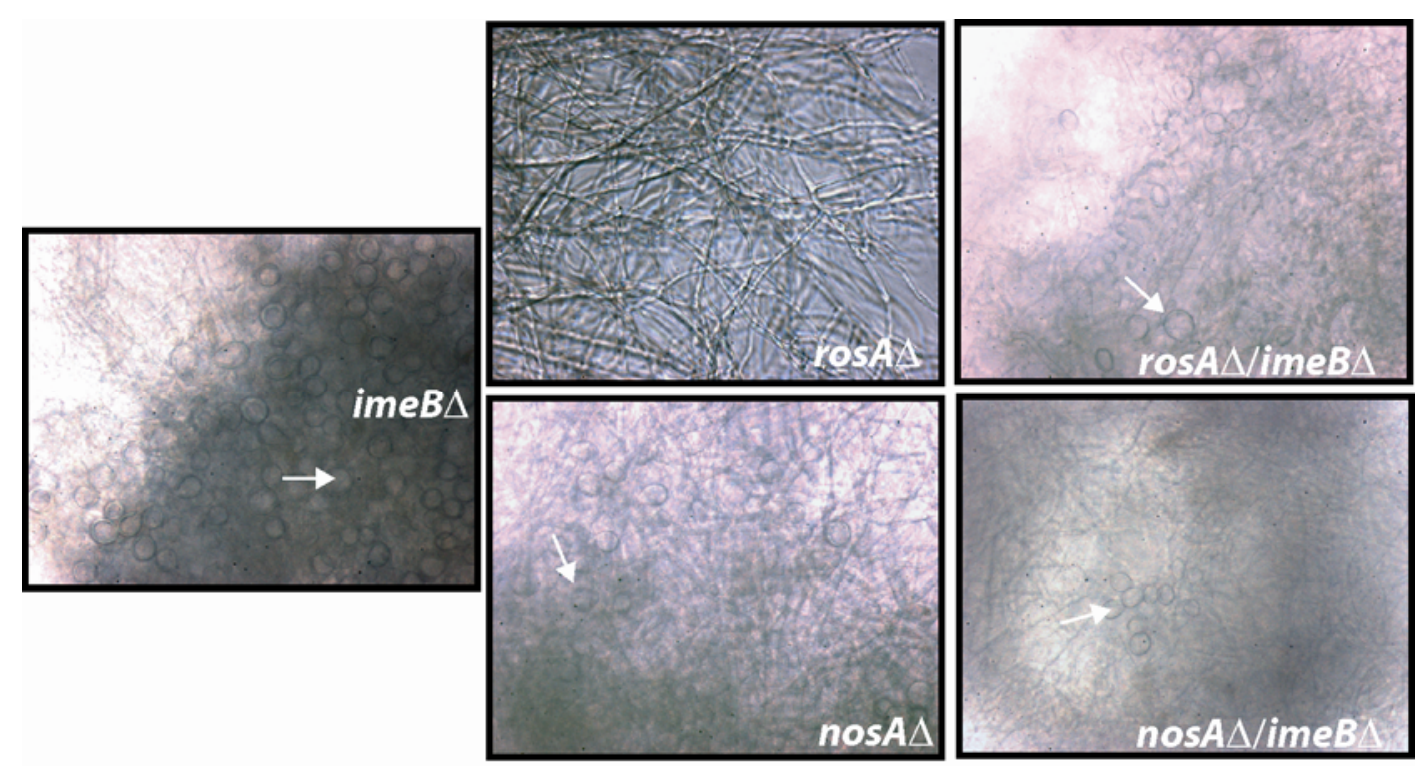

Fig. 2 Phenotypes of $\triangle i m e B / \Delta \operatorname{ros} A$ and $\Delta i m e B / \Delta$ nos $A$ double knock out strains in liquid culture

The $\triangle i m e B$ mutant, $\triangle \operatorname{ros} A, \triangle \operatorname{nos} A$, and the two double knock out strains $\triangle i m e B / \Delta \operatorname{ros} A$ and $\triangle i m e B / \Delta$ nos $A$ were inoculated in liquid minimal media for $48 \mathrm{~h}$.

We observed Hülle cell production in $\triangle$ nosA strain, but not in $\triangle$ rosA strains when grown in normal minimal media containing glucose. Previously, Vienken et al. (2004) showed that $\Delta$ rosA mutants form Hülle cells in liquid culture, whereas we observed no Hülle cell formation of $\Delta$ rosA mutants. The discrepancy between these two conflicting results can be resolved, if one considers that we 
feed the cells with glucose, a good carbon source, whereas the others used glycerol, a nonfermentable carbon source. Thus Vienken et al. designated RosA as a repressor of sexual development under low-carbon conditions. Indeed, non of the mutations observed in this study forms more Hülle cells in liquid culture than $\triangle i m e B$ strains do. Also the initiation of Hülle cell formation ( $12 \mathrm{~h}$ after spore germination) in $\triangle i m e B$ mutants takes place before the other investigated single or double knock-out mutants. First Hülle cells in $\triangle \operatorname{nos} A, \Delta \operatorname{nos} A / \Delta i m e B$, and $\Delta \operatorname{ros} A / \Delta i m e B$ came up after 48 hours of vegetativ growth.

In summary, ImeB is a strong repressor of sexual development in A. nidulans having functions early in development. Our preliminary data propose an interplay between ImeB and the regulators RosA and NosA, but this has to be confirmed by more detailed studies. 


\section{Curriculum vitae}

\section{Education}

1989-1995

\section{Primary education Bremen}

1995- 1999

Secondary education at the Lerchenstr.-Gymnasium, Bremen

\section{Scientific background}

$1999-2003$

Study of Biologie at the Georg August University, Göttingen

2003-2004

Diploma thesis in Mikrobiologie: "Der Einfluss eines stabilisierten Ime2 auf den meiotischen Zellzyklus von Saccharomyces cerevisiae"

2004-2007

Scientific assistant at the Institute of Microbiology \& Genetics, Georg August University, Göttingen 
Fatih Sari, Dipl. Biol.

\section{Curriculum vitae/Lebenslauf}

geb. am 2.6.79 in

Osnabrück, Germany

Schulische Laufbahn

1989-1995

Grundschule in Bremen

1995- 1999

Sekundarstufe I an der Lerchenstr.-Gymnasium, Bremen

Wissenschaftliche Karriere

$1999-2003$

Biologiestudium an der Georg August Universität, Göttingen

2003-2004

Diplomarbeit in Mikrobiologie: "Der Einfluss eines stabilisierten Ime2 auf den meiotischen Zellzyklus von Saccharomyces cerevisiae"

2004-2007

Wissenschaftlicher Mitarbeiter im Institut für Microbiology \& Genetik, Georg August Universität, Göttingen 
